\title{
EXPERIMENTAL PARAMETRIC STUDY OF THE FACTORS LEADING TO \\ ELEVATED FEMORAL INTRAMEDULLARY PRESSURE AND FAT \\ EMBOLUS SYNDROME IN ORTHOPAEDIC PROCEDURES
}

\author{
By \\ Daniel Dobrjanski, B.Eng \\ Ryerson University \\ A thesis \\ presented to Ryerson University \\ in partial fulfillment of the requirements for the degree of \\ Master of Applied Science \\ in the program of \\ Mechanical Engineering
}

Toronto, Ontario, Canada, 2005

Daniel Dobrjanski 2005 C 
UMI Number: EC53015

All rights reserved

INFORMATION TO USERS

The quality of this reproduction is dependent upon the quality of the copy submitted. Broken or indistinct print, colored or poor quality illustrations and photographs, print bleed-through, substandard margins, and improper alignment can adversely affect reproduction.

In the unlikely event that the author did not send a complete manuscript and there are missing pages, these will be noted. Also, if unauthorized copyright material had to be removed, a note will indicate the deletion.

\section{UMI}

UMI Microform EC53015

Copyright 2008 by ProQuest LLC

All rights reserved. This microform edition is protected against unauthorized copying under Title 17, United States Code.

ProQuest LLC

789 East Eisenhower Parkway

P.O. Box 1346

Ann Arbor, MI 48106-1346 


\begin{abstract}
AUTHOR'S DECLARATION
I hereby declare that I am the sole author of this thesis

I authorize Ryerson University to lend this thesis to other institutions or individuals for the purpose of scholarly research.
\end{abstract}

I further authorize Ryerson University to reproduce this thesis by photocopying or by other means, in total or in part, at the request of other institutions or individuals for the purpose of scholarly research. 


\section{BORROWER'S PAGE}

Ryerson University requires the signatures of all persons using or photocopying this thesis. Please sign below and give the address and date. 


\begin{abstract}
Experimental Parametric Study of the Factors Leading to Elevated Femoral

Intramedullary Pressure and Fat Embolus Syndrome in Orthopaedic Procedures
\end{abstract}

Master of Applied Science 2005, Daniel Dobrjanski

School of Graduate Studies, Ryerson University

During orthopaedic procedures such as total knee arthroplasty (TKA), total hip arthroplasty (THA), and intramedullary nailing, it is necessary to hammer implants into the intramedullary canal of long bones. This hammering action can generate a high intramedullary pressure, leading to the release of bone marrow fat globules into the cardiovascular system, and ultimately, the possible development of fat embolism syndrome. In the present study, the effect of parameters such as implant tip geometry, peak impact force, hammer tip material, bone to implant radial gap, and marrow viscosity, on the resulting intramedullary pressure generated when hammering implants into a simulated femur analogue was examined. The bone analogue consisted of a porous plastic cylinder, having similar porosity and pore size to human femoral bone, with bone marrow being represented by a paraffin wax/petroleum jelly mixture. It was found that intramedullary pressure is only slightly lowered by a change in implant tip geometry, and that use of a steel tipped (as apposed to rubber) hammer resulted in an increase in average pressure in the proximal portion of the bone, but a decrease distally. A lower implant insertion speed, lower hammering force, and a larger bone to implant radial gap were found to significantly reduce the intramedullary pressure. The number of hammer strikes required to insert an implant was found to increase significantly with marrow viscosity, but the average intramedullary pressure was found to decrease with increasing viscosity. Numerical modeling was also found to offer great promise for analyzing hammering procedures for orthopaedic research into fat embolism syndrome. Numerical and experimental results were matched with approximately a $20 \%$ deviation. 


\section{ACKNOWLEDGMENTS}

First and foremost I would like to thank my supervisor, Dr. Marcello Papini for his time, encouragement and assistance during the past two years. Without his guidance and push for perfection over the past two years, the present thesis would have never been completed on time. I would also like to thank my co-supervisors; Dr. Ziad Saghir and Dr. Kamran Behdinan for their help and support in the research. Additional thanks go to the medical supervisors, Dr. Paul Zalzal and Dr. Justin DeBeer for their insightfulness into fat embolism syndrome and orthopaedic procedures. I would also like to thank my colleagues and now good friends, Omar Gaber, Azar Hojabr and Paul Saadetian for their valuable contribution of time and research. Additional thanks go to Joseph Amankrah for his countless hours of support at the machine shop. I would also like to thank my dad, Jerry Dobrjanski for his help with the experimental apparatus, my mom, Anna and brother, Jarek for their encouragement and support. Notable thanks also go out to my close friends; Natalka, Christina, Andrei, Kasia, Natania, Marta and Roman for their help and moral support during the past few months of thesis writing. Finally, I would also like to acknowledge the financial support of the Natural Sciences and Engineering Council of Canada (NSERC). 


\section{TABLE OF CONTENTS}

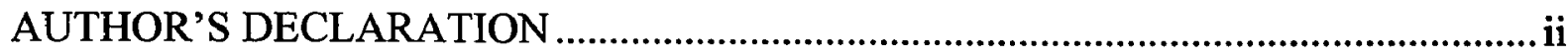

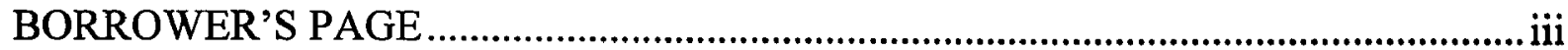

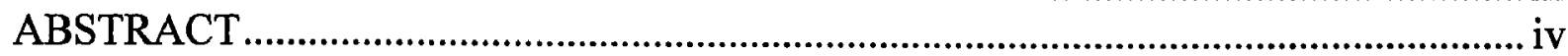

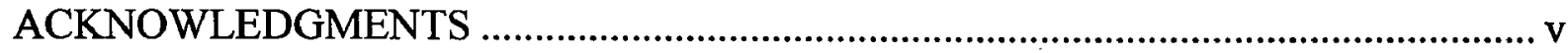

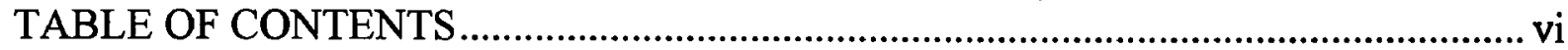

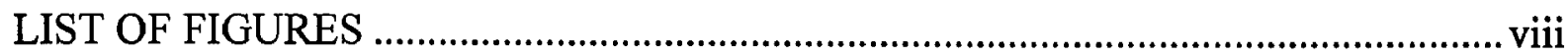

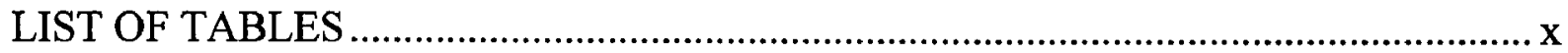

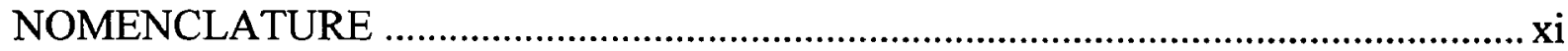

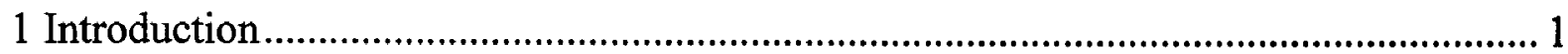

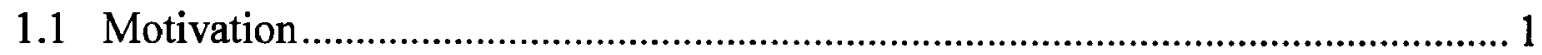

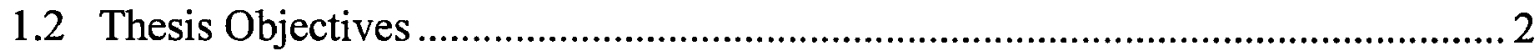

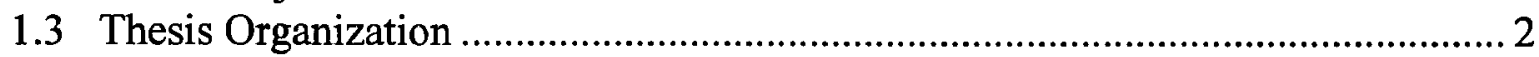

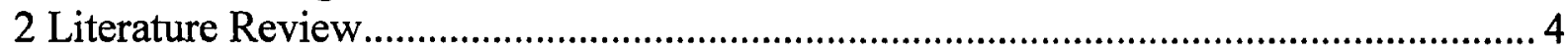

2.1 Diagnosis of Fat Embolism Syndrome .......................................................... 4

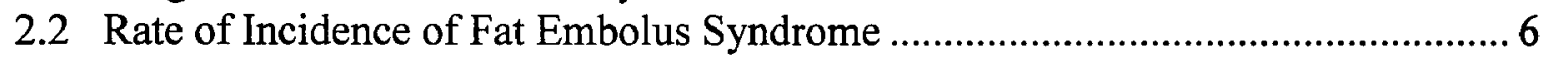

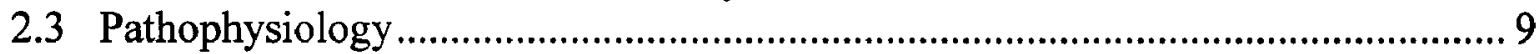

2.4 Elevated Intramedullary Pressure During Various Orthopaedic Procedures........ 10

2.4.1 Total Hip and Knee Arthroplasty........................................................... 10

2.4.2 Intramedullary Nailing ............................................................................. 14

2.4.3 Reaming of the Intramedullary Canal ........................................................... 16

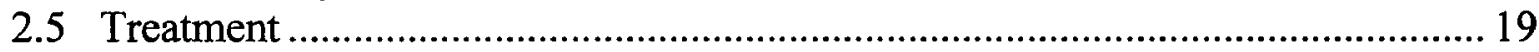

3 Experimental Apparatus and Procedure ........................................................................ 20

3.1 Synthetic Bone Analogue............................................................................... 20

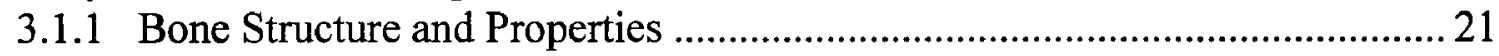

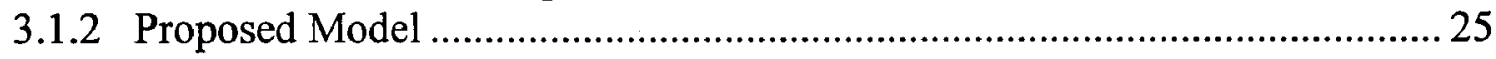

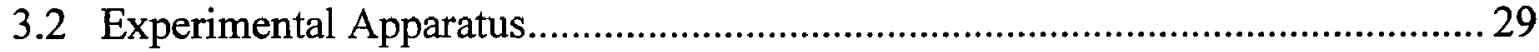

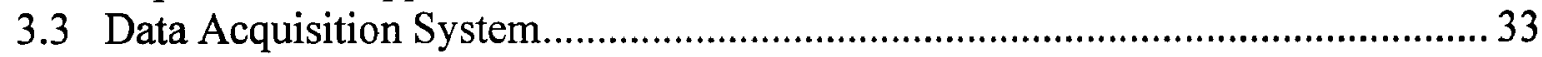

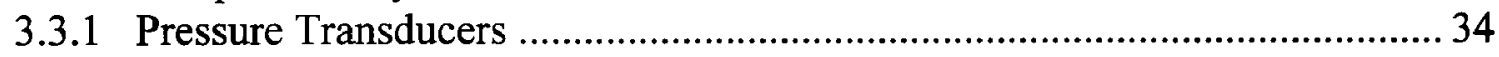

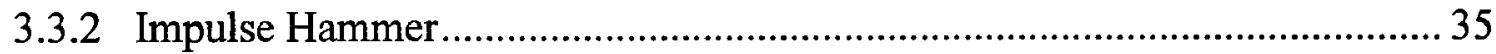

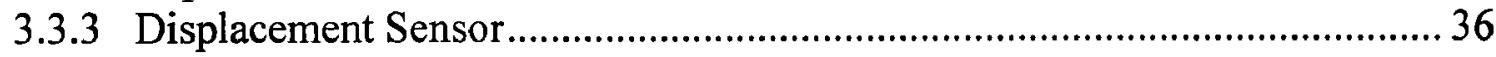

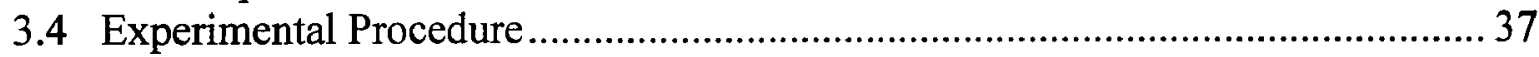

3.5 Synthetic Bone Analogue Performance ………................................................... 39

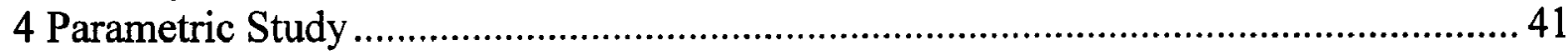

4.1 Experimental Method........................................................................................... 41

4.1.1 Parametric Study 1: Effect of implant tip geometry and hammer tip material

4.1.2 Parametric study 2: Effect of bone marrow viscosity, bone to implant radial gap, and peak hammering force .............................................................................. 44

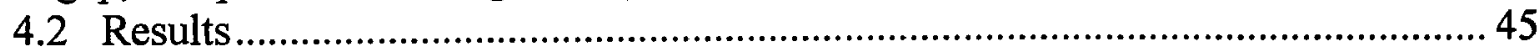

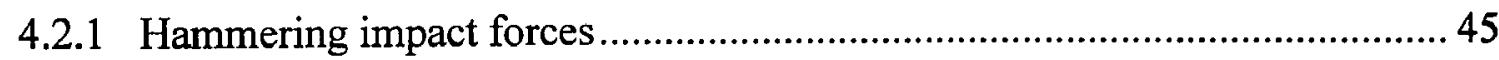

4.2.2 Typical pressure data ................................................................................ 46

4.2.3 Parametric Study 1: Effect of implant tip geometry and hammer tip material 
4.2.4 Parametric Study 2: Effect of Bone Marrow Viscosity / Bone to Implant Radial Gap / Impact Force

4.3 Discussion

4.3.1 Comparison of presently measured intramedullary pressures with cadaveric data from the literature 59

4.3.2 Effect of operative parameters and clinical implications.................................60

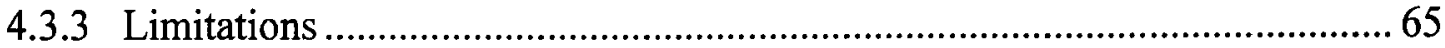

5 Numerical and Experimental Comparison.............................................................6

5.1 Comparison of Experimental Results to Computational Fluid Dynamics Model of

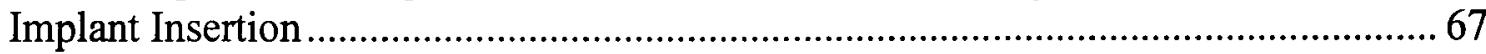

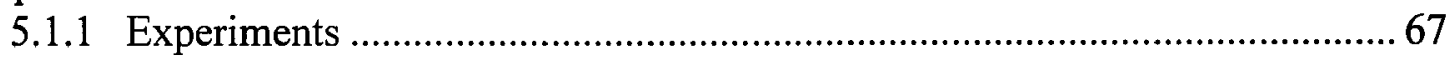

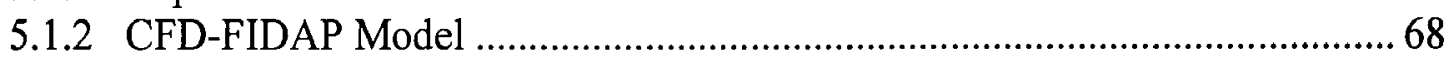

5.1.3 Comparison of Experimental and CFD-FIDAP Results ..................................69

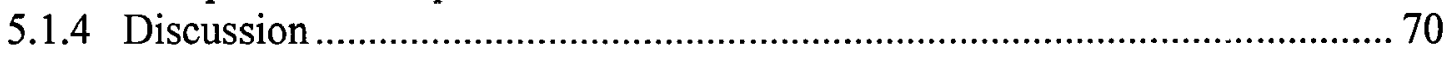

5.2 Comparison of Experimental Results to Finite Element Model of Implant

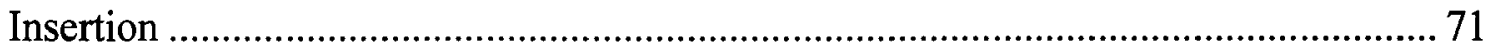

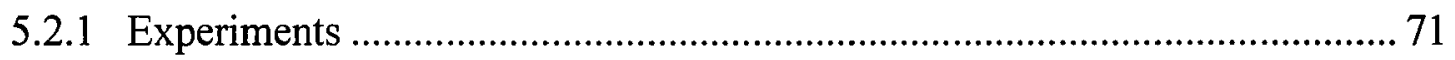

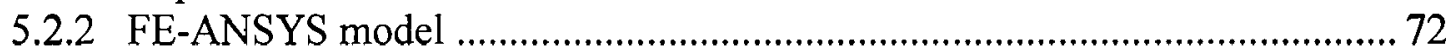

5.2.3 Comparison of Experimental and FE-ANSYS Results.................................. 72

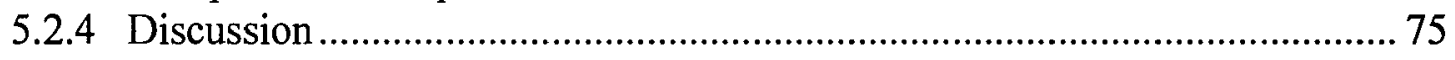

6 Limitations, Recommendations and Conclusions.................................................... 77

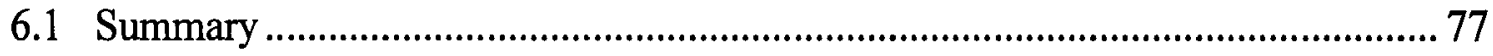

6.2 Limitations of Approach ................................................................................. 78

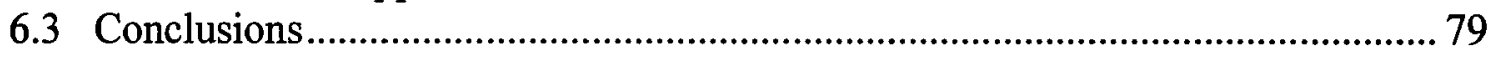

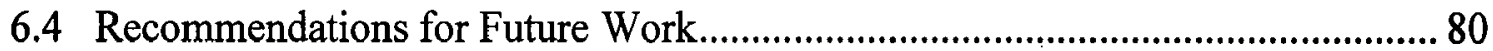

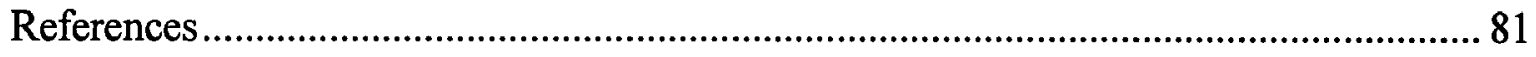




\section{LIST OF FIGURES}

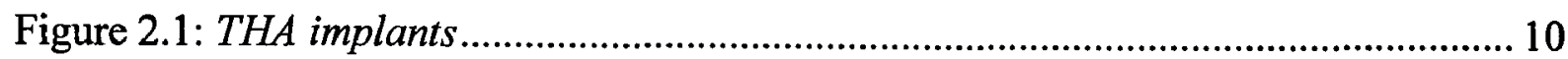

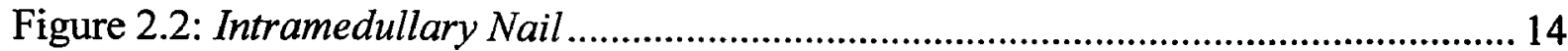

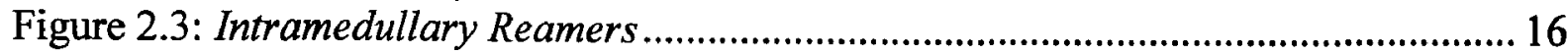

Figure 3.1: Synthetic bone analogue diagram (dimensions in $\mathrm{mm}$ )................................ 27

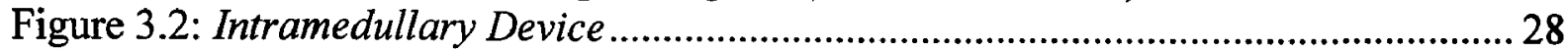

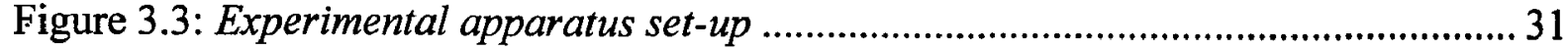

Figure 3.4: Bone analogue with locations of pressure transducers. Note that the implant

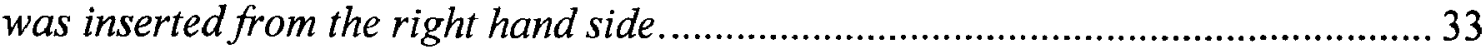

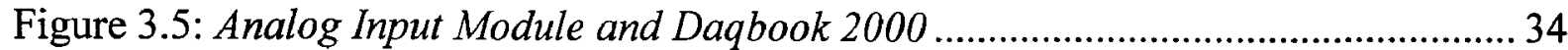

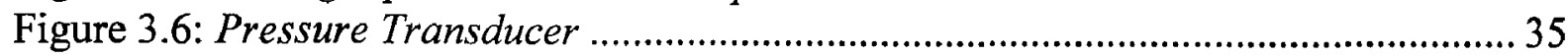

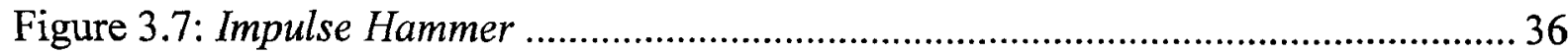

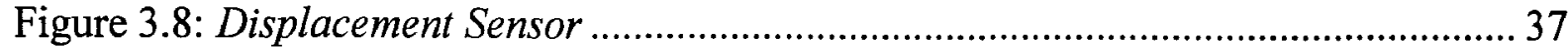

Figure 4.1: Impact force generated by striking implant with the rubber tipped hammer (RH) from release points of: $45^{\circ}(\mathrm{LF}$, peak $=90 \mathrm{~N}) ; 60^{\circ}(\mathrm{MF}$, peak $=115 \mathrm{~N}) ; 75^{\circ}$

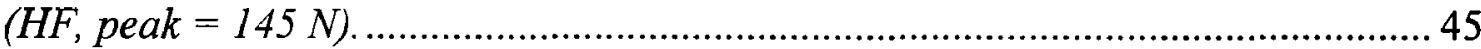

Figure 4.2: Impact force generated by striking implant with the steel tipped hammer from release points of: $45^{\circ}(\mathrm{LF}$, peak $=900 \mathrm{~N})$ and $75^{\circ}(\mathrm{HF}$, peak $=1100 \mathrm{~N})$.............. 46

Figure 4.3: Typical pressure variation encountered during parametric studies versus distance implant moved. Values obtained using rubber hammer tip, flat implant tip geometry, $1.0 \mathrm{~mm}$ bone to implant radial gap, $82.6 \mathrm{cP}$ synthetic bone marrow viscosity and a $90 \mathrm{~N}$ peak impact force. Each data point represents one strike. Transducer 1, - Transducer 2, $\mathbf{\Delta}$ - Transducer 3, - Transducer 4. Position of

first 2 pressure transducers is shown by the two vertical bars................................ 48

Figure 4.4: Number of impacts required to hammer implant into canal with the given peak impact force, bone to implant radial gap $(0.5 \mathrm{~mm}$ and $1.5 \mathrm{~mm})$, implant tip geometry and hammer type. - LF with flat tip, - HF with flat tip, $\square-L F$ with tapered tip, $O-H F$ with tapered tip. In all cases, a viscosity of $82.6 \mathrm{cP}$ was used.49

Figure 4.5: Effect of implant tip geometry on mean pressure for $0.5 \mathrm{~mm}$ bone to implant gap with $\square_{-} L F$ with flat tip, $\square_{-}$LF with tapered tip, $\square_{-} H F$ with flat tip, $\mathbf{Z}_{-}$ $H F$ with tapered tip. In all cases, a viscosity of $82.6 \mathrm{cP}$, and the rubber hammer (RH) tip were used. Bars indicate maximum and minimum pressure for each transducer.

Figure 4.6: Effect of implant tip geometry on mean pressure for $1.5 \mathrm{~mm}$ bone to implant gap with $\square-L F$ impact with flat tip, $\square-L F$ with tapered tip, $\square_{-} H F$ with flat tip, - HF with tapered tip. In all cases, a viscosity of $82.6 \mathrm{cP}$, and the rubber hammer (RH) tip were used. Bars indicate maximum and minimum pressure for

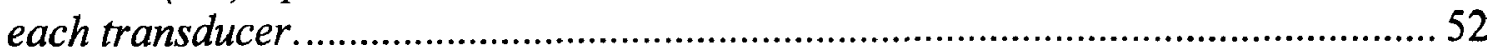

Figure 4.7: Effect of hammer tip material and peak impact force on mean pressure for 0.5 $m m$ bone to implant radial gap with $\square-R H L F, \square-S H L F, \square-R H H F, \square_{-S H}$ $H F$. In all cases, a viscosity of $82.6 c P$, and a flat implant tip were used. Bars indicate maximum and minimum pressure for each transducer .............................. 53

Figure 4.8: Effect of hammer tip material and peak impact force on mean pressure for 1.5 mm bone to implant radial gap with $\square-R H L F, \square-S H L F, \square_{-R H} H F, \mathbf{D}_{-} S H$ 
HF. In all cases, a viscosity of $82.6 \mathrm{cP}$, and a flat implant tip were used. Bars indicate maximum and minimum pressure for each transducer.

Figure 4.9: Effect of marrow viscosity on number of hammer strikes required to hammer flat tipped implant into canal. Rubber hammer $(R H)$ used in all cases, with peak forces of $\mathbf{\square}-\mathrm{A}, \mathbf{\mathbf { A }}-M F, \mathbf{0}-H F$.

Figure 4.10: Effect of fluid viscosity on pressure values at transducer 4. Rubber hammer (RH) and a flat tipped implant used in all cases, with bone to implant gaps and peak forces given by: $\square-0.5 \mathrm{~mm}, L F ; \square-0.5 \mathrm{~mm}, M F ; \square-0.5 \mathrm{~mm}, \mathrm{HF} ;-1.0$

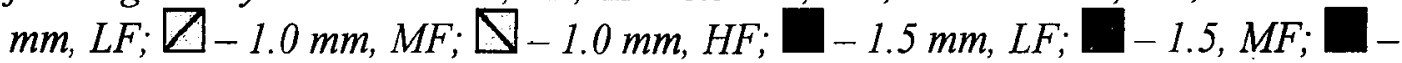
$1.5 \mathrm{~mm} \mathrm{HF}$

Figure 5.1: Experimental and numerical pressure values (FIDAP) - Numerical pressure results, $\boldsymbol{\Delta}$ - Experiment 1 pressure results, $\bullet$ - Experiment 2 pressure results

Figure 5.2: Experimental and numerical pressure values for test case 1 (FE-ANSYS) Numerical pressure results, $\boldsymbol{\Delta}$ - Experiment pressure results. .73

Figure 5.3: Experimental and numerical pressure values for test case 2 (FE-ANSYS) Numerical pressure results, $\boldsymbol{\Delta}$ - Experiment pressure results. 74

Figure 5.4: Experimental and numerical pressure values for test case 3 (FE-ANSYS) Numerical pressure results, $\mathbf{\Delta}$ - Experiment pressure results.

Figure A.1-39: Experimental pressure values for each pressure transducer.....................85 


\section{LIST OF TABLES}

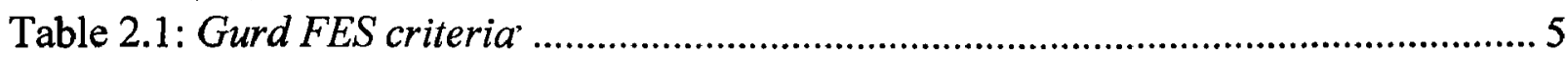

Table 2.2: Incidence and Mortality due to FES .............................................................. 6

Table 3.1: Properties of distal femur considered for this study ......................................... 23

Table 3.2: Candidate cortical bone analogues ................................................................ 32

Table 4.1: Peak impact forces generated by releasing the hammer from various angles,

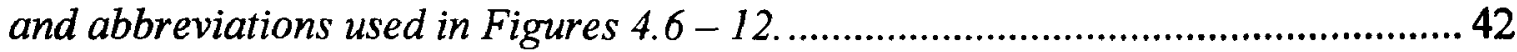

Table 4.2: Summary of parameter variation between corresponding studies.................. 43

Table 5.1: Experimental and numerical (CFD-FIDAP) comparison of pressure results. 70

Table 5.2: Experimental test cases................................................................................. 72

Table 5.3: Summary of experimental and numerical (FE-ANSYS) results ........................ 75

Table B.1-6: Experimental pressure data......................................................................125 


\section{NOMENCLATURE}

The definition of symbols will be done in alphabetical order:

$$
\begin{array}{ll}
d_{m} & : \text { Diameter of the intramedullary canal }[\mathrm{m}] \\
L & : \text { Piston length }[\mathrm{m}] \\
h & : \text { Implant to bone radial gap }[\mathrm{m}] \\
p & : \text { Intramedullary pressure }[\mathrm{Pa}]
\end{array}
$$

\section{Greek symbols}

$$
\begin{array}{ll}
\mu & : \text { Viscosity }[\mathrm{Pa} . \mathrm{s}] \\
\nu & : \text { Advancement velocity }[\mathrm{m} / \mathrm{s}] \\
\varepsilon & : \text { Eccentricity }
\end{array}
$$




\section{Chapter 1}

\section{Introduction}

\subsection{Motivation}

Fat embolism (FE) refers to the presence of fat globules within the peripheral circulation, and the associated clinical symptoms are collectively termed Fat embolism syndrome (FES). ${ }^{1}$ In many orthopaedic procedures, it is necessary to breach the intramedullary canal of long bones, so that prosthetic stems, intramedullary nails, and other devices can be inserted. One complication that arises from these procedures is the ejection of fat globules into the cardiovascular system which can possibly lead to FES. Though its etiology is not completely understood, it is generally accepted that FES results from the release of the fat from the intramedullary contents into the bloodstream, due to elevated pressure within the intramedullary canal. ${ }^{2}$ The reported incidence and mortality of FES varies from study to study; however, based on a recent 10 year retrospective study, the incidence of FES was identified in $0.9 \%$ of cases with a mortality of $7 \%{ }^{3}$

Due to the aging population, there is an increasing demand for orthopaedic procedures such as total hip and total knee arthroplasty. With this great demand the incidence of FES is becoming more frequent, and it is therefore very important that operative techniques and equipment be modified to reduce the risk of this complication. 


\subsection{Thesis Objectives}

The main objective of the present thesis is to examine the factors that lead to elevated intramedullary (i.e., the canal inside long bones in which the marrow resides) pressure, and ultimately provide suggestions for alternate process parameters and operative techniques aimed at decreasing the occurrence of the syndrome in orthopaedic procedures that require hammering of an implant into the intramedullary canal. To meet the primary objective, three secondary objectives will be explored: (i) The creation of a synthetic bone analogue model that can be used in hammering and reaming experiments to mimic the fluid flow in a human cadaveric femur. (ii) To use the bone analogue to perform experiments aimed at verifying numerical (FIDAP computational fluid dynamics and ANSYS finite element) models of fluid flow and elevated pressure in bone, developed by other members of the research team. (iii) To perform an experimental parametric study aimed at establishing the process parameters that most affect intramedullary pressure, so that an optimal operative procedure which reduces the risk of FES can be established.

\subsection{Thesis Organization}

The present thesis is divided into six chapters based on a two year long research initiative into the study of FES. Chapter one presents a review of the structure of the thesis, and its objectives. Chapter two presents a review of previous clinical and biomechanical research performed in the study of FES. Chapter three presents a detailed description of the experimental setup and the bone analogue utilized in the parametric studies. Chapter four presents a comparison of the experimental results obtained using the 
bone analogue with those obtained by other members of the research team using numerical models. This chapter is a collaborative effort with two other MASc students on the research team, who developed numerical models of fluid flow in bone.

Chapter five presents the results of an experimental parametric study aimed at determining the operative parameters that can be adjusted to reduce the intramedullary pressure, and thus the occurrence of FES. Finally, chapter six presents the major conclusions and recommendations of the work, and highlight proposed future research. 


\section{Chapter 2}

\section{Literature Review}

This chapter presents a literary review of past research that has been completed on the study of fat embolism syndrome. It also gives insight into orthopaedic procedures that are seen to be a direct cause of fat embolism syndrome.

\subsection{Diagnosis of Fat Embolism Syndrome}

Fat embolism (FE) was discovered by F. A. Zenker in 1862, who found fat droplets in the pulmonary circulation of the lungs of a railroad worker who had suffered a severe thoraco abdominal crush injury. The first clinical study of fat embolism syndrome (FES) was carried out by Von Bergman in 1873, who described how a man suffering from a femur fracture died due to respiratory distress. ${ }^{4}$ A century passed and work on understanding the pathophysiology and pathogenesis of FE continued until in 1969, Peltier published a paper on the pulmonary consequences and treatments of FE. ${ }^{5}$

The use of the term Fat Embolism Syndrome to describe the clinical diagnosis was first used by A.R. Gurd in 1970, who described its clinical manifestations. ${ }^{6}$ FES is a multi-system disorder which consists of a number of signs and symptoms, making it a difficult disorder to diagnose. The onset of FES is a gradual process, taking 
approximately 12-36 hours for symptoms to appear. The most common symptoms include hypoxaemia, fever, petechial rash, and neurological symptoms. ${ }^{5}$ FES was first detected in common orthopaedic procedures in the early 1970 s. $^{7}$ Gurd established a collection of symptoms and laboratory parameters which aid in the diagnosis of FES (Table 2.1). To diagnose FES using the Gurd criterion, at least one major and four minor symptoms must be detected. ${ }^{7}$

Major Criteria Hypoxemia

Cerebral disfunction

Axillary or conjunctival petechiae

Pulmonary edema

Minor Criteria

Tachycardia $>120$ beat $/ \mathrm{min}$

Pyrexia $>39.4^{\circ} \mathrm{C}$

Fat in the urine or sputum

Emboli present in retina on funduscopic examination

Laboratory Features Thrombocytopenia $>50 \%$ decrease on admission value

Sudden decrease in haemoglobin level $>20 \%$ of admission value

High erythrocyte sedimentation $>71 \mathrm{~mm} / \mathrm{h}$

Fat macroglobulaemia

Table 2.1: Gurd FES criteria ${ }^{4,8}$

It has been suggested that the Gurd criterion may under diagnose the syndrome, since fat globules have been found in the blood of seemingly healthy trauma patients. ${ }^{9}$ In 
1987, Lindeque et al, proposed a criterion to diagnose FES based on respiratory parameters ${ }^{10}$. Lindeque's criterion increases the incidence of FES for patients with fractured long bones and is applied to a number of orthopaedic procedures in which FES can occur: intramedullary nailing/reaming, total knee arthroplasty (TKA), and total hip arthroplasty (THA).

\subsection{Rate of Incidence of Fat Embolus Syndrome}

The reported incidence and mortality of FES vary significantly from study to study. Table 2.2, taken from the paper by Mellor ${ }^{1}$ summarizes several studies performed in the last decade.

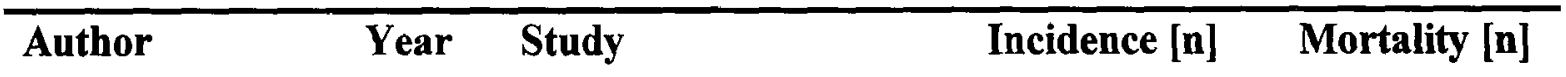

Retrospective Studies

Bulger et al

199710 Years review of trauma cases

$0.9 \%[27]$

$7 \%[2]$

Robert et al

1993

25 Years retrospective review

$0.26 \%$ [20]

$20 \%[4]$

Prospective Studies

Fabian et al

1990

96 Long bone fractures

$11 \%[10]$

$10 \%[1]$

Kallenbach et al

1987

82 Corticosteroids Patients

$13 \%$ [11]

Nil

Lindeque et al

1987

55 Corticosteroids Patients

Chan et al

1984

80 Trauma Patients

$13 \%$ [7] - Gurd

Nil

$29 \%$ [16] - Lindeque

Schonfield et al

1983

62 Corticosteroids Patients

$8.75 \%$ [7]

$2.5 \%[2]$

Myers et al

1977

100 Long bone trauma patients

$15 \%$ [9]

$\mathrm{Nil}$

$17 \%$ [17]

$1 \%[1]$

\section{TOE Studies}

Christie et al

1995

111 Long bone fracture fixations

$87 \%$ [97] - Emboli Nil

Pell et al

1993

24 Tibial and femoral nailings

$41 \%$ [10]-Emboli

$4.1 \%[1]$

$12.5 \%$ [3] - FES

Table 2.2: Incidence and Mortality due to FES ${ }^{1}$ 
Based on the findings of Bulger, in which diagnosis was based on the Gurd criteria, 27 cases of FES were identified from a population of 3026 patients. $^{3}$ This gives an incidence of $0.9 \%$, which differs from the $8.75-29 \%$ reported in prospective studies. The incidence rose for prospective studies, which were based on physiological monitoring, because the evaluation is based on the end organ effect of FE. For example, the Fabian study monitored the alveolar-arterial oxygen tension difference to predict lung injury. ${ }^{1}$

Studies utilizing transesophageal echocardiography (TOE) to detect fat globules in the cardiovascular circulation resulting from a fracture of the femur, tibia or pelvis generally show high incidences of FES (as high as $90 \%$ ). ${ }^{11}$ TOE has also revealed the presence of embolic showers in the lungs and heart, which leads to the formation thrombotic masses. Some emboli have been reported to between 1 and $8 \mathrm{~cm}$ in diameter, and are believed to be directly related to the development of FES. ${ }^{11}$

Intramedullary procedures such as total hip arthroplasty (THA) and total knee arthroplasty (TKA) are very common in hospitals around the world. Over 100,000 THA's are performed annually in the United States alone. ${ }^{2}$ Therefore, procedural complications that arise from these surgeries should be carefully overviewed. Complications such as decreased cardiac output, elevated pulmonary artery pressure, hypoxemia, systematic hypotension, and cardiac arrests have been reported during cemented THA. Mortality rates have been reported to be in the range of $0.02 \%$ to $0.5 \%$ for THA procedures. Many experimental and clinical tests have been performed to find relationships between THA, 
TKA and marrow embolization. ${ }^{2}$ This research has become vital in understanding FES during orthopaedic surgery.

In 1974, Tronzo et al. discovered that during the insertion of a cemented prosthesis into the femur, the pressure increased to over $300 \mathrm{~mm} \mathrm{Hg}$. He concluded that marrow embolization was related to the pressure in the femoral canal. This research proved that FES could be a direct cause of THA and TKA procedures. ${ }^{12}$ It wasn't until 1985 that Heinrich et al. used TOE to actually detect the release of bone marrow into the right atrium during an implantation of cemented THA. FES was thus positively linked to be a direct cause of THA, and in a recent publication it was stated that approximately $0.1 \%$ of patients develop the syndrome. The preceding statement only applies to cemented THA. ${ }^{13}$

In a study involving 38,488 THA's performed between 1969 and 1997 at a Mayo Clinic, it was reported that no perioperative deaths $(0.0 \%)$ occurred during uncemented arthroplasties, whereas 23 deaths $(0.1 \%)$ occurred during cemented arthroplasties. Out of the 38,488 THAs performed: approximately $40 \%$ where uncemented and $60 \%$ where cemented procedures. ${ }^{13}$

The incidence of mortality due to FES increases when the patient has signs of previous cardiovascular problems. It is therefore imperative to determine beforehand if a patient can withstand embolic events during the fixation of a femoral component. The parameters that decide which particular operative technique for a THA procedure will be used include: age, gender, weight, bone quality, anatomy of the proximal portion of the femur, and the activity level of the patient. Personal experience also plays a major factor in determining if the femoral component should be inserted with or without cement. ${ }^{14}$ 


\subsection{Pathophysiology}

The aetiology of FES is not fully understood; however, two theories have been proposed to explain the development of the syndrome: the mechanical theory and the biochemical theory. These theories are not mutually exclusive; however, they both clarify the source of the fat in FES. ${ }^{7}$

The mechanical theory suggests that during the disruption of intramedullary veins during a long bone fracture, fat globules gain access to the capillary shunts and travel to the pulmonary veins. Through the venous circulation network (cardiovascular system), the fat globules circulate and lodge themselves into the lungs and right atrium of the heart. ${ }^{4}$ This theory, which is also referred as the Infiltration Theory, has experimental evidence to support its claims. Utilizing TOE, fat globules have been found in the pulmonary arterial circulation following fractures and orthopaedic surgeries. ${ }^{15}$

During orthopaedic surgeries such as cemented THA, intramedullary pressure increases to $1400 \mathrm{~mm} \mathrm{Hg}$ in the distal femur following cement application and prosthesis insertion. ${ }^{16}$ This greatly exceeds the allowable diastolic blood pressure of approximately $25 \mathrm{~mm} \mathrm{Hg} .{ }^{11}$ Diastolic blood pressure has also been said to be in the range of $30-50 \mathrm{~mm}$ $\mathrm{Hg}$ in other publications; however, this small difference is minimal compared to the overall pressures which occurs during orthopaedic surgeries. ${ }^{4,7}$ Exceeding this allowable diastolic blood pressure causes bone debris (fat globules) from the medullary cavity to be transferred into the venous circulation. The excess pressure also causes damage to the osseous vascular supply through obliteration of the haversian canals. ${ }^{10}$

The biochemical theory suggests that catecholamines are released during a long bone fracture and mobilize together with the lipids from adipose tissue. Tissue damage is 
also created by the free fatty acids released from the fracture site. These free fatty acids are released from the lysis of triglycerides and cause toxic damage to endothelial cells and pneumocytes. In turn, these events cause acute respiratory deficiency syndrome. When the lipase hydrolyzes the natural fat, the two grow in size and travel through the cardiovascular system to be trapped in the lung capillaries. ${ }^{2,13}$

\subsection{Elevated Intramedullary Pressure During Various Orthopaedic Procedures}

\subsubsection{Total Hip and Knee Arthroplasty}

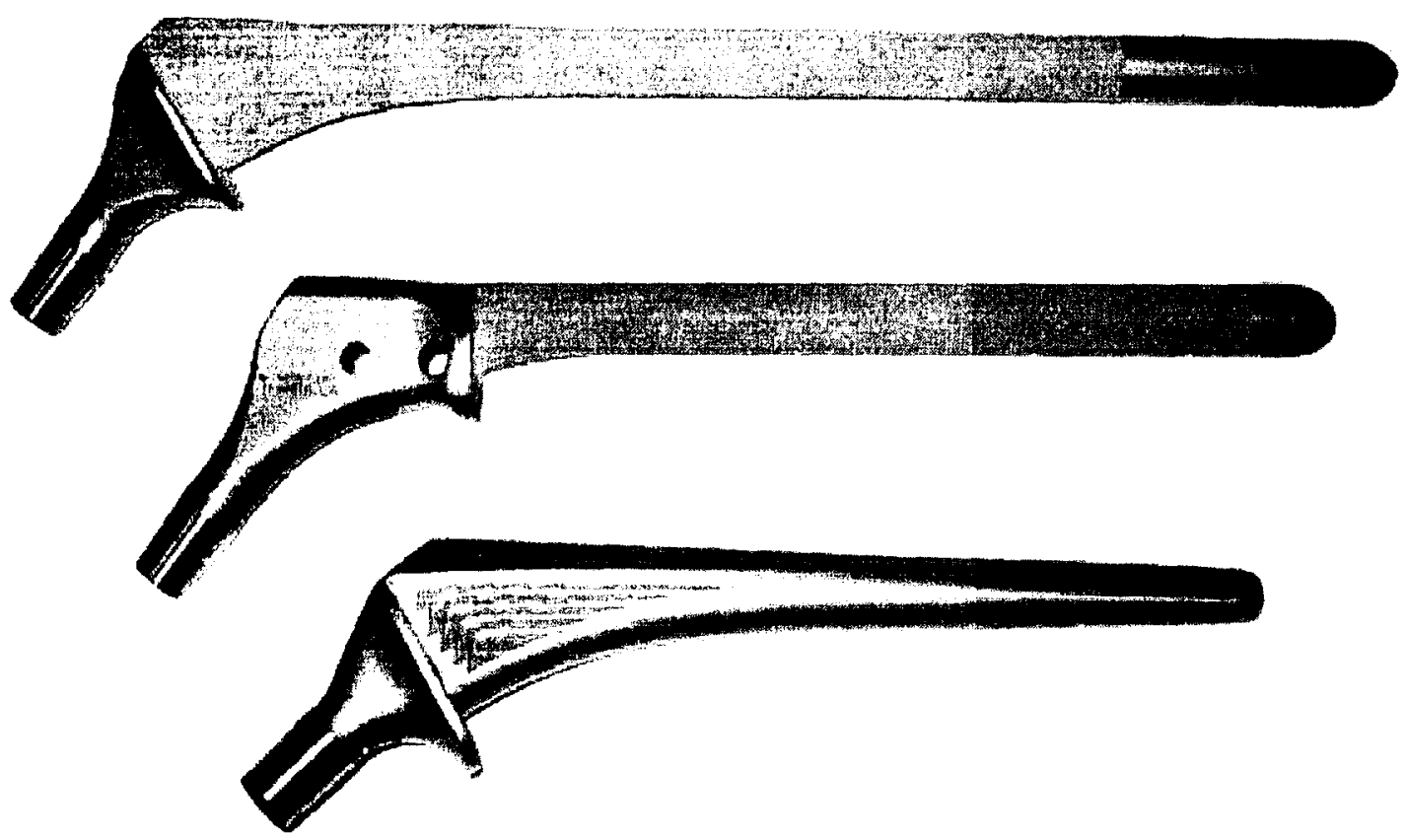

Figure 2.1: THA implants

It is generally accepted that orthopaedic procedures (Figure 2.1, example of THA implants) that tend to raise the pressure inside the intramedullary canal lead to a higher risk of FES. ${ }^{17}$ A number of investigators have studied the effect of intramedullary pressure during the insertion of a femoral component. Inadome et al. found that the mean 
pressure during the insertion of a stem with cement was $3190.6 \mathrm{~mm} \mathrm{Hg}$, whereas the mean pressure during the insertion of the stem without cement was only $125.8 \mathrm{~mm} \mathrm{Hg}{ }^{17}$ It is thus clear that certain measures should be taken during the insertion of the stem, and that this is of particular importance during procedures utilizing cemented implants. A number of modifications to the technique have been proposed to minimize the spread of embolic materials into the cardiovascular system.

Pitto et al. studied the effect of different fixation methods during the insertion of an implant stem during THA. ${ }^{14}$ The purpose of the study was to find the optimal fixation technique to minimize the embolic phenomena and cardiopulmonary impairment. Three groups of twenty patients were assigned to the clinical trial, in an attempt to find the most optimal insertion technique. The three insertion techniques utilized in the study were: (1) without cement, (2) with a conventional cementing technique, (3) with a modified bonevacuum cementing technique. The third technique involved creating a vacuum between the linea aspera and diaphysis of the femur, by placing 800 millibars of suction at those locations. This created a vacuum in the medullary cavity during the insertion of the cement and stem into the femur. TOE was used to analyze any embolization activity of bone marrow into the cardiovascular system. With the conventional cementing technique, $85 \%$ of the patients suffered severe signs of FE. No cases of FE occurred during the insertion of the stem without cement. With the modified cemented technique, only $5 \%$ of the patients experienced signs of FE. ${ }^{16}$ The study showed that it is not possible to completely eliminate the onset of FE during a cemented THA

Other operative measures that have been studied to minimize the risks of FES during the preparation of the femoral canal in THA include: a distal venting hole, 
pulsatile lavage and cannulated awls/rasps. It was found that use of a venting hole in the cortex resulted in a significant reduction (up to $90 \%$ ) in the intramedullary pressure in the femoral canal. ${ }^{18}$ However, the distal venting hole is impractical in a clinical setting, because, in reality, bone debris and fatty marrow become blocked in the hole preventing pressure release. ${ }^{13}$ Research regarding venting holes led to the development of the bonevacuum cemented technique, which has greatly increased the pressure reduction benefits during a THA. Pulsatile lavage of bone marrow and bone debris resulted in a decrease in the volume of fat emboli; however, it was unable to decrease the pulmonary shunt volume during the fixation of the stem with cement. Cannulated awls and rasps have also been shown to reduce the incidence of embolic showers during the preparation of the femoral canal during a THA, over non-cannulated ones. ${ }^{18}$

Maharaj et al. studied the impact force measurements on composite hip prostheses. Experiments were conducted on cadaveric femurs and polyurethane foamfilled PVC bone cylinders. A drop-weight impact device was used to drive the stems into the specified mediums. The experiments found that the mean velocity of the hammer at impact was $5.15 \pm 0.14 \mathrm{~m} / \mathrm{s}$ and a total of 6 impacts were required to insert the stem into the cavity. The mean impact forces where calculated to be $6.20 \pm 0.15 \mathrm{kN}$ and $5.83 \pm 0.67$ $\mathrm{kN}$ for the polyurethane cylinders and cadavers, respectively. This experiment effectively demonstrated that artificial bone materials can simulate the characteristics of cadaveric bone in impact testing. ${ }^{19}$

It appears that no one modification to an operative technique can completely eliminate the onset of FE. In reality, it appears that the best alternative is to use the uncemented THA, whenever possible, particularly when dealing with high-risk patients 
having previous cardiovascular problems. ${ }^{16}$ However, it is sometimes unavoidable to use the cemented technique, because some patients have long bones (femur, tibia) which are unable to accept procedures with the press fit. Their bones are sometimes too weak to encounter the stresses associated with the press fit technique. Thus, there is still a real and important need for new modified operative techniques that can reduce the chance of the onset of FES.

Total knee arthroplasty (TKA) has also become a common orthopaedic procedure in hospitals around the world, although the frequency of TKA procedures is not as high as that of THA procedures. Many modifications have been proposed to decrease the amount of marrow embolization during TKA. ${ }^{16}$ Ries et al. studied a number of parameters aimed at finding a more optimal procedure to reduce the occurance of FES in TKA. ${ }^{20}$ The study concluded that overdrilling the distal femur by a diameter larger than the stem, following slow insertion and use of a fluted stem (rather than a round one), greatly decreased the intramedullary pressure in the femoral canal. These benefits were possible because the bone marrow was able to travel along the channels of the stem. These modifications are used in both bilateral and unilateral TKA procedures, though research has shown that bilateral TKA has a higher incidence of FE than its unilateral counterpart. This incidence gap for the bilateral TKA has been reduced with modified surgical techniques, as discussed above. ${ }^{20}$

With the large number of THAs and TKAs being performed annually, revisions to these procedures have become a common practice in orthopaedics. Revision rates range from $8.9 \%$ to $22 \%$ of the patients following surgery. ${ }^{21}$ A number of studies report that the onset of FES during revision of a THA procedure. ${ }^{2}$ For example, Woo et al. have 
reported the development of FES during a revision cemented THA, which resulted in fatal intraoperative cardiac arrest. The study concluded that the removal of the cement plugs using osteotomes, or a high speed burr, created lighter showers of emboli compared to the ultrasonic tool. The use of the ultrasonic tool during cement removal in patients with poor cardiorespiratory reserve could be life threatening. Therefore, the author suggests screening patients to determine the appropriate mechanical procedure during revisions of THAs and TKAs.

\subsubsection{Intramedullary Nailing}

Figure 2.2: Intramedullary Nail

Since the 1960s, intramedullary nailing has become a common procedure in early stabilization of fractured femurs and tibias. In the procedure, an intramedullary nail, i.e., a long rod (Figure 2.2) is implanted within the intramedullary canal of the fractured bone, thus bridging the two fragments of bone. In recent years, the procedure has been modified to accompany restrictions that are present with the simple nailing procedure. Surgeons now have the option of a reamed or unreamed nailing procedure when dealing with fractured femurs and tibias. ${ }^{22}$ Reamed procedures are performed when the intramedullary canal requires sizing for certain prosthetic nails.

Though intramedullary nailing in general has seen great success regarding reunion of fractures, complications remain. Rommens et $\mathrm{al}^{23}$ presented a case regarding an 
unsuccessful unreamed nailing of the tibia. The patient who was a 17-year-old woman sustained a closed, short, oblique fracture of the tibia. Early stabilization of the tibia fracture consisted of an unreamed nailing procedure with a $10 \mathrm{~mm}$ Brooker-Wills tibial nail. The procedure failed because the $10 \mathrm{~mm}$ nail was too thick for the narrow medullary canal, resulting in a failed advancement of the nail through the intramedullary canal. At that time, the $10-\mathrm{mm}$ tibial nail was the smallest diameter available to surgeons. The surgeons were left with no option but to insert an $11 \mathrm{~mm}$ reamed AO tibial nail. Unfortunately, this ultimately resulted in the development of FES by the patient. This particular case demonstrates how smaller intramedullary canals may result in a higher risk of FES and how restrictions exist in unreamed nailing procedures. ${ }^{23}$

The relative merits of reamed versus unreamed intramedullary nails remains a subject of controversy. Heim et $\mathrm{al}^{24}$ studied the intramedullary pressure during the nailing of intact cadaveric femurs and tibias using reamed and unreamed techniques. The results showed that the first $9.0 \mathrm{~mm}$ reamer displayed the highest value of intramedullary pressure. However, as the reamer size increased by $0.5 \mathrm{~mm}$ intervals up to $12.5 \mathrm{~mm}$, the intramedullary pressure began to decrease. For femoral nailing, results indicated that there was no significant difference in the intramedullary pressure when comparing the reamed and unreamed nailing procedures, but for tibial nailing, the intramedullary pressure did show a significant decrease for unreamed nailing. ${ }^{24}$ These results are in disagreement with those of Kropfl et $\mathrm{al}^{25}$ who showed that, in the case of femoral nailing, use of an unreamed nail insertion exhibited a smaller rise in pressure in the intramedullary cavity than a reamed case. Kropfl et al. also found a correlation between the amount of bone marrow fat intravasation and if the procedure was reamed or 
unreamed. It was discovered that the reamed procedure had a higher level of fat intravasation when compared to the unreamed procedure. ${ }^{25}$

\subsubsection{Reaming of the Intramedullary Canal}

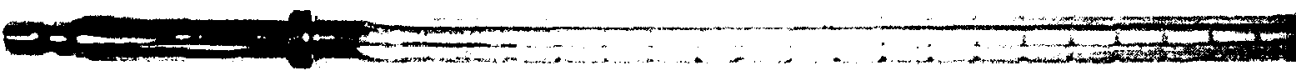

Figure 2.3: Intramedullary Reamers

For reamed intramedullary nailing, and for some TKA and THA procedures, it is necessary to first ream the intramedullary canal before insertion of the implant (using intramedullary reamers, Figure 2.3). Muller et $\mathrm{al}^{26}$ studied the effect of blunt and sharp reamers on intramedullary pressure and cortical temperature. The measurements were carried out using human femora submerged in a water bath at $37^{\circ} \mathrm{C}$ to simulate normal body conditions. The main findings of the research were that the temperature and pressure increased more using the blunt reamers. For example, the intramedullary pressure increased by a factor of 2.1 times in the diaphyseal area of the femur and 1.7 times in the metaphyseal. The maximum pressure that was calculated using the experimental setup was $953 \mathrm{~mm} \mathrm{Hg}$, whilst the peak cortical temperature for the sharp reamer was $40.1^{\circ} \mathrm{C}$, and for the blunt reamer it was $46.3^{\circ} \mathrm{C}$. The study effectively demonstrated the importance of using sharp reamers to reduce the risk of both high 
cortical temperature, because of possible damage to cell enzymes within bone (increases the healing time of fracture site), and intramedullary pressure. ${ }^{26}$

Conflicting results exist in the literature regarding the effect of force applied to the reamer on the resulting intramedullary pressure. Muller et al. ${ }^{27}$ also studied the effect of compression force on a reaming procedure of the femoral canal. When a $107 \mathrm{~N}$ compression force was applied to the femur, diaphyseal pressure was $970 \mathrm{~mm} \mathrm{Hg}$, and metaphyseal was $1152 \mathrm{~mm} \mathrm{Hg}$. However, with a $59 \mathrm{~N}$ compression force, the diaphyseal pressure was $206 \mathrm{~mm} \mathrm{Hg}$, and metaphyseal was $367 \mathrm{~mm} \mathrm{Hg}$. The metaphyseal pressure refers to the proximal part of the femur, whereas the diaphyseal pressure refers to the distal part of the femur. These results suggested that the pressure in the medullary cavity may be reduced, if the surgeon performs the operation with less compression force. However, the results of Johnson et al indicated no correlation between pressure and applied force on the drill. ${ }^{28}$

When examining the effect of flexible drive diameter and reamer design on intramedullary pressure, Muller et $\mathrm{al}^{29}$ found that the pressure build-up in the intramedullary cavity is primarily due to the flexible drive shaft. The results were compared to a conventional reamer system $(9.0 \mathrm{~mm}$ drive with a $9.5 \mathrm{~mm}$ AO reamer). When the conventional reamer system was replaced with a $9.5 \mathrm{~mm}$ hollow reamer, the diaphyseal pressure dropped by $19 \%$, and the metaphyseal by $21 \%$. However, when the $9.0 \mathrm{~mm}$ drive shaft was compared with a $7.0 \mathrm{~mm}$ drive setup, the diaphyseal pressure dropped by $61 \%$ and the metaphyseal by $66 \%$. With an $\mathrm{AO}$ reamer setup, the diaphyseal pressure only decreased by $48 \%$ and the metaphyseal by $49 \%$. From these results, it was concluded that a hollow reamer with the smallest possible drive shaft should display the 
lowest possible pressure in the intramedullary cavity. It was also concluded that there was little pressure difference between individual reamer designs (AO, short and hollow) ${ }^{29}$

Frolke et $\mathrm{al}^{30}$ studied the intramedullary pressure using a new generation of Howmedica reamers that had large cutting flutes and a small core compared to an older conventional AO reamer which had small cutting flutes and a large core. The results suggested that the new reamer design resulted in a much lower pressure build up in the intramedullary cavity. This was based on the idea that the new reamer had a larger clearance area for debris escape, which caused a lower pressure generation during the reaming process. ${ }^{30}$ This study suggests and shows that there are numerous possibilities for modification of operative equipment to reduce the pressure within the intramedullary cavity.

Martin et $\mathrm{al}^{31}$ have studied the effect of using proximal and distal venting during intramedullary nailing. A $4.5 \mathrm{~mm}$ hole in the cortex was created, opposite from the pressure transducer, and the intramedullary pressure resulting from reaming of cadaveric femurs with a $9 \mathrm{~mm} \mathrm{AO}$ reamer was measured. It was found that proximal venting reduced proximal pressures to $460 \mathrm{~mm} \mathrm{Hg}$, a $70 \%$ reduction from the unvented case. Distal venting, on the other hand, reduced distal pressures to $30 \mathrm{~mm} \mathrm{Hg}$, a $90 \%$ reduction from the unvented case. The pressure reduction, however, only occurred in the insertion section. For example, when the reamer was inserted distally, the distal pressure was reduced, whereas the proximal pressure saw very little change. Therefore, venting does not solve the problem of high pressure during intramedullary nailing, but rather helps reduce the pressure at the venting location of insertion. However, there is still the 
benefit of reducing the pressure locally by minimizing the time frame of high pressure generation.

\subsection{Treatment}

FES is a serious complication resulting from a long bone fracture and has been widely researched since the early 1860 s. However, the pathogenesis of the syndrome is not fully understood, because of its possible mulitfactorial components. Treatment of FES is non-specific and supportive. Supportive recommendations to offset FES include minimizing the stress response and oxygenation of peripheral tissues (humidified oxygen therapy) ${ }^{4,12}$ Other supportive treatments do exist; however, none of them are widely used to treat the onset of FES. As more is learned about the pathophysiology of FES, the potential for finding a treatment for the syndrome in the near future will become greater. 


\section{Chapter 3}

\section{Experimental Apparatus and Procedure}

The goal of the present chapter is to describe the experimental apparatus that was developed for the parametric studies. The chapter details the selection of a synthetic bone analogue that was used during experimentation.

\subsection{Synthetic Bone Analogue}

Biomechanical studies of the factors leading to the development of FES have generally relied on cadaveric bone specimens, ${ }^{24,25,30}$ which reported intramedullary pressures range from 20 to $1950 \mathrm{~mm} \mathrm{Hg}$. Unfortunately, the large specimen to specimen variability associated with cadaveric bones makes it difficult to generalize or compare the results from various studies. In the mechanical characterization of bone-implant systems, this variability, along with the desire to have a standardized geometry in the research community, has led to the introduction of synthetic bone analogues such as the $2^{\text {nd }}$ and $3^{\text {rd }}$ Generation Composite bones (Pacific Research Laboratories, Vashon, WA, USA). In contrast to cadaveric specimens, composite bones are easily stored, do not age, and have low specimen to specimen variability, whilst retaining mechanical properties that have been shown to be in the range of human cadaver bones. ${ }^{32-35}$ 
Unfortunately, composite bones, which are manufactured from E Glass fibre and polyurethane foam, are unsuitable for studies involving fluid flow through a porous media such as bone, and cannot be realistically machined to reproduce reaming operations. To the author knowledge, not only does there appear to be no commercially available synthetic bones suitable for study of fluid flow, but there also appears to be no literature addressing this question. This is probably due to the difficulty in finding suitable synthetic materials that have an open pore structure and have both the proper pore size and porosity. In the present work, a simplified synthetic bone analogue model system, suitable for simulation of fluid flow through bone, is proposed. The simple geometry and uniform material properties allows for excellent repeatability in experimental parametric studies, and allows for numerical modeling (e.g., Computational Fluid Dynamics studies) of bone fluid flow problems.

\subsubsection{Bone Structure and Properties}

Bone is composed of organic protein collagen and inorganic mineral hydroxyapatite. Together, these components provide mechanical support to various parts of the body. The mineral hydroxyapatite consists of calcium, phosphate, calcium carbonate, calcium fluoride, calcium hydroxide and citrate, comprising approximately 65 to $70 \%$ of the bone's dry weight. The remaining of the bone's dry weight is composed of collagen fibers, making up approximately $95 \%$ of the organic extracellular matrix. The organic material provides flexibility, whereas the inorganic material provides resilience. ${ }^{36}$ 
Long bones (i.e., femur, tibia, etc.) generally consist of both cancellous (also referred to as trabecular, spongy, or non-lamellar) and cortical (also referred to as compact or lamellar) material. Within cortical bone, both haversian and laminar regions are found. The haversian region is composed of an osteon and a haversian canal. Osteons run longitudinally in long bones (femur, tibia) and have a diameter of approximately 200 $\mu \mathrm{m} .{ }^{37}$ The haversian canals consist of blood vessels and nerves supplying nutrients and blood to osteocytes, which are surrounded by lamellae, lacunae, and osteocytes. Lamellae are concentric layers of a mineralized matrix which compose cortical bone, while lacunae are small cavities bordering the concentric layers of lamellae. The lamellae are connected via numerous small channels called canaliculi. Cancellous bone is much more porous than cortical bone and is spongy in appearance. The composition is similar to that of cortical bone, with the presence of lamellae, lacunae and osteocytes. Within the cancellous bone is bone marrow, whose primary purpose is to generate blood cells. ${ }^{37}$

\subsubsection{Porous properties of bone}

It would be very difficult to model a bone analogue which possesses the detailed structure and network of canaliculi described in Section 3.1.1. However, for the purposes of biomechanical parametric studies which require comparative, rather than absolute measurements, a reasonable first approximation would be to assume that bone has an approximately homogeneous porous open cell structure. With this approximation in mind, for study of fluid flow, the properties of human bone that an analogue must match are porosity and pore size. Variation of these properties causes major differences in fluid flow and indeed can be used to distinguish between the cortical and cancellous material. 
The material density of the cortical bone is defined as the wet weight divided by the total volume. It is a function of porosity and mineral content. For cortical bone, the apparent density is the same as the material density as there is no bone marrow space in the bone. The apparent density of the cancellous bone, on the other hand, is related to its mechanical properties such as compressive stiffness and strength. ${ }^{38}$

Porosity is defined as the ratio of void volume to total volume. Bone structural properties are greatly dependent on the loading, disease and aging parameters. ${ }^{39}$ Overall, the porosity of cortical and cancellous bone ranges from $5 \%$ to $30 \%$ and $30 \%$ to $90 \%$, respectively. ${ }^{40}$ For human femurs, Wang and Oingwen recently studied the relationship between age and changes in bone porosity and pore size, using the pulsed nuclear magnetic resonance (NMR) process. ${ }^{41}$ Their findings suggest that cortical porosity ranges from $8 \%$, for young individuals, to $24-28 \%$ for elderly individuals. Typical values for Haversian canal pore size and osteocytic lacunae size were reported as $58 \mu \mathrm{m}$, and $4 \mu \mathrm{m}$, respectively. ${ }^{41}$ The osteocytic lacunae pore sizes are of less importance in choosing a cortical bone substitute, because Haversian canals make up most of the cortical bone structure. Table 3.1, compiled from the literature, shows the porosity and pore size which a reasonable cortical bone analogue must possess.

\begin{tabular}{|c|c|c|c|c|c|}
\hline Bone Type & $\begin{array}{c}\text { Porosity } \\
{[\%]}\end{array}$ & $\begin{array}{c}\text { Apparent } \\
\text { Density } \\
{\left[\mathbf{k g} / \mathbf{m}^{\mathbf{3}}\right]}\end{array}$ & $\begin{array}{c}\text { Pore Size } \\
{[\boldsymbol{\mu} \mathbf{m}]}\end{array}$ & $\begin{array}{c}\text { Modulus } \\
\text { of elasticity } \\
{[\mathbf{M P a}]}\end{array}$ & $\begin{array}{c}\text { Ultimate } \\
\text { strength } \\
{[\mathbf{M P a}]}\end{array}$ \\
\hline Cortical & $5-30$ & 1810 & $3-78$ & $14700-34300$ & $133-295$ \\
\hline Cancellous & $30-90$ & 320 & $100-400$ & $74-522$ & $1.8-9.4$ \\
\hline
\end{tabular}

Table 3.1: Properties of distal femur considered for this study ${ }^{42,43}$ 


\subsubsection{Bone Marrow Properties}

Bone marrow consists of stroma, myeloid tissue, fat, and lymphatic tissues. There are two types of marrow: red, highly vascularized, and consisting of haemopoetic tissue and yellow, not as highly vascularized, and consisting of a large amount of fat cells. ${ }^{44}$ From the point of view of fluid mechanics, bone marrow is classified as a non-Newtonian fluid, as the shear stress is not proportional to the deformation rate. The viscosity of marrow also changes with shear rate and temperature. ${ }^{45}$ These factors have made it difficult to find a suitable replacement for bone marrow. From the structural standpoint, the purpose of marrow is to provide hydraulic resistance and strengthening; in other words, to both provide resistance to fluid flow through the pores and viscous interaction between bone and marrow. ${ }^{45}$

There has unfortunately been very little study of the rheology of bone marrow. Bryant et al. ${ }^{46}$ measured the effect of temperature and shear rate on the viscosity of bovine bone marrow, taken from proximal and distal sites of five radii. The viscosity was found to be independent of temperature above $37^{\circ} \mathrm{C}$ for distal samples, and above $42^{\circ} \mathrm{C}$ for proximal samples. The investigators also found that proximal and distal marrow solidified below $30^{\circ} \mathrm{C}$ and $20^{\circ} \mathrm{C}$, respectively. A very large difference in viscosity between marrow taken from the distal and proximal portions of the femur was also reported. For the temperature range of $20^{\circ} \mathrm{C}$ to approximately $40^{\circ} \mathrm{C}$, the viscosity varied from $0.05 \mathrm{~Pa} \cdot \mathrm{s}(50 \mathrm{cP})$ to $1.0 \mathrm{~Pa} \cdot \mathrm{s}(1000 \mathrm{cP}) .{ }^{46}$ Although the rectal temperature of the human body is approximately $37.1^{\circ} \mathrm{C}$, one can not assume that this is also the temperature at which bone marrow is found ${ }^{47}$ The measurements of Petrakis indicate that the temperature of bone marrow in humans is, on average, $3.2^{\circ} \mathrm{C}$ below the rectal 
temperature, ${ }^{48}$ yielding a temperature of approximately $33.9^{\circ} \mathrm{C}$ for bone marrow in a human femur. Considering the $33.9^{\circ} \mathrm{C}$ temperature, the viscosity representing the distal and proximal regions of the femur yields $50 \mathrm{cP}$ and $600 \mathrm{cP}$, respectively.

\subsubsection{Proposed Model}

\subsubsection{Cortical Bone Substitute}

In order to find an appropriate substitute for the cortical bone for the purposes of reaming studies, only the porous properties of human bone need be matched, as significant amounts of cortical bone are rarely reamed in orthopaedic procedures. The most important of the properties mentioned in Table 3.1 are open cell porosity and pore size, the proper choice of which will ensure that the synthetic bone marrow mixture can escape through the pores when an intramedullary device is inserted.

Several commercially available bone substitutes exist for orthopaedic applications and are summarized in Table 3.2. These non-metallic materials are of organic and inorganic origin, and are often in powder form or small geometric shapes (cubes, cones, squares). The most common application of these is as bone scaffolding, to repair defects or fill in screw holes as a result of orthopaedic procedures. Unfortunately, the majority of these materials have a very large porosity $(60-80 \%)$, compared to what is required to simulate fluid flow in cortical bone (5 - 30 \%). Moreover, most of the materials also have manufacturing restrictions; often, only small geometric shapes can be manufactured, because larger geometric shapes become brittle and impossible to mold. ${ }^{49}$

Polyurethane foam was also considered, as a bone substitute, as it can be manufactured in both solid and cellular form, and has often used as an analogue material 
for characterizing the mechanical properties of bone. For example, Bredbenner and Haug evaluated various substitutes for human cadaveric bone, and concluded that polyurethane foams, such as Synbone and Sawbone, may be used as substitutes in rigid fixation research $^{50}$. These materials have porosity of approximately $20-30 \%$, but the structure of the foams are closed cell, and therefore unsuitable for the present application which requires an open structure, allowing fluid flow through the pores. Recently Pacific Research Laboratories (Seattle, WA, USA) has introduced cellular polyurethane foams with an open cell structure, but the high porosity of $90 \%$ and pore size of $1.5-2.5 \mathrm{~mm}$ make them unsuitable for realistic simulation of flow in bone.

Porous ceramics are another material considered for the present application because of the potential to match cortical bone structural properties, such as pore size and porosity, in an open cell structure. They are currently utilized as aerators, diffusers and purifiers. Some of their applications include: biological purification, ozone injection for drinking water and dispersion of compressed air. Unfortunately, these materials generally have a bubbling pressure characteristic that stops the out flow of liquid through the pores unless a critical pressure is reached, making them unsuitable for the present purposes.

Sintered powder metal porous products (e.g., sintered Stainless Steels tubes) are manufactured by Mott Corporation (Farmington, CT, USA) in standard tube shapes with the pore size of 2, 5, 20, 40, and $100 \mu \mathrm{m}$. The 40 micron pore size with approximate $40.8 \%$ porosity closely imitates the cortical bone properties. This material can also be custom manufactured from metals such as stainless steel, Bronze, Nickel, and Titanium. Although this material closely resembles cortical bone properties, a more cost effective material was selected for the present application. 
Porex Porous Products Group (Fairburn, GA, USA) manufactures ultra high molecular weight Polyethylene (UHMW-PE) that can be custom manufactured in a variety of shapes, sizes, porosities, and pore sizes in an open cell structure. The material has a wide range of applications and used in the healthcare, consumer and industrial markets. This material was found to best meet the requirements for a suitable cortical bone analogue. A porous open-cell plastic cylinder was thus custom manufactured (Porex Porous Products Group, Fairburn, GA, USA) with average porosity of $22.5 \%$ and 40-60 microns pore size, matching the requirements of cortical bone reasonably well. The dimensions were: $32 \mathrm{~mm}$ outer diameter, $16 \mathrm{~mm}$ inner diameter and $350 \mathrm{~mm}$ long tube of porous plastic, custom manufactured with an open cell structure. The porous tube was closed at one end, so that the inner canal was $340 \mathrm{~mm}$ in total length. (Figure 3.1) The other end was left open, allowing for insertion of simulated marrow contents, and the intramedullary device.

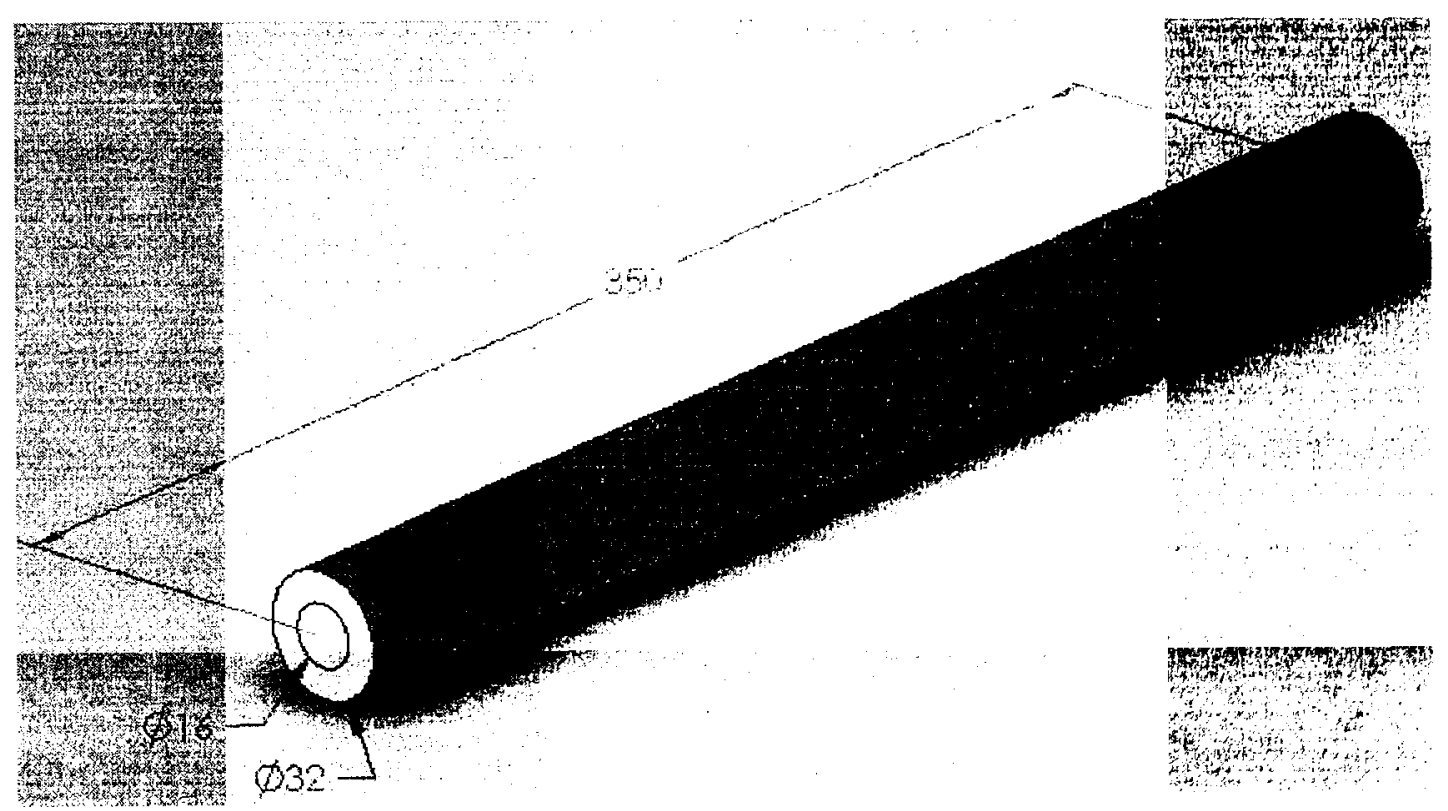

Figure 3.1: Synthetic bone analogue diagram (dimensions in $\mathrm{mm}$ ) 


\subsubsection{Idealized Implants}

A stainless steel cylinder (Length of $200 \mathrm{~mm}$ and diameter of $10 \mathrm{~mm}$, Figure 3.2) with a Teflon end was chosen to represent the intramedullary device, a reasonable approximation to intramedullary devices, such as intramedullary nails and hip prosthetic stems. The Teflon end was chosen to reduce any friction between the inner walls of the cylinder, thereby eliminating one parameter that is, in any case, impossible to control in a clinical setting. Standard flat and tapered tips were custom manufactured to represent intramedullary stem variation in geometry (Figure 3.2).

\section{Llimplant Tp (Tefon)}

\section{Itedinplant Tip (Teilon)}

Figure 3.2: Intramedullary Device

\subsubsection{Bone Marrow Analogue}

To reproduce the viscoelastic properties of bone marrow, a petroleum jelly and liquid paraffin mixture has been proposed by a number of researchers. ${ }^{29,51}$ The most common ratio of paraffin to petroleum jelly used has been approximately $1: 2$, giving viscoelastic properties at $20^{\circ} \mathrm{C}$ equivalent to those of bone marrow fat at approximately $36^{\circ} \mathrm{C}^{29}$ These studies, however, failed to measure the viscosity of the mixture, and it was found to be so viscous as to not allow liquid to escape through the cortical bone analogue. A more realistic behaviour that allowed more easy flow through the porous cortical bone substitute, necessary for comparison with numerical models, was found with a $45 / 55 \%$ 
petroleum jelly/paraffin mixture. Glass and stainless steel balls were used in a Gilmont falling ball viscometer (Gilmont Instruments, Barrington, IL, U.S.A.) to measure the viscosity of the mixtures in the $20-1000 \mathrm{cP}$ range. The mixture of petroleum jelly and paraffin was heated to $60^{\circ} \mathrm{C}$ and then cooled to a room temperature of approximately $20^{\circ} \mathrm{C}$, to eliminate the bubble formation during the mixing and to create a homogenous thick fluid substance.

The experiments for the calculation of the viscosity of the petroleum jelly and paraffin mixture were repeated three times to ensure accuracy and repeatability $(2.5 \%$ variation). The $45 / 55 \%$ petroleum jelly to paraffin mixture was used as the standard for experiments aimed at verifying the numerical models of fluid flow in bone ${ }^{52}$ and had a viscosity of $82.6 \mathrm{cP}$, which is still in the range $(50 \mathrm{cP}$ to $600 \mathrm{cP})$ of that found between the distal and proximal bone marrow in the femur. For the experimental parametric studies of Section 4.0, which aim to determine the effect of viscosity on intramedullary pressure, 40/60, 45/55 and 50/50 ratio of petroleum jelly/paraffin, yielding viscosities of $59.4 \mathrm{cP}, 82.6 \mathrm{cP}$ and $146.4 \mathrm{cP}$, respectively, were used. These viscosities fall within the realistic range for human marrow.

\subsection{Experimental Apparatus}

An experimental apparatus (Figure 3.3) capable of measuring simulated intramedullary pressures in response to insertion of an intramedullary device into the bone analogue utilizing various implant tip geometries, peak hammering forces, hammer tip material, implant to bone cortical wall gaps and fluid viscosities, was constructed. A swinging pendulum with an adjustable hammer mount was used to generate a controlled 
hammering force. An impulse hammer (Dytran 5800B4, Dytran Instruments, Inc., Chatsworth, CA, USA), having the capability to measure the force of the hammering as a function of time, was attached to the hammer mount, together with a weight, which controlled the peak hammering force. The bone analogue was filled with the petroleum jelly/liquid paraffin bone marrow analogue and mounted on a rail system, which allowed it to move forward after each hammer strike. The cylinder was tapped at four locations (75 mm apart) along the span, and a pressure transducer (Kulite XTM190 5-Wire, Kulite Semiconductor Products Inc., Leonia, NJ, USA) was inserted into each hole (Figure 3.4). The displacement of the implant in response to the hammering was obtained from a draw-wire displacement sensor (MicroEpsilon WDS-500, Micro-Epsilon Messtechnik GmbH \& Co., Ortenburg, Germany). All instruments were calibrated by the corresponding manufacturer and verified by A-Tech instruments (Toronto, ON, Canada). 


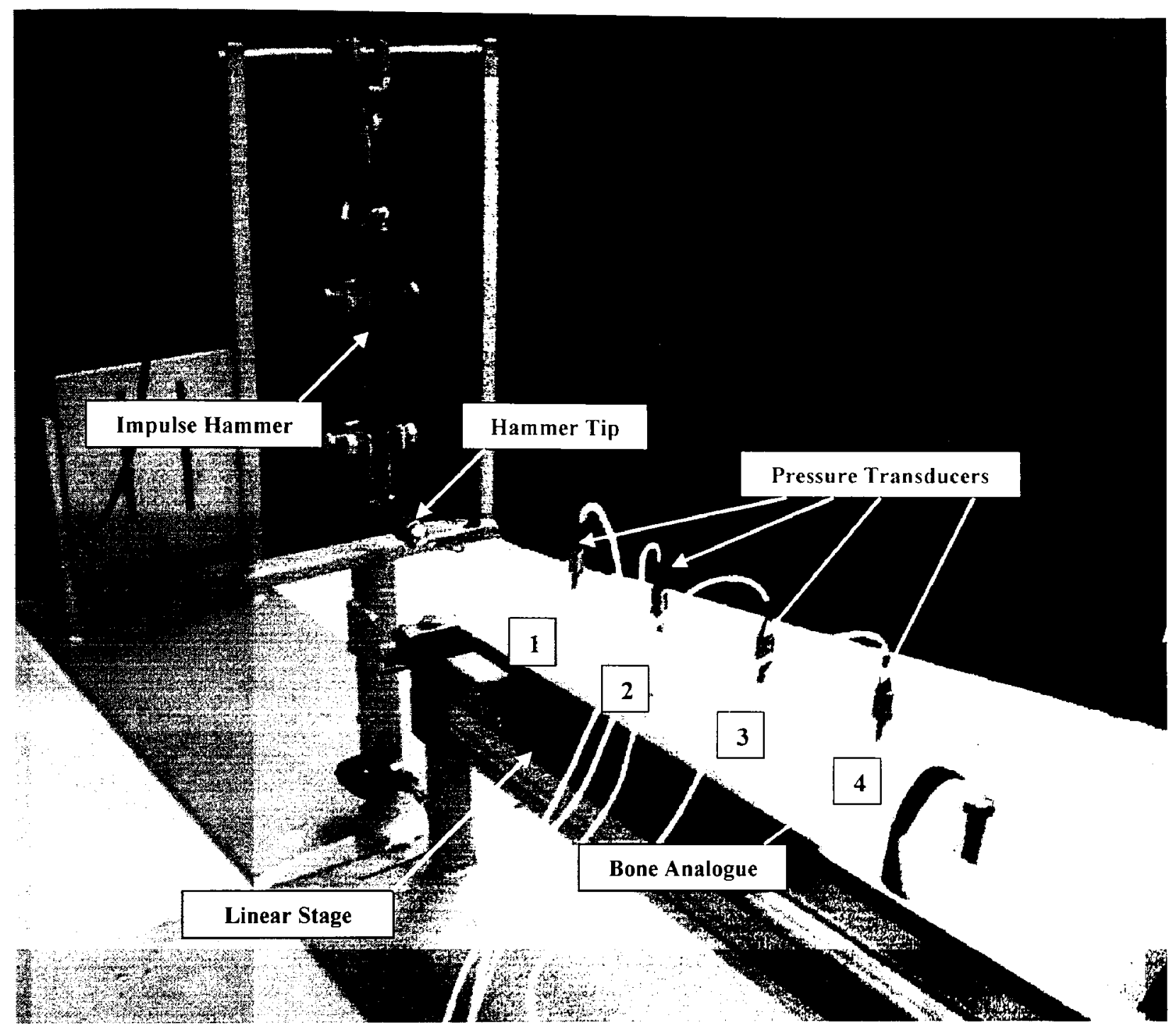

Figure 3.3: Experimental apparatus set-up 


\begin{tabular}{|c|c|c|c|c|c|c|}
\hline $\begin{array}{c}\text { Material/Trade } \\
\text { Name }\end{array}$ & Supplier & $\begin{array}{l}\text { Available } \\
\text { Porosity }\end{array}$ & $\begin{array}{l}\text { Available } \\
\text { Pore Size }\end{array}$ & Composition & Common Use & $\begin{array}{c}\begin{array}{c}\text { Suitability as a cortical } \\
\text { analogue }\end{array} \\
\end{array}$ \\
\hline ProOsteon & $\begin{array}{l}\text { Interpore (Irvine, PA, } \\
\text { USA) }\end{array}$ & $65 \%$ & N.A. & $\begin{array}{l}\text { Coral converted into Hydroxyapatite and } \\
\text { Carbonated Hydroxyapatite }\end{array}$ & $\begin{array}{l}\text { Ttreatment of metaphysical } \\
\text { fractures of long bones. }\end{array}$ & Porosity too high. \\
\hline Cem-Ostetic & $\begin{array}{l}\text { Berkeley Advanced } \\
\text { Biomaterials (Berkeley, } \\
\text { CA, USA) } \\
\end{array}$ & $60-99 \%$ & $\begin{array}{l}100-500 \\
\mu \mathrm{m}\end{array}$ & Hydroxyapatite - Tricalcium Phosphate & $\begin{array}{l}\text { Porous granules used as } \\
\text { resorbable bone defect filler } \\
\text { (putty paste) }\end{array}$ & Porosity too high. \\
\hline Vitoss / Crotoss & $\begin{array}{l}\text { Orthovita (Malvern, PA, } \\
\text { USA) }\end{array}$ & $90 \% / 55 \%$ & $\begin{array}{c}1-1000 \\
\mu \mathrm{m} / \\
280- \\
779 \mu \mathrm{m}\end{array}$ & $\begin{array}{l}\text { Terpolymer of Bisphenol } \alpha \text { Glycidyl } \\
\text { Dimethacrylate, Bisphenol } \alpha \text { Ethoxy } \\
\text { Dimethacrylate and Triethylene Glycol } \\
\text { Dimetha-Crylate }\end{array}$ & Bone defect filler & Porosity too high \\
\hline BoneSource & $\begin{array}{l}\text { Stryker_(Kalamazoo, } \\
\text { MI, USA) }\end{array}$ & N.A. ${ }^{\prime}$ & N.A. $\dagger$ & Hydroxyapatite & Bone defect filler. & $\begin{array}{l}\text { Manufacturability } \\
\text { restrictions }\end{array}$ \\
\hline ChronOs & $\begin{array}{l}\text { Synthes (West Chester, } \\
\text { PA, USA) }\end{array}$ & N.A. $\dagger$ & N.A. $†$ & $\beta$ Tricalcium Phosphate & $\begin{array}{l}\text { Bone filler and used in spinal } \\
\text { fusion applications }\end{array}$ & $\begin{array}{l}\text { Manufacturability } \\
\text { restrictions }\end{array}$ \\
\hline Collagraft & $\begin{array}{l}\text { Zimmer (Warsaw, IN, } \\
\text { USA) }\end{array}$ & N.A. $\dagger$ & N.A. $\dagger$ & Hydroxyapatite-Tricalcium Phosphate & $\begin{array}{l}\text { Total joint replacement and } \\
\text { fracture repairs. Bone defect } \\
\text { filler }\end{array}$ & $\begin{array}{l}\text { Manufacturability } \\
\text { restrictions }\end{array}$ \\
\hline Osteoset & $\begin{array}{l}\text { Wright Medical } \\
\text { (Arlington, TN, USA) }\end{array}$ & N.A. ${ }^{\top}$ & N.A. $\dagger$ & $\begin{array}{l}\text { Calcium phosphate and demineralized } \\
\text { bone }\end{array}$ & $\begin{array}{l}\text { Spine and pelvis } \\
\text { applications, bone filler }\end{array}$ & $\begin{array}{l}\text { Manufacturability } \\
\text { restrictions }\end{array}$ \\
\hline Skelite & $\begin{array}{l}\text { Millenium Biologix } \\
\text { (Kingston, ON, Canada) }\end{array}$ & N.A. $\dagger$ & N.A. $\dagger$ & Synthetic resorbable bone graft & - Bone defect repair. & $\begin{array}{l}\text { Manufacturability } \\
\text { restrictions }\end{array}$ \\
\hline $\begin{array}{l}\text { Polyurethane } \\
\text { Foam }\end{array}$ & $\begin{array}{l}\text { Pacific Research } \\
\text { Laboratories (Seattle, } \\
\text { WA, USA) }\end{array}$ & $20-30 \%$ & $0.5-1.0 \mathrm{~mm}$ & $\begin{array}{l}\text { Cellular rigid polyurethane foam with a } \\
\text { cell structure that is } 95 \% \text { closed. }\end{array}$ & $\begin{array}{l}\text { Alternative test medium for } \\
\text { human bone. }\end{array}$ & Closed cell structure \\
\hline Porous Ceramics & $\begin{array}{l}\text { Advanced Cerametrics } \\
\text { (Lambertville, } \mathrm{NJ}, \\
\text { USA) }\end{array}$ & $15-30 \%$ & $55 \mu \mathrm{m}$ & High purity aluminum oxide & $\begin{array}{l}\text { Used as aerators, diffusers } \\
\text { and purifiers. }\end{array}$ & $\begin{array}{l}\text { Bubbling pressure restraint } \\
\text { and material is very brittle }\end{array}$ \\
\hline Porous Plastics & $\begin{array}{l}\text { Porex Porous Products } \\
\text { Group (Fairburn, GA, } \\
\text { USA) }\end{array}$ & $15-30 \%$ & $40-60 \mu \mathrm{m}$ & UHMW- Polyethylene & $\begin{array}{l}\text { Wide range of applications } \\
\text { in the healthcare, consumer } \\
\text { and industrial markets. }\end{array}$ & $\begin{array}{l}\text { Very good candidate for } \\
\text { cortical bone replacement }\end{array}$ \\
\hline $\begin{array}{l}\text { Sintered Stainless } \\
\text { Steels }\end{array}$ & $\begin{array}{l}\text { Mott Corporation } \\
\text { (Farmington, CT, USA) }\end{array}$ & $50 \%$ & $60-70 \mu \mathrm{m}$ & $\begin{array}{l}\text { Open cell porous Stainless Steel. 316L } \\
\text { Stainless steels. Also available in 304L, } \\
310,347 \text { and } 430 \text { stainless steel, Nickel } \\
200 \text {, and titanium. }\end{array}$ & $\begin{array}{l}\text { Filtration purposes in } \\
\text { chemical, food, and refinery } \\
\text { industry }\end{array}$ & $\begin{array}{l}\text { Very good candidate for } \\
\text { cortical bone replacement if } \\
\text { customized into required size }\end{array}$ \\
\hline
\end{tabular}

Table 3.2: Candidate cortical bone analogues

$\dagger$ Information not released by the manufacturer due to proprietary reasons. 


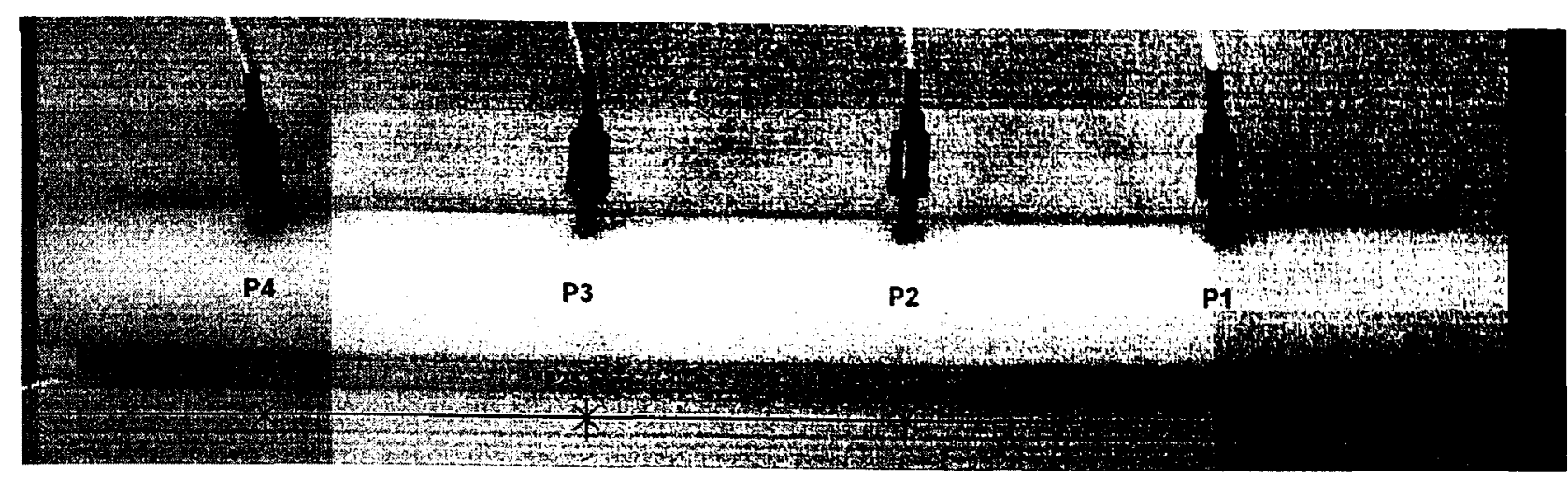

Figure 3.4: Bone analogue with locations of pressure transducers. Note that the implant was inserted from the right hand side.

\subsection{Data Acquisition System}

The data acquisition (DAQ) system (IOtech DaqBook 2000, IOtech Inc, Cleveland, $\mathrm{OH}, \mathrm{USA}$ ) that was selected for data collection was an external module system (Figure 3.5). The 32 channel DAQ was connected via a parallel cable to a Pentium 4-2.6GHz computer. The raw data were collected at $200 \mathrm{kHz}$ acquisition rates from the 32 possible transducers. The system can accept inputs from a number of sensors such as strain gauges, thermocouples and generic inputs.

The analog input module (Figure 3.5) is composed of two DBK207 carrier boards. The DBK207 carrier boards were connected to analog input module boards, which allowed the DaqBook2000 system to use various combinations of sixteen signalconditioning modules. For the present work, six channels were used to collect data from the sensors (four pressure sensors, one impulse sensor and one displacement sensor). The system was built for flexibility to carry out experiments in the FES research area. 


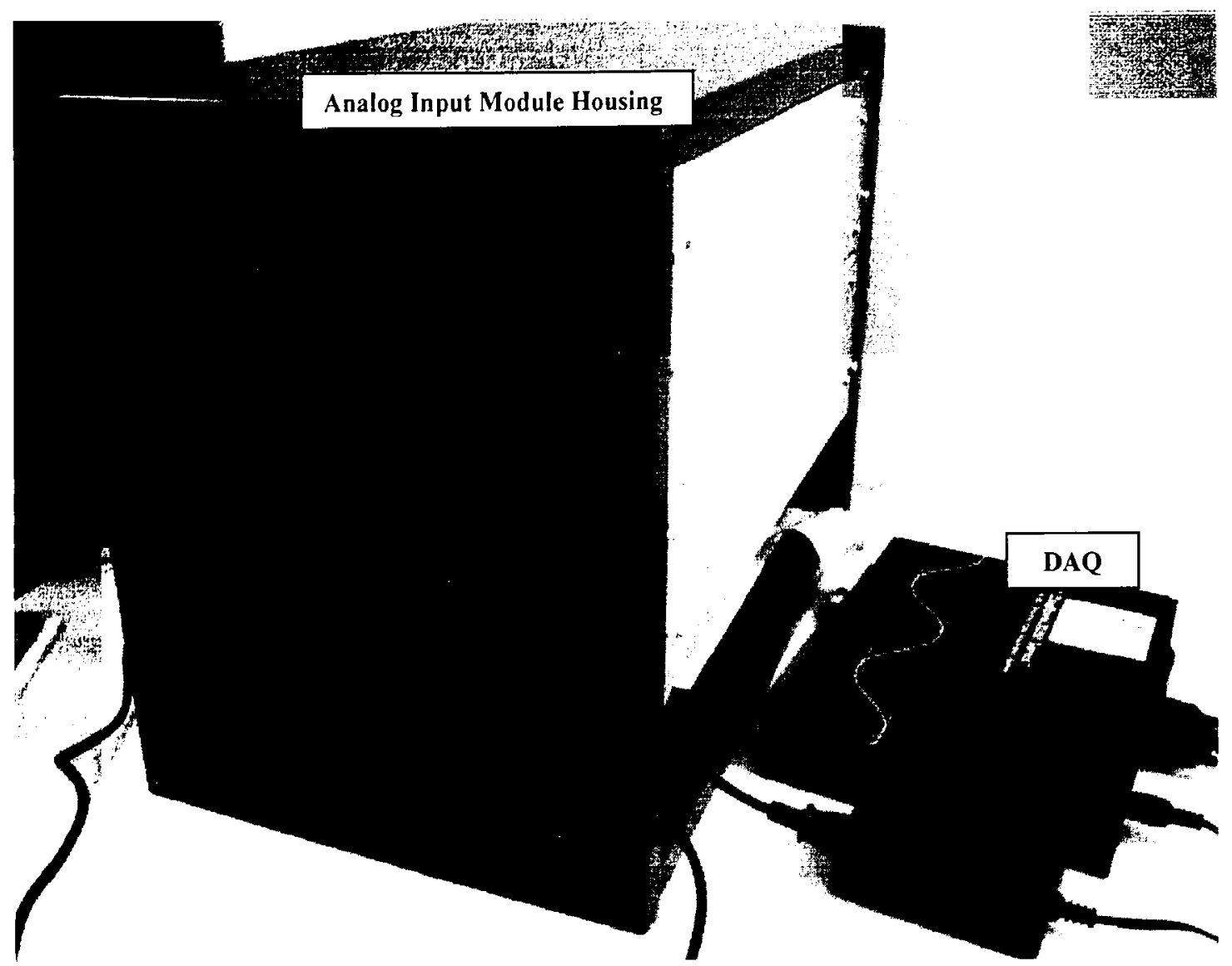

Figure 3.5: Analog Input Module and Daqbook 2000

\subsubsection{Pressure Transducers}

The pressure transducer (Figure 3.6) that was chosen to measure the intramedullary pressure within the canal was the Kulite XTM190 miniature pressure transducer (Kulite Semiconductor Products Inc., Leonia, USA). The transducer utilizes a metal flush diaphragm housing as the force collector and Piezoresistive sensor as its sensing element. It also has the capability to measure the temperature at the diaphragm location because of the additional $5^{\text {th }}$ wire thermocouple system. The maximum rated pressure of the transducer is $50 \mathrm{PSI}(2585 \mathrm{mmHg})$. 


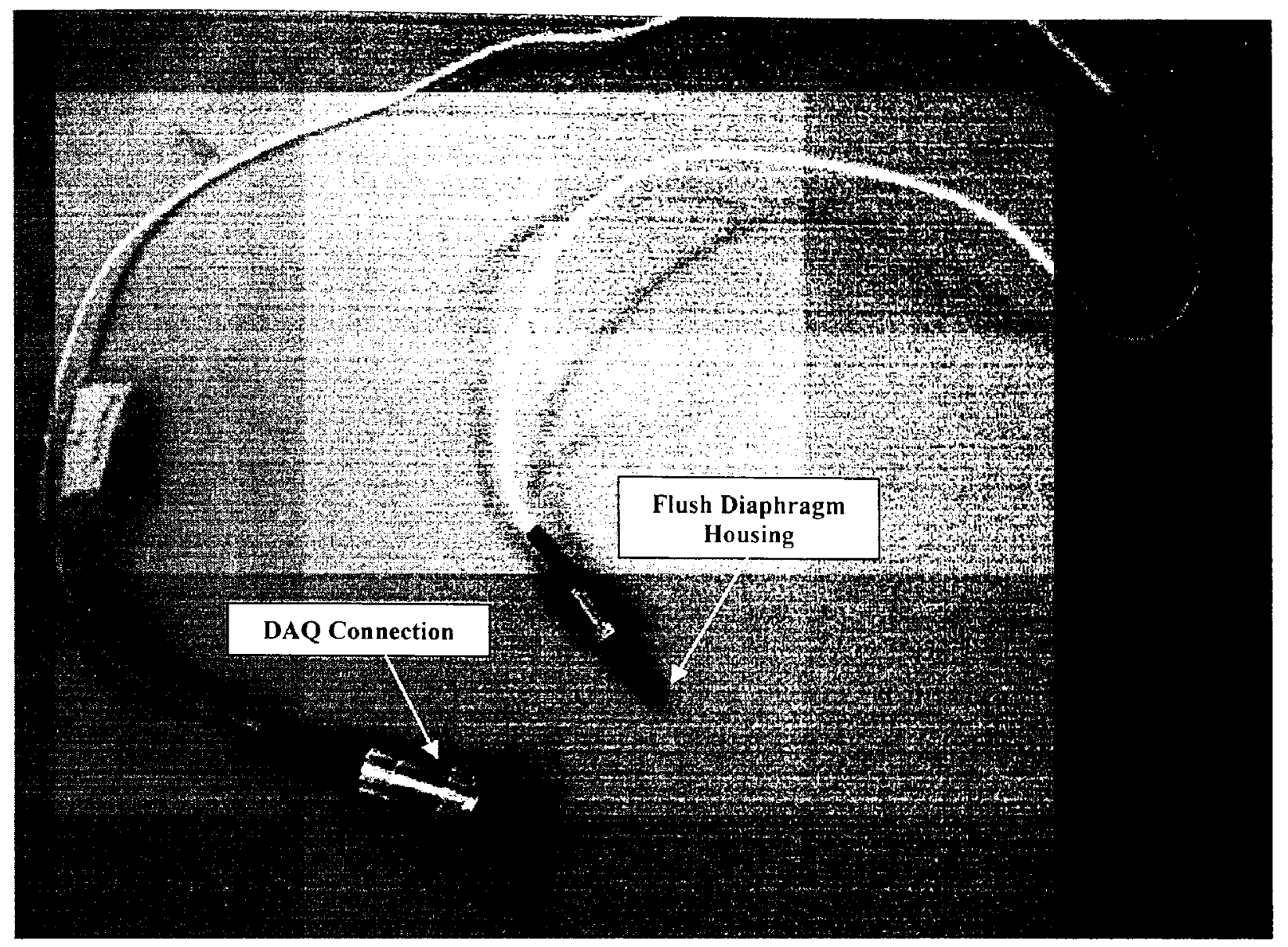

Figure 3.6: Pressure Transducer

\subsubsection{Impulse Hammer}

The impulse hammer (Figure 3.7) that was chosen to measure the impulse forces during the hammering procedure was the Dynapulse 5800B4 impulse hammer (Dytran Instruments, Inc., Chatsworth, USA). The Dytran impulse hammer uses an acceleration compensated piezoelectric force sensor. On the tip of the hammer, impact tips of various materials can be placed (aluminium, steel, plastic and rubber). The maximum rated impulse force for the hammer is $2224 \mathrm{~N}$. 


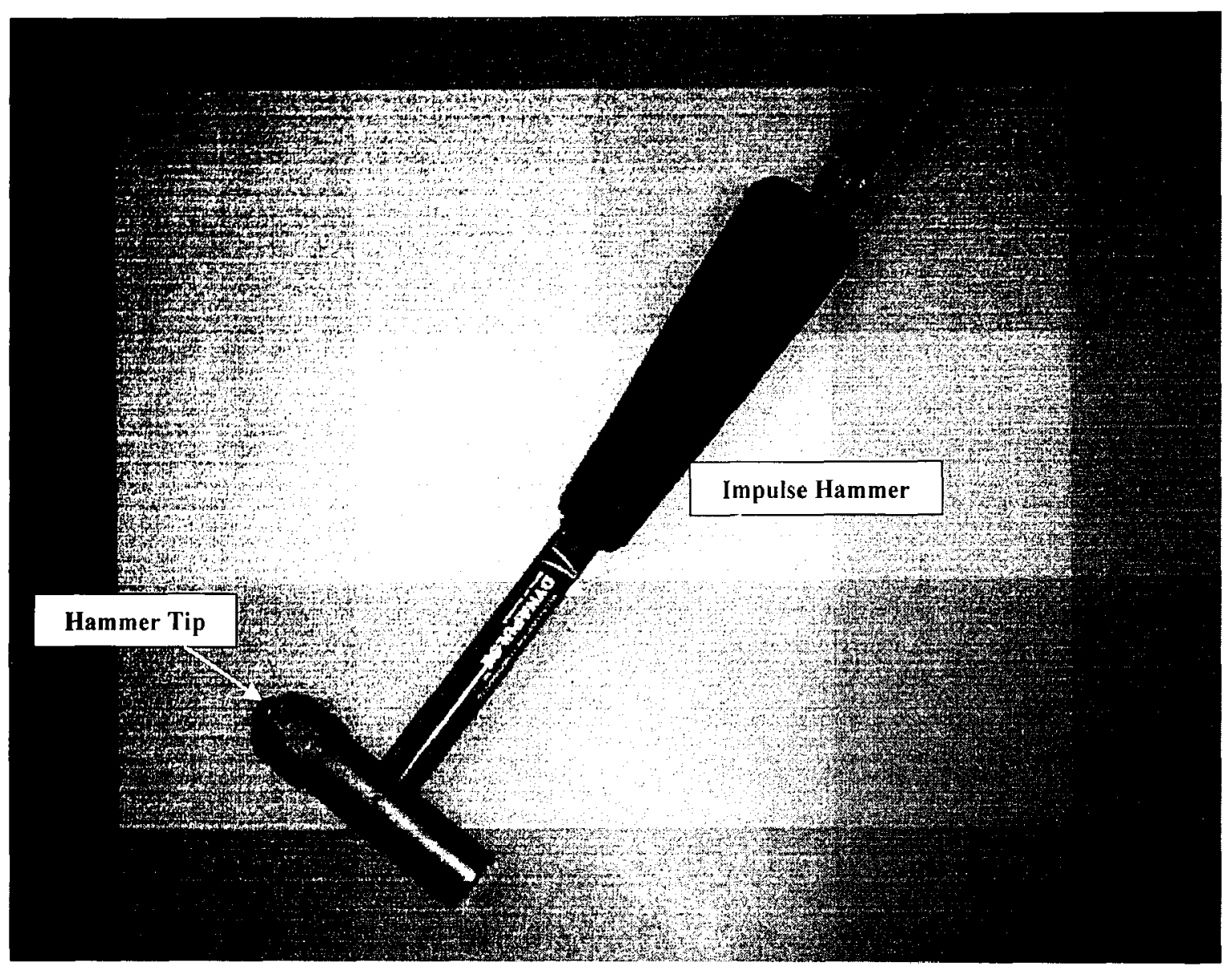

Figure 3.7: Impulse Hammer

\subsubsection{Displacement Sensor}

The displacement sensor (Figure 3.8) that was chosen to measure the displacement of the intramedullary device after each strike during the hammering procedure was the MicroEpsilon WDS-500 draw-wire displacement sensor (MicroEpsilon Messtechnik GmbH \& Co., Ortenburg, Germany). The sensor features a robust sensor housing and a $0.45 \mathrm{~mm}$ diameter wire that is able to measure displacements of 500 $\mathrm{mm}$. The only drawback of the sensor is that the wire exhibits a negative tension force which made it difficult to attach to the apparatus. However, the price/performance ratio made the sensor very attractable for the application. 


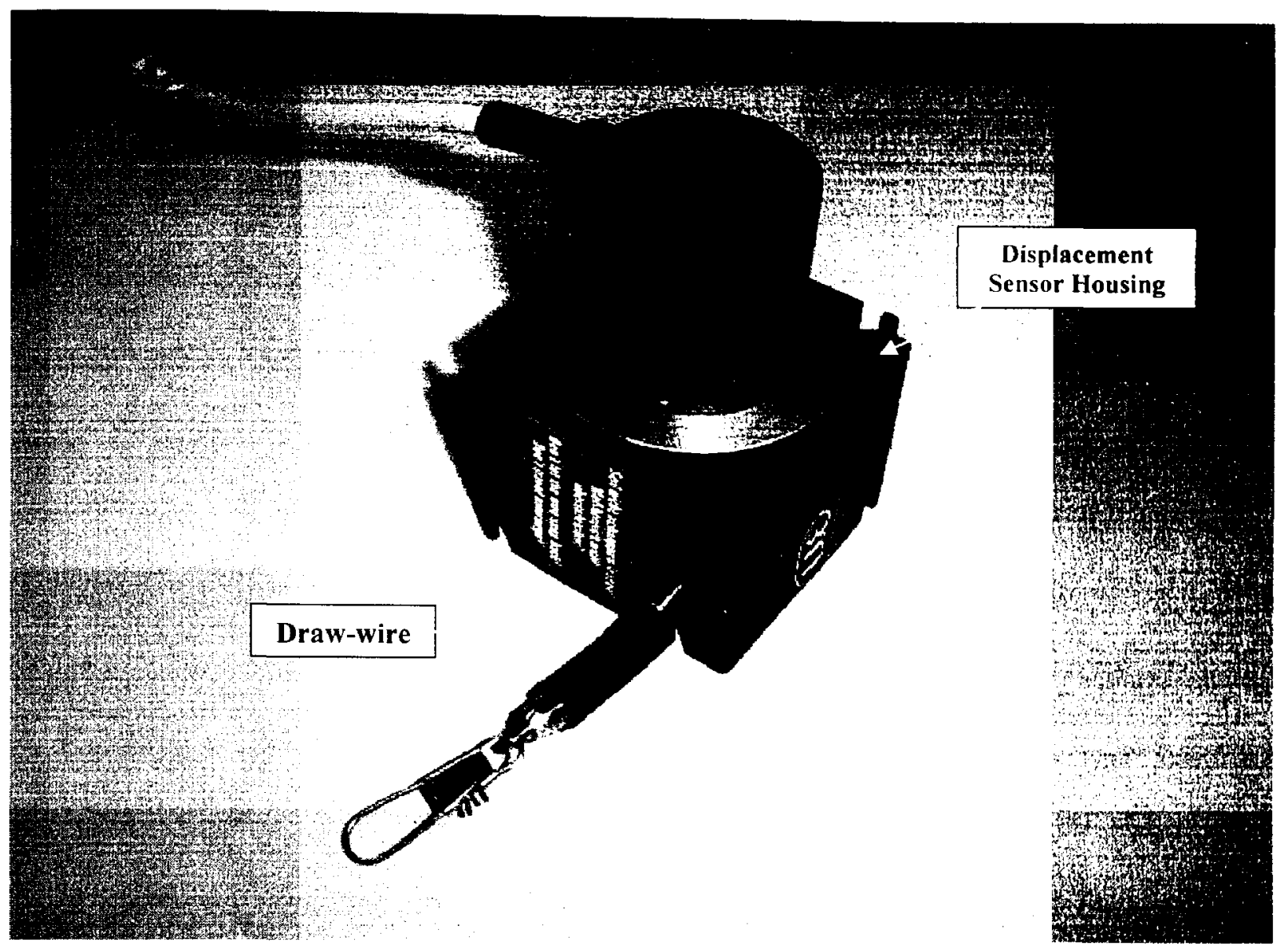

Figure 3.8: Displacement Sensor

\subsection{Experimental Procedure}

A large number of experiments were performed to carry out an experimental parametric study (see Chapter 4) and verify numerical models of fluid flow in bone (see Chapter 5). The parameters of interest were: fluid viscosity, hammering force, clearance between implant and cylinder, hammer tip material, and implant tip geometry. Each experiment involved the insertion of the implant into the cylindrical bone analogue to a depth of $15 \mathrm{~cm}$, using a varying number of hammer strikes, whilst recording the resulting intramedullary pressures at the four locations shown in Figure 3.4. Insertion rate and total number of hammer strikes are resulting parameters based on specific experiment. The bone analogue was first completely filled with the synthetic bone marrow and then placed 
horizontally on the rail system, with the pressure transducers located a the top surface of the cylinder, and facing downwards. The impulse forces were created by the impact of the hammer pendulum setup described in Section 3.2 at various release points corresponding to $45^{\circ}, 60^{\circ}$ and $75^{\circ}$ angles, measured with respect to the horizontal. The shape and magnitude of the resulting impulse forces are described in more detail in Chapter 4.

In many cases, the synthetic bone marrow was seen escaping through the open cell structure to the exterior of the tube subsequent to each hammer strike. Attempts to calculate the mass flow escape of fluid proved fruitless, because the fluid tended to retract into the porous tube after each strike. Therefore, there was no clear indication of how much liquid actually was escaping during the experiment, because after the completion of the experiment, the liquid that escaped retracted back into the pores.

Depending on the particular parametric values, the experiments took between 120 and 300 seconds to perform, resulting in between 3 to 6 million data samples per transducer. In all, two bone analogue systems were used for all the experiments performed; after each experiment was performed, the porous plastic tubes were cleaned to remove any fluid within the pores. To establish the repeatability of the experiments, one set of experiments (rubber hammer tip, standard stem tip geometry, $1.0 \mathrm{~mm}$ clearance gap, $82.6 \mathrm{cP}$ synthetic bone marrow viscosity and a $90 \mathrm{~N}$ peak impulse force) was repeated three times. The maximum variation in pressures between runs was found to be $5 \%$, confirming the excellent repeatability associated with artificial bone analogue systems. 


\subsection{Synthetic Bone Analogue Performance}

The synthetic bone analogue (discussed in Section 3.1) can be used for a variety of experimental studies. For applications in which simulation of hammering of a press fit implant into a bone is desired, the cortical bone substitute can be used without the cancellous bone substitute, as the cancellous porosity is much higher than that of cortical bone. In any case, in press fit applications, most of the cancellous bone is reamed away before insertion. Numerous experiments have been performed with the presently proposed cortical synthetic bone analogue for a parametric study involving the effect of parameters such as: impulse force of the hammering, stem tip geometry, clearance gap between the implant and intramedullary cavity and fluid viscosity, on the resulting pressure inside the bone cavity (discussed in Chapter 4). Each set of experiments involved the hammering of the implant into the cylindrical bone analogue. The stem was hammered into a total depth of $150 \mathrm{~mm}$, and after each impulse force, the pressure values were obtained. The variability between the experimental runs was minimal with an approximate variation of $5.0 \%$ or less, based on three sets of experiments. The pressure range obtained with the synthetic bone analogue, $263-2200 \mathrm{~mm} \mathrm{Hg}$, are in good agreement with the range reported in previous studies based on cadaveric specimens, which resulted in measured intramedullary pressures of $20-1950 \mathrm{~mm} \mathrm{Hg}$.

The proposed cortical synthetic bone analogue has also been used in experimental and numerical comparison studies. Experimental pressure values were obtained with the same procedure as the parametric study, and these values were compared to CFD numerical models. The pressure variation between the two models was approximately 20 
$\%$ when comparing the peak pressures generated during the insertion of the stem into the cylinder (discussed in Chapter 5) 


\section{Chapter 4}

\section{Parametric Study}

The objective of the present work was to use a synthetic bone analogue to examine the effect of operative process parameters and implant design on the intramedullary pressure resulting from the insertion of an intramedullary device into the femur. The use of the bone analogue provides a well defined and repeatable baseline on which to study the relative effects of changes in process parameters, which cadaveric experiments unfortunately cannot provide. In particular, the effect of varying implant tip geometry, peak hammering force, hammer tip design, bone to implant radial gap, and marrow viscosity will be examined. The results will be used to suggest modified operative procedures aimed at reducing intramedullary pressure build-up, and thus also reducing the risk of FES.

\subsection{Experimental Method}

Parametric studies were performed to study the effect of fluid viscosity, hammering force, radial gap between implant and simulated bone, hammer tip material, and implant tip geometry. In all experiments, the bone analogue was first filled with the petroleum jelly/paraffin wax mixture, and then mounted horizontally with the pressure 
transducers on the top of the bone, on a rail system, which allowed it to move forward after each hammer strike. Each experiment involved the insertion of the implant into the cylindrical bone analogue to a depth of $175 \mathrm{~mm}$, using a varying number of hammer strikes, whilst recording the resulting intramedullary pressures at the four locations shown in Figure 3.4. The implant was initially inserted $25 \mathrm{~mm}$ into the bone analogue, and experiments begun from this initial offset. The bone analogue was subjected to a controlled hammering, created by the impact of the hammer pendulum setup described in Section 3.1, at various release points corresponding to $45^{\circ}, 60^{\circ}$ and $75^{\circ}$ angles, measured with respect to the horizontal. Table 4.1 summarizes the impact forces resulting from release from these points. The abbreviations used in the table are as follows: $\mathrm{RH}$ and $\mathrm{SH}$ represent rubber and steel hammers, respectively; HF, MF and LF represent high, medium and low forces created during the strike of the hammer, respectively. For example a rubber hammer with a medium force would be represented as RH-MF. The impulse forces are in the same order of magnitude as those recorded when the author struck the implant by hand.

\begin{tabular}{|c|c|c|c|c|}
\hline $\begin{array}{c}\text { Hammer } \\
\text { Type }\end{array}$ & $\mathbf{4 5}^{\circ}$ Release & $\mathbf{6 0}^{\circ}$ Release & $\mathbf{7 5}^{\circ}$ Release & $\begin{array}{c}\text { Abbreviations } \\
{\left[\mathbf{4 5}^{\circ} / \mathbf{6 0}^{\circ} / \mathbf{7 5}^{\circ} \text { Release }\right]}\end{array}$ \\
\hline Rubber Tip & $90 \mathrm{~N}$ & $115 \mathrm{~N}$ & $145 \mathrm{~N}$ & $\mathrm{RH}$ LF/ RH MF / RH HF \\
\hline Steel Tip & $900 \mathrm{~N}$ & N.A. & $1100 \mathrm{~N}$ & $\mathrm{SH} \mathrm{LF} /$ N.A. / SH HF \\
\hline
\end{tabular}

Table 4.1: Peak impact forces generated by releasing the hammer from various angles, and abbreviations used in Figures $4.6-12$.

In many cases, the synthetic bone marrow was seen escaping through the open cell structure to the exterior of the tube subsequent to each hammer strike. However, 
after each strike, the fluid quickly retracted back into the pores, and it was thus impossible to measure how much escaped.

In total, thirty-nine experiments were performed, divided into two sets of parametric studies, as described in Table 4.2. After each experiment, the bone analogue was washed with water to flush out any remaining petroleum jelly/paraffin mixture within the porous of the cylinder, and then allowed to dry. Depending on the particular parametric values, the experiments took between 120 and 300 seconds to perform, resulting in between 3 to 6 million data samples per transducer.

\begin{tabular}{|c|c|c|c|c|c|}
\hline $\begin{array}{c}\text { Parametric } \\
\text { Study }\end{array}$ & $\begin{array}{c}\text { Viscosity } \\
{[\mathbf{c P}]}\end{array}$ & $\begin{array}{c}\text { Bone to } \\
\text { Implant } \\
\text { Radial Gap } \\
{[\mathbf{m m}]}\end{array}$ & $\begin{array}{c}\text { Impact } \\
\text { Force } \\
{[\mathbf{N}]}\end{array}$ & $\begin{array}{c}\text { Implant Tip } \\
\text { Geometry }\end{array}$ & $\begin{array}{c}\text { Hammer } \\
\text { Type }\end{array}$ \\
\hline 1 & 82.6 & $0.5,1.5$ & $\begin{array}{c}90,145 \text { and } \\
900,1100\end{array}$ & Flat, Tapered & $\begin{array}{c}\text { Rubber, } \\
\text { Steel }\end{array}$ \\
\hline 2 & $59.4,82.6,146.4$ & $0.5,1.0,1.5$ & $90,115,145$ & Flat & Rubber \\
\hline
\end{tabular}

Table 4.2: Summary of parameter variation between corresponding studies.

To establish the repeatability of the experiments, one set of experiments (rubber hammer tip, flat implant tip geometry, $1.0 \mathrm{~mm}$ gap, $82.6 \mathrm{cP}$ synthetic bone marrow viscosity and a $90 \mathrm{~N}$ peak impact force) was repeated three times. The standard deviation varied between $200 \pm 5.1,136 \pm 3.6,150 \pm 4.4$ and $133 \pm 4.1$ for pressure transducers 1 through 4, respectively. The maximum variation in instantaneous pressure at any transducer was found to be $5 \%$, confirming the excellent repeatability associated with artificial bone analogue systems. The advancement of the implant was found to be constant with each hammer strike during a specified parametric study. The advancement 
rate increased or decreased depending on the parameters performed in a certain experimental run.

\subsubsection{Parametric Study 1: Effect of implant tip geometry and hammer tip material}

The first row of Table 4.2 represents experiments whose primary purpose was to determine the effect of implant tip geometry and hammer tip material on resulting intramedullary pressure. To determine the effect of varying implant tip geometry, the rubber hammer tip (RH) was used to generate two levels of peak force, $90 \mathrm{~N}(\mathrm{LF})$ and $145 \mathrm{~N}(\mathrm{HF})$, while the viscosity of the fluid was held constant at $82.6 \mathrm{cP}$ (density $=862$ $\mathrm{kg} / \mathrm{m}^{3}$ ). For each of these two peak impact forces, four experiments were performed, varying the bone to implant gap $(0.5$ and $1.5 \mathrm{~mm})$ and the implant tip (flat and tapered). To determine the effect of using steel, as opposed to rubber tip on the implant hammer, a second series of eight experiments was run at the same levels of implant to bone gap and implant tip, with the steel hammer (SH) tip creating peak forces of $900 \mathrm{~N}$ and $1100 \mathrm{~N}$.

\subsubsection{Parametric study 2: Effect of bone marrow viscosity, bone to implant radial gap, and peak hammering force}

The second row of Table 4.2 represents experiments whose primary purpose was to determine the effect of marrow viscosity, bone to implant gap and impact force on resulting intramedullary pressure. For these experiments a flat implant tip and a rubber hammer (RH) was used at three peak impact forces, $90 \mathrm{~N}(\mathrm{LF}), 115 \mathrm{~N}(\mathrm{MF})$ and $145 \mathrm{~N}$ (HF) while the fluid viscosity, the implant to bone gap, and the impact force were varied in the range shown in Table 4.2, resulting in a total of 27 experiments. 


\subsection{Results}

\subsubsection{Hammering impact forces}

Figures 4.1 and 4.2 show typical impact forces generated by the rubber and steel hammer tips when measured under the following condition: fluid viscosity of 82.6 $\mathrm{cP}, 1.0 \mathrm{~mm}$ gap (steel tip under a $1.5 \mathrm{~mm}$ gap) and flat implant tip. The impulse duration for the rubber hammer tip was approximately 3 milliseconds, while for the steel hammer tip it was approximately 0.35 milliseconds. In Figure 4.2, for the steel hammer tip, it can be noted that the peak impact force duration in reality was only 0.20 milliseconds; the additional 0.15 milliseconds of signal corresponded to a vibration, which was damped rapidly.

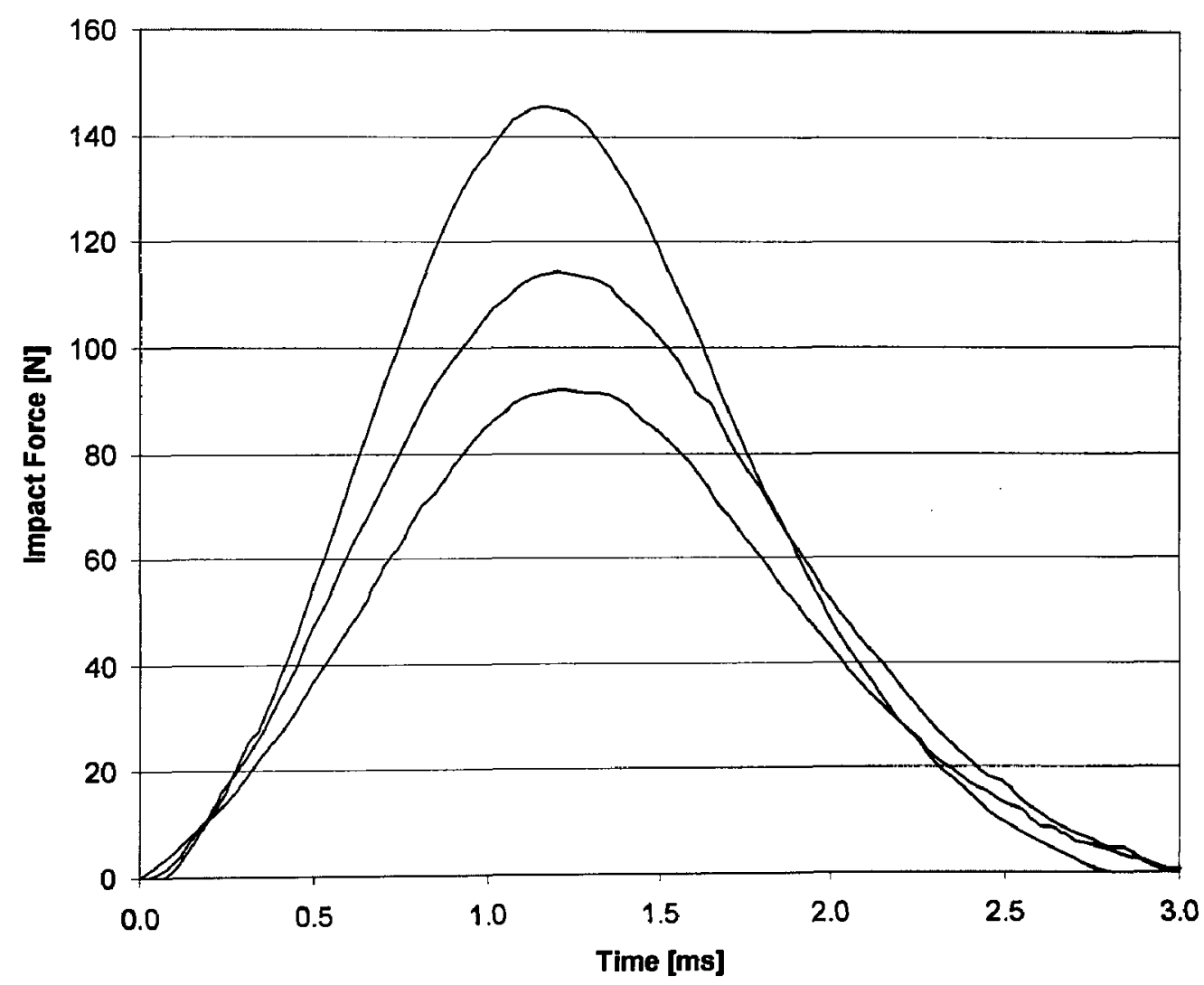

Figure 4.1: Impact force generated by striking implant with the rubber tipped hammer (RH) from release points of: $45^{\circ}(L F$, peak $=90 \mathrm{~N}) ; 60^{\circ}(\mathrm{MF}$, peak $=115 \mathrm{~N}) ; 75^{\circ}(\mathrm{HF}$, peak $=145 \mathrm{~N}$ ). 


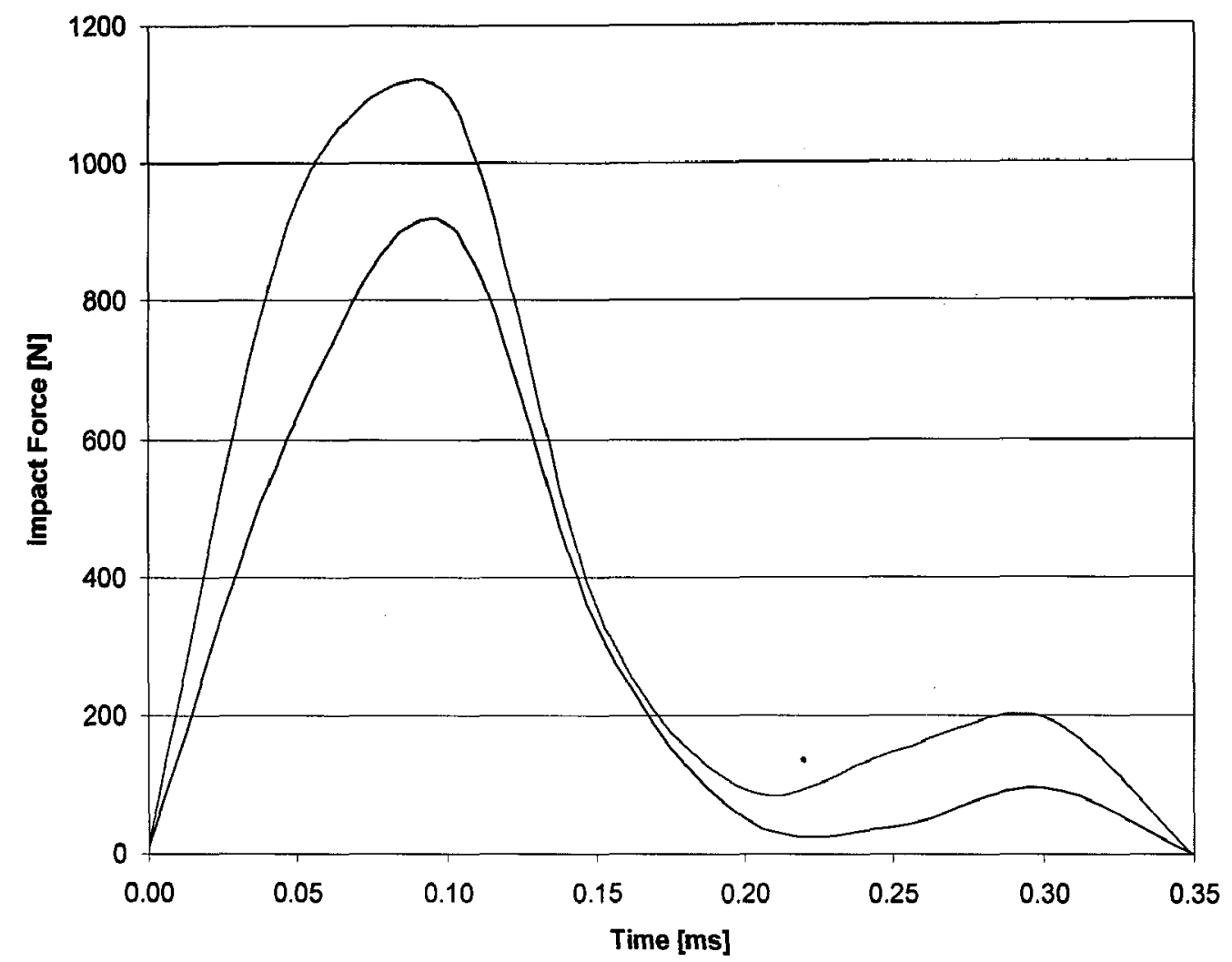

Figure 4.2: Impact force generated by striking implant with the steel tipped hammer from release points of: $45^{\circ}(L F$, peak $=900 \mathrm{~N})$ and $75^{\circ}(\mathrm{HF}$, peak $=1100 \mathrm{~N})$.

It should also be noted that the peak impact force was found to increase with increasing fluid viscosity, and decreasing bone to implant gap. However, this variation was less than $5 \%$ of that reported in Figures 4.1 and 4.2, which can thus be taken as average values, representative of all experiments.

\subsubsection{Typical pressure data}

Typical peak pressure versus time curves generated during the parametric studies, are shown in Figure 4.3, for each of the four pressure transducers (Figure 3.4). The pressure at all locations initially increased during the first strikes, as the contents of the 
bone became pressured. After the $5^{\text {th }}$ strike, the first pressure transducer was approached and passed by the implant. After the $13^{\text {th }}$ strike, the second pressure transducer was approached and passed by the implant, and the same behaviour was exhibited as when the implant passed the first pressure transducer. After the initial sharper rise, pressure transducers 3 and 4 exhibited a slow pressure increase as the analogue continued to be pressurized, until a slight pressure reduction near the end of the experiment, as the reduction in the amount of fluid ahead of the implant tip became significant.

A similar general trend was observed for all other experiments, and thus, to facilitate comparison between various combinations of parameters, only the maximum minimum, and mean value of pressures from each of the transducers is reported in the parametric studies (Refer to Appendix A and B for pressure profiles and data). There were variations from the general trend illustrated in Figure 4.3; however, those were only isolated conditions, where high viscosities and small clearance gaps were present.

\subsubsection{Parametric Study 1: Effect of implant tip geometry and hammer tip material}

\subsubsection{Number of strikes required to insert implant to a depth of $175 \mathbf{m m}$} Tapered versus flat implant tips

Figure 4.4 shows that use of the tapered, as opposed to flat tip, reduced the number of strikes needed for insertion by zero to one for a $1.5 \mathrm{~mm}$ bone to implant radial gap, and one to three, for the $0.5 \mathrm{~mm}$ gap case. The implant tip geometry apparently has only a small effect on the fluid force resisting its advancement. 


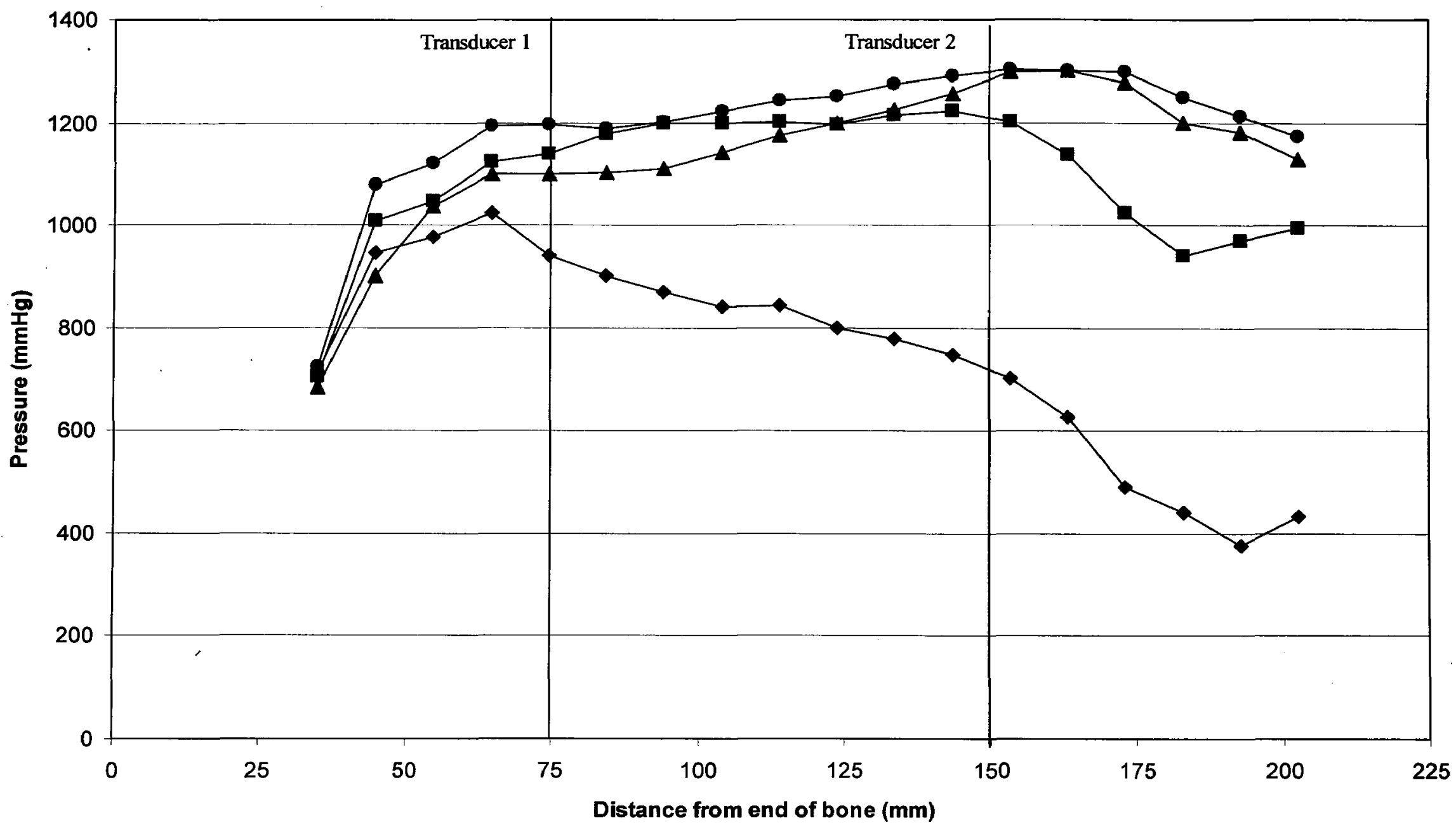

Figure 4.3: Typical pressure variation encountered during parametric studies versus distance implant moved. Values obtained using rubber hammer tip, flat implant tip geometry, $1.0 \mathrm{~mm}$ bone to implant radial gap, $82.6 \mathrm{cP}$ synthetic bone marrow viscosity and a $90 \mathrm{~N}$ peak impact force. Each data point represents one strike. - Transducer 1, $\mathbf{m}$ - Transducer 2, $\Delta$ - Transducer 3 , $\mathbf{0}$ - Transducer 4. Position of first 2 pressure transducers is shown by the two vertical bars. 


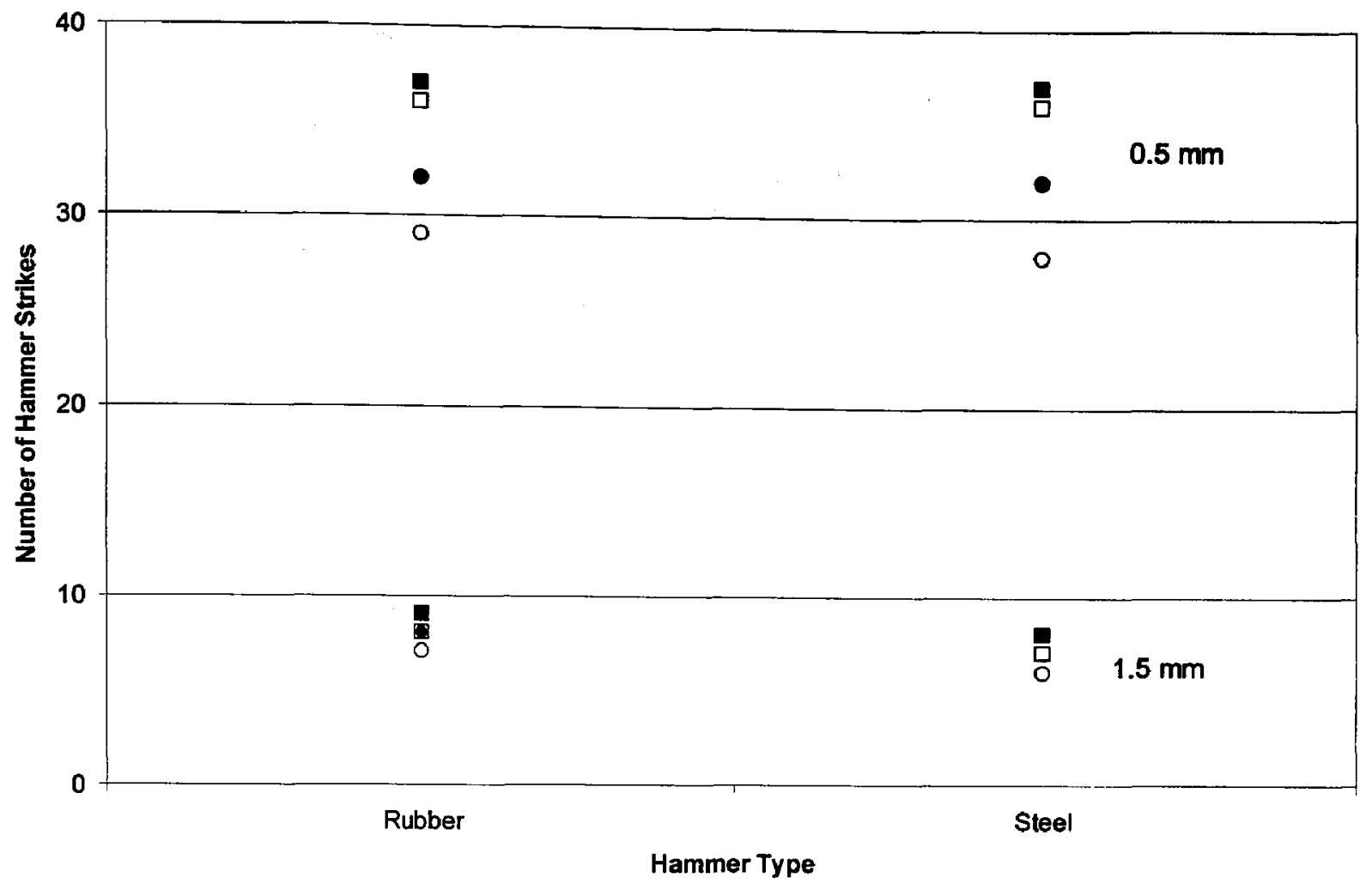

Figure 4.4: Number of impacts required to hammer implant into canal with the given peak impact force, bone to implant radial gap $(0.5 \mathrm{~mm}$ and $1.5 \mathrm{~mm})$, implant tip geometry and hammer type. - LF with flat tip, - HF with flat tip, $\square-L F$ with tapered tip, $\mathrm{O}_{-} \mathrm{HF}$ with tapered tip. In all cases, a viscosity of $82.6 \mathrm{cP}$ was used.

Steel versus rubber hammer material

Figure 4.4 also shows that for both bone to implant gaps and implant tip geometries considered, the effect of changing the hammer tip from rubber to steel was quite small, in terms of number of strikes required for implant insertion. This is somewhat unexpected, given the order of magnitude difference in impact force (see Table 4.1). When changing to the hammer tip from rubber to steel, for the $1.5 \mathrm{~mm}$ gap case, a one strike reduction in 3 out of the 4 cases was noted, whereas for the $0.5 \mathrm{~mm}$ gap, a one strike reduction was noted in 1 out of the 4 cases. 


\subsubsection{Intramedullary pressures}

In Figures 4.5 and 4.6 the mean pressure is displayed as a bar; whereas, minimum and maximum pressures are displayed as error bars. From this point forward, same display properties apply to all figures.

Tapered versus flat implant tips

Figures 4.5 and 4.6 show the maximum, mean, and minimum pressures generated during the hammering of the implant into the simulated intramedullary canal at 0.5 and $1.5 \mathrm{~mm}$ implant to bone gaps. There are only slight decreases in both mean and maximum pressures when using a tapered, compared to flat tip, and, consistent with Fig. 4.3, the mean pressure increased when moving proximally to distally. Overall, the reduction in mean pressure varied between 0.1 (nearest to implant) and $9.4 \%$ (furthest from the implant). Similar percentage reductions were noted for the maximum pressures $(0.1-14.5 \%$ reduction). The total average mean pressure reduction was $3.3 \%$, whereas the total average maximum pressure reduction was $4.7 \%$. Implant tip geometry apparently has only a small effect on the pressure generated within the intramedullary canal.

Steel versus rubber hammer material

Figures 4.7 and 4.8 illustrate the pressures resulting from the hammering of a flat tipped implant into the simulated bone using two types of hammer tips. For both values of bone to implant gap, use of the rubber hammer tip, as opposed to the steel hammer tip, resulted in a marked reduction of mean pressure $(1.3-23.9 \%)$ in the two most proximal 
transducers, but resulted in a mean pressure increase $(1.1-23.1 \%)$ in the most distal transducers. The maximum pressure values followed a similar trend. For both values of bone to implant gap, use of the rubber hammer tip, as opposed to the steel hammer tip, resulted in a marked reduction of maximum pressure $(0.6-29.6 \%)$ in the two most proximal transducers, but resulted in a mean pressure increase $(3.1-13.9 \%)$ in the most distal transducers.

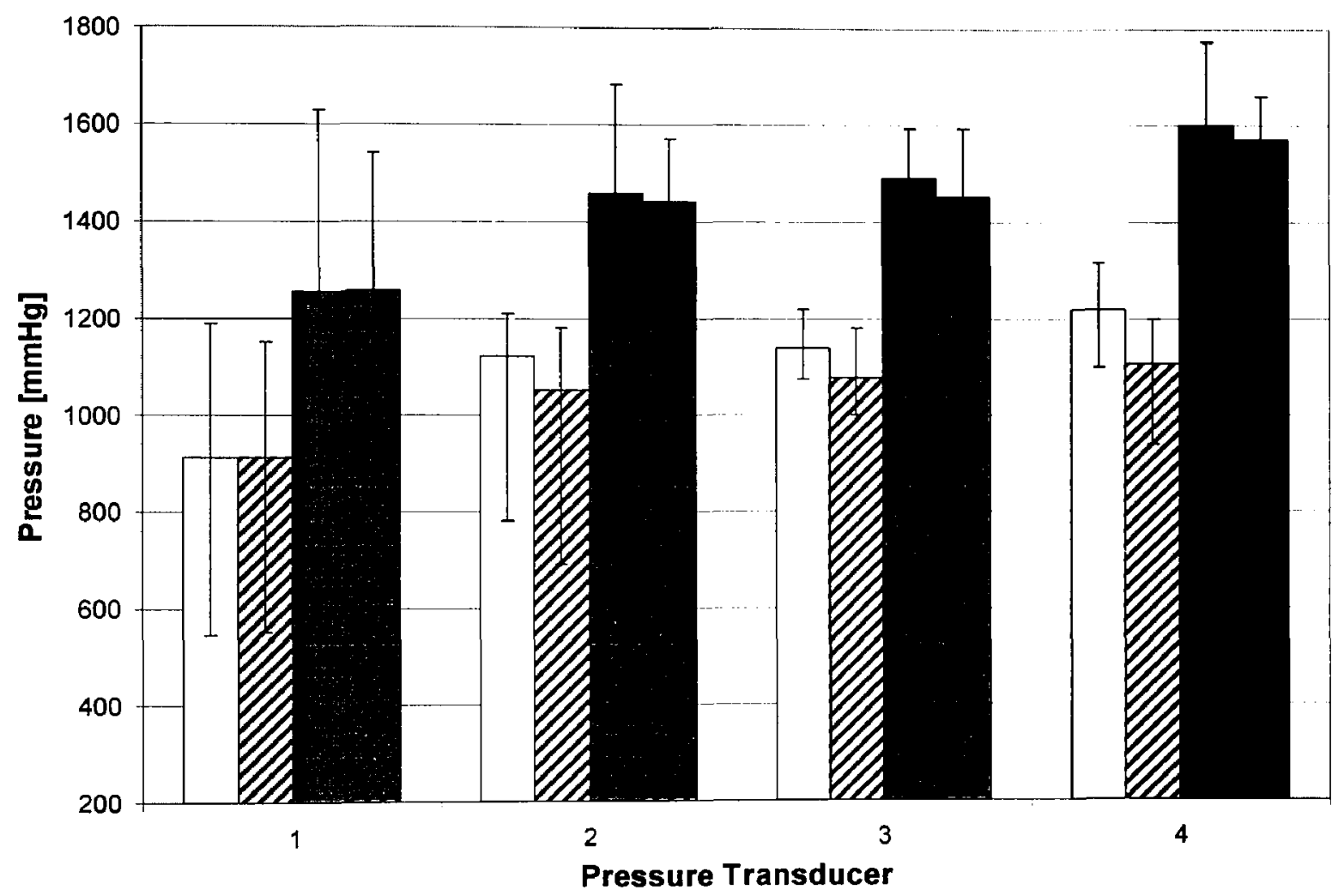

Figure 4.5: Effect of implant tip geometry on mean pressure for $0.5 \mathrm{~mm}$ bone to implant gap with $\square-L F$ with flat tip, $\square-L F$ with tapered tip, $\square_{-} H F$ with flat tip, $\square-H F$ with tapered tip. In all cases, a viscosity of $82.6 \mathrm{cP}$, and the rubber hammer (RH) tip were used. Bars indicate maximum and minimum pressure for each transducer. 


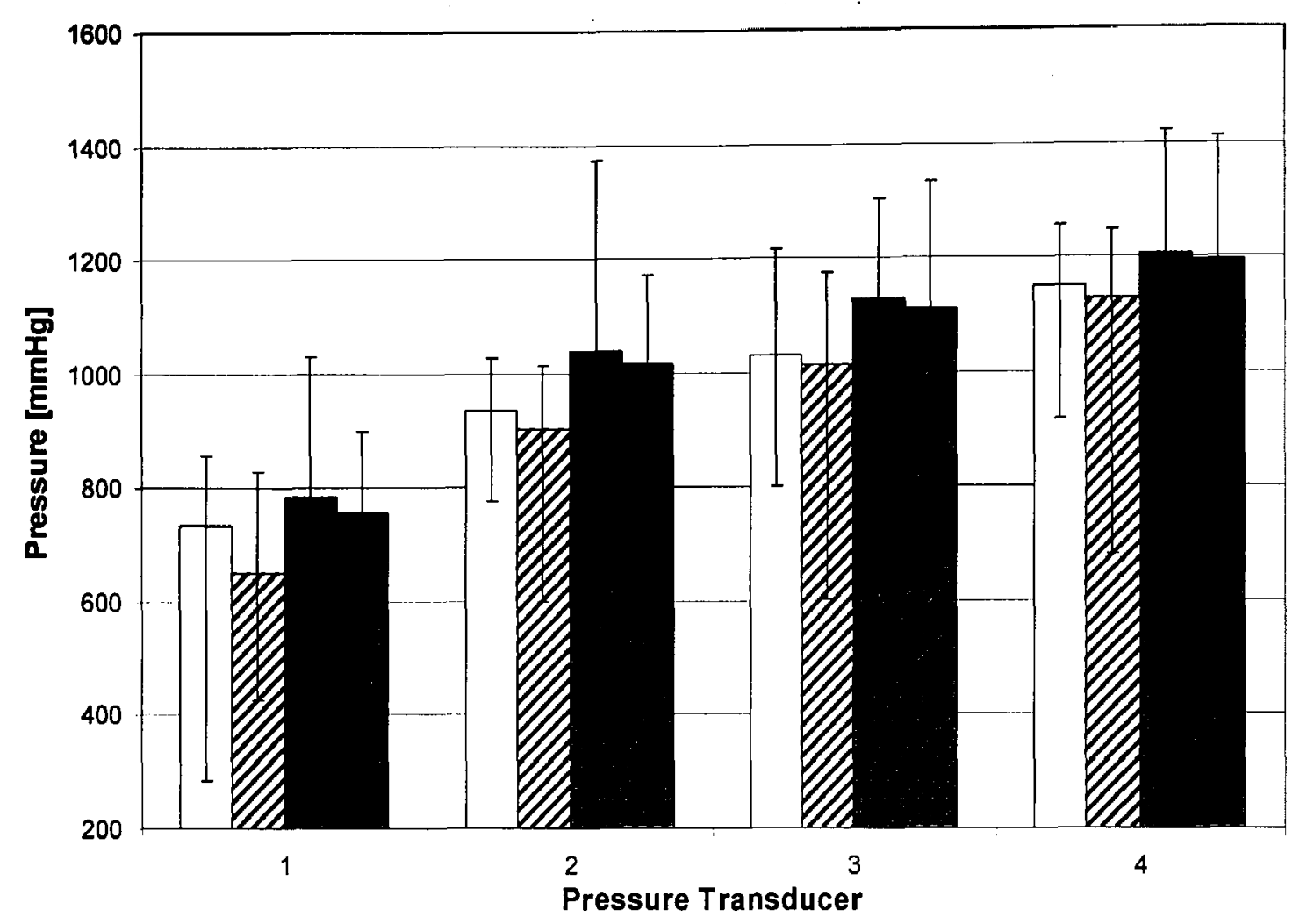

Figure 4.6: Effect of implant tip geometry on mean pressure for $1.5 \mathrm{~mm}$ bone to implant gap with $\square_{-}$LF impact with flat tip, $\square_{-}$LF with tapered tip, $\mathbf{Q}_{-}$HF with flat tip, $\mathbf{\square}_{-}$ $H F$ with tapered tip. In all cases, a viscosity of $82.6 \mathrm{cP}$, and the rubber hammer $(R H)$ tip were used. Bars indicate maximum and minimum pressure for each transducer.

It is worth noting results very similar to Figures 4.7 and 4.8 , which utilize flat implant tips, where also found (not shown) with a tapered implant tip. Overall, use of the tapered stem tips lowered the mean pressure values in Figures 4.7 and 4.8 by an average of $4.5 \%$, which is consistent with the results of Figures 4.5 and 4.6 . With the tapered implant tip, the mean pressures in the proximal part of the simulated bone saw a reduction of $2.4-24.9 \%$ when using the rubber versus the steel hammer tip, but in the distal part of the simulated bone, the use of a rubber tip resulted in mean pressures that were between $0.6-37.4 \%$ higher than those for the steel tip. The maximum pressure values followed a similar trend. With the tapered implant tip, the maximum pressures in 
the proximal part of the simulated bone saw a reduction of $1.5-31.1 \%$ when using the rubber versus the steel hammer tip, but in the distal part of the simulated bone, the use of a rubber tip resulted in mean pressures that were between $3.0-30.3 \%$ higher than the steel tip.

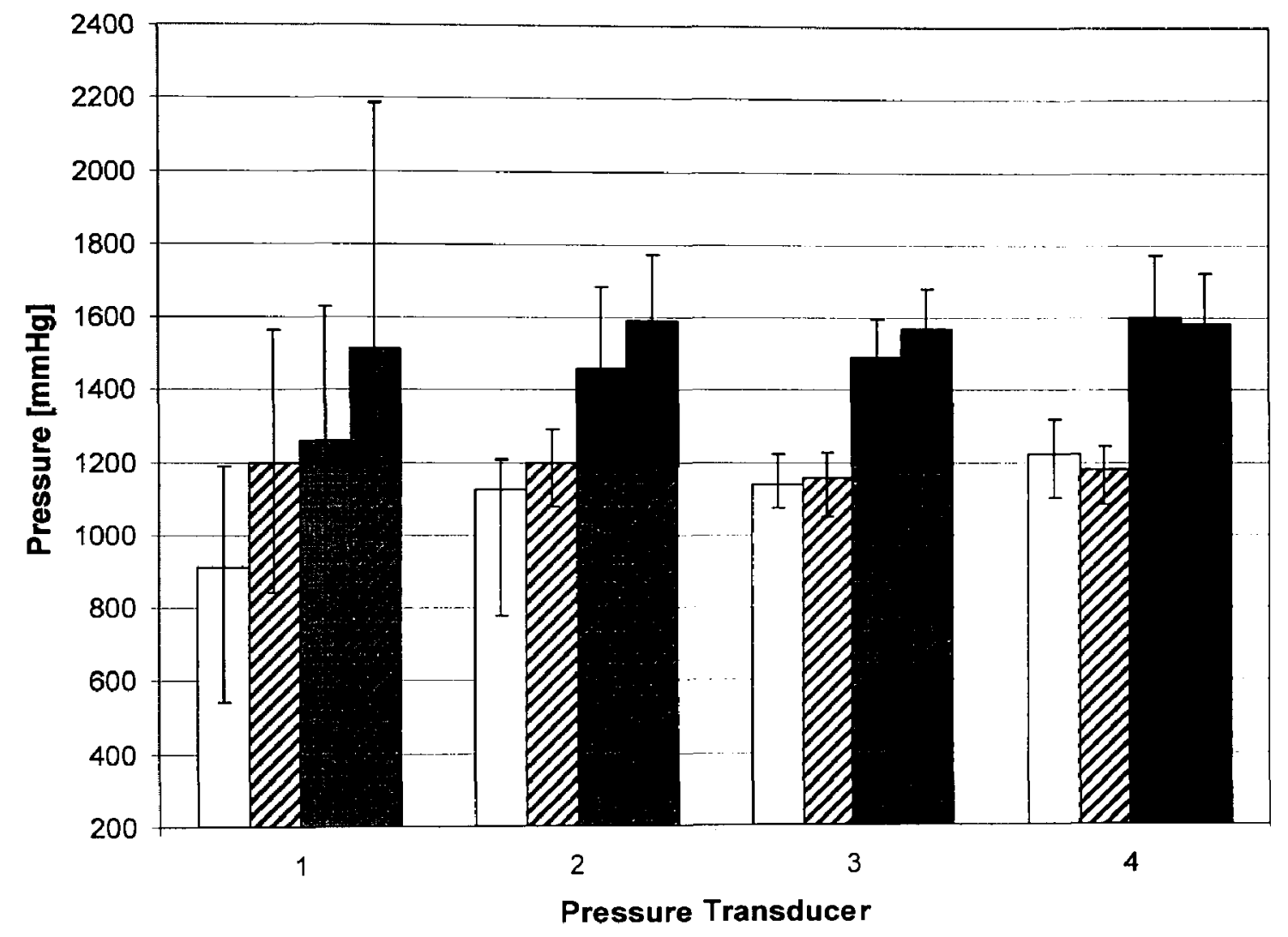

Figure 4.7: Effect of hammer tip material and peak impact force on mean pressure for $0.5 \mathrm{~mm}$ bone to implant radial gap with $\square-R H L F, \square_{-} S H L F, \square_{-}$RH HF, $-S H$ $H F$. In all cases, a viscosity of $82.6 \mathrm{cP}$, and a flat implant tip were used. Bars indicate maximum and minimum pressure for each transducer. 


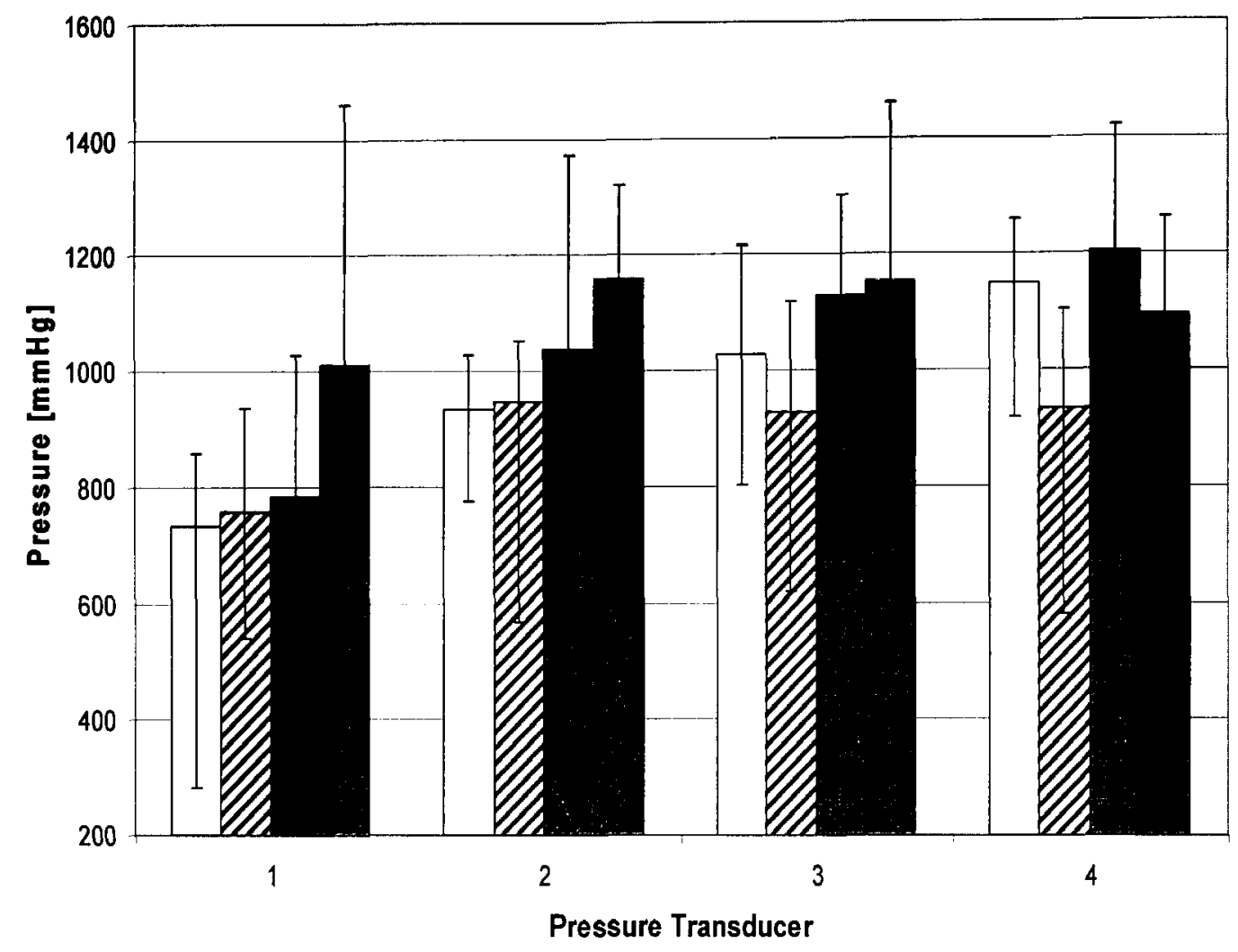

Figure 4.8: Effect of hammer tip material and peak impact force on mean pressure for $1.5 \mathrm{~mm}$ bone to implant radial gap with $\square-R H L F, \square-S H L F, \square-R H H F, \square-S H$ $H F$. In all cases, a viscosity of $82.6 c P$, and a flat implant tip were used. Bars indicate maximum and minimum pressure for each transducer.

\subsubsection{Parametric Study 2: Effect of Bone Marrow Viscosity / Bone to Implant Radial Gap / Impact Force}

\subsubsection{Number of strikes required to insert implant to a depth of $175 \mathrm{~mm}$}

Bone marrow viscosity

Figure 4.9 shows that, as expected, the number of hammer strikes necessary to completely insert the implant significantly increased with increasing fluid viscosity. This effect was most marked for smaller bone to implant gaps. Increasing the viscosity from 
59 to $146 \mathrm{cP}$ resulted in an increase of 21 strikes for the $0.5 \mathrm{~mm}$ gap, whereas, for the 1.5 mm gap, the increase was only 3 strikes.

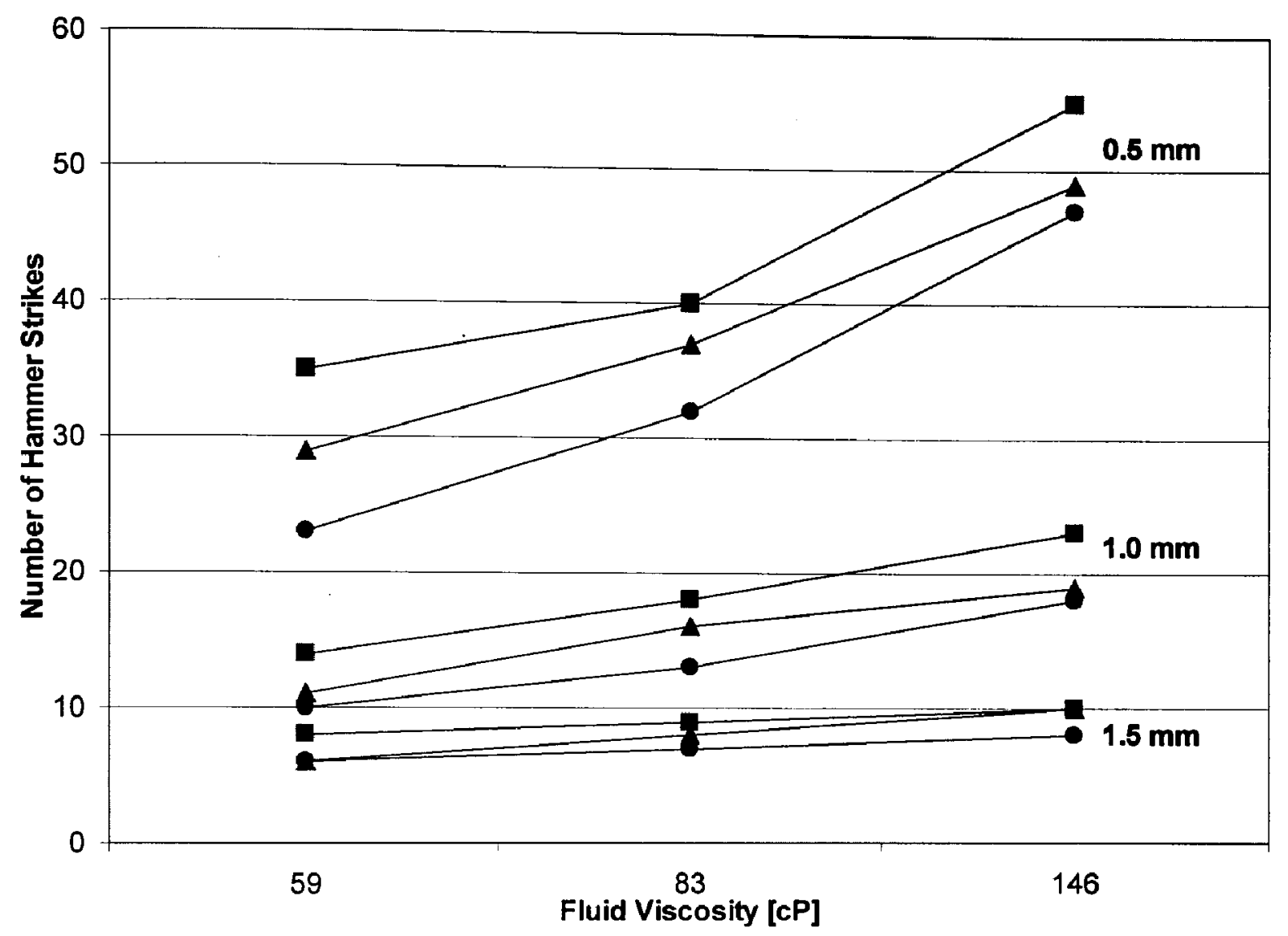

Figure 4.9: Effect of marrow viscosity on number of hammer strikes required to hammer flat tipped implant into canal. Rubber hammer $(R H)$ used in all cases, with peakforces of $-L F, \mathbf{\Delta}-M F, \mathbf{0}-H F$.

\section{Bone to Implant Radial Gap}

Figure 4.9 , consistent with the results of Figure 4.4 , also clearly shows the dramatic increase in number of strikes necessary to insert the implant when a smaller bone to implant gap was present, and that a larger gap was less sensitive to the effect of viscosity. For example, with a $90 \mathrm{~N}$ peak impact force and a viscosity of $146 \mathrm{cP}, 32$ fewer hammer strikes were required for implant insertion when the gap was $1.0 \mathrm{~mm}$ compared to when it was $0.5 \mathrm{~mm}$. 


\section{Impact force}

Figure 4.9 also shows that, all other factors being equal, for the rubber hammer tip, an increase in impact force resulted in fewer hammer strikes required to insert the implant. This was particularly evident for the smaller bone to implant gaps. For example, for a $0.5 \mathrm{~mm}$ gap, 12 less strikes were required for a $145 \mathrm{~N}$ peak impact force, than for a $90 \mathrm{~N}$ force.

\subsubsection{Intramedullary pressure}

Effect of bone marrow viscosity

Because the maximum pressures were generally encountered in the distal portion of the simulated bone for the sake of clarity, only the results for transducer 4 are shown in Figure 4.10, which examines the effect of fluid viscosity on pressure. Similar trends were found with pressure transducers 1 through 3 (not shown). For the majority of the cases, the pressure decreased with increasing viscosity, a somewhat counter intuitive result which will be discussed in Section 4.3. This effect was most evident for small bone to implant gaps. 


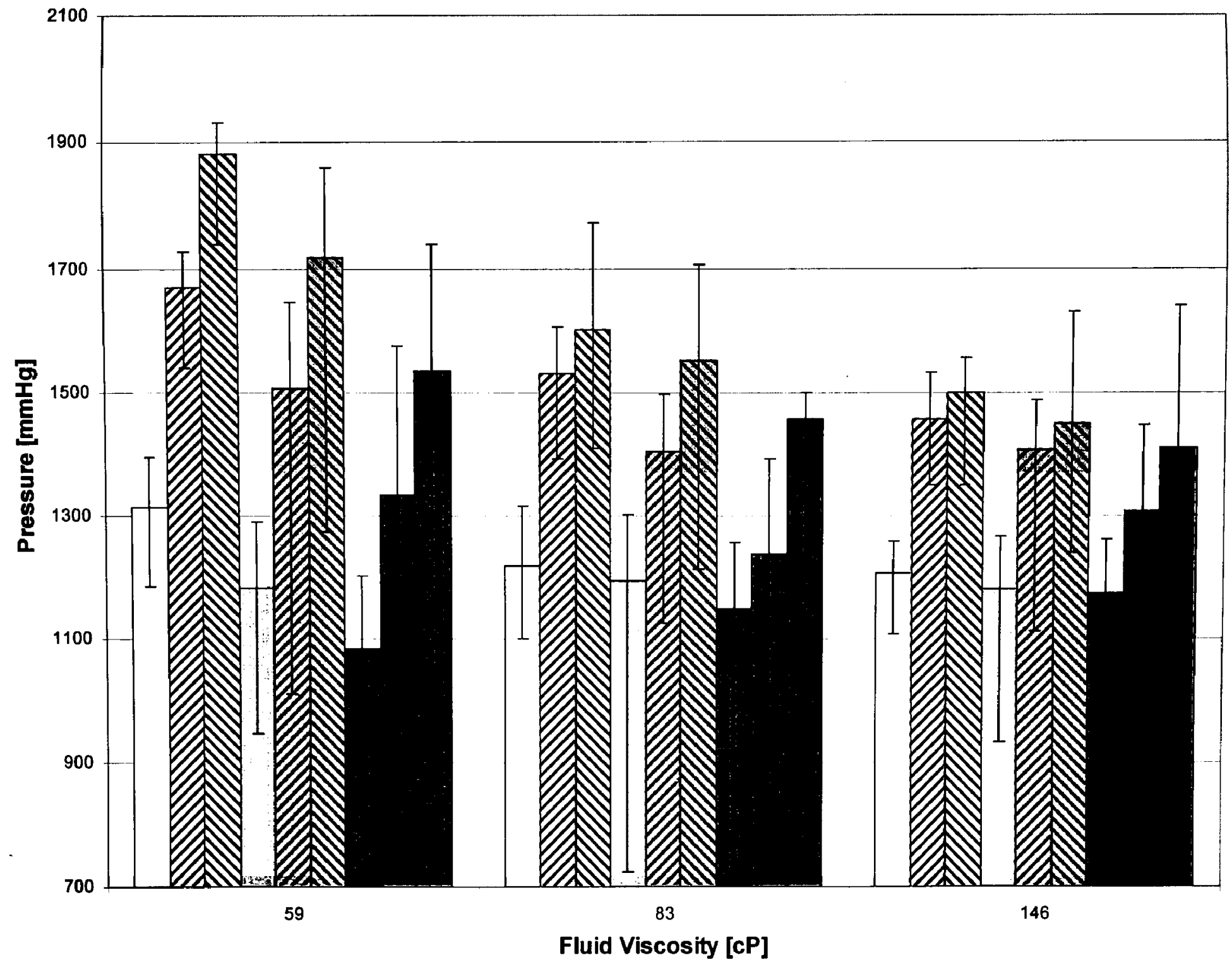

Figure 4.10: Effect of fluid viscosity on pressure values at transducer 4. Rubber hammer (RH) and a flat tipped implant used in all cases, with bone to implant gaps and peak forces given by: $\square-0.5 \mathrm{~mm}, L F ; \square-0.5 \mathrm{~mm}, \mathrm{MF} ; \square_{-}-0.5 \mathrm{~mm}, \mathrm{HF} ;$; $-1.0 \mathrm{~mm}, \mathrm{LF}$;

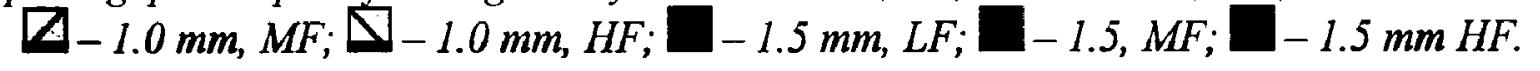




\section{Effect of bone to implant gap}

Regardless of the particular value of impact force and fluid viscosity, Figures 4.5

- 4.8 and 4.10 show that the pressure increased with decreasing implant to bone radial gap, as expected. For example, Figure 4.10 shows that decreasing the gap from $1.5 \mathrm{~mm}$ to $1.0 \mathrm{~mm}$ resulted in mean pressure increases between 0.4 and $19.6 \%$, depending on the particular values of viscosity and impact force, and decreasing the gap to $0.5 \mathrm{~mm}$ further increased the mean pressure by $0.6-22.6 \%$. Figure 4.10 also shows that these pressure increases were most marked when the viscosity of the fluid was lower. For the $59.4 \mathrm{cP}$ case, when decreasing the gap from 1.5 to $0.5 \mathrm{~mm}$, the mean pressure increased by $23.4 \%$, whereas, in the $82.6 \mathrm{cP}$ and $146.4 \mathrm{cP}$ cases, the pressures increased by $16.7 \%$ and $11.8 \%$, respectively. Similar trends in the maximum pressure values were noted.

\section{Effect of peak impact force}

Regardless of the particular value of gap or fluid viscosity, Figures $4.5-4.8$ and 4.10 show that both the maximum and mean pressure increased with increasing impact force, as expected. The pressure increases were most marked when the viscosity of the fluid was low. For example, Figure 4.10 shows that, for the $59 \mathrm{cP}$ case using a rubber hammer with a $0.5 \mathrm{~mm}$ gap, the mean pressure at transducer 4 increased $30.1 \%$ when the peak impact force was increased from $90 \mathrm{~N}$ to $145 \mathrm{~N}$, whereas the corresponding pressure increases for the 83 and $146 \mathrm{cP}$ cases, were $23.8 \%$ and $19.4 \%$, respectively. Overall, for all the experiments of parametric study 2 (Table 4.2, row 2), the average increase in mean pressure for all pressure transducers was $24.1 \%$ (increase in peak impact force, $90 \mathrm{~N}-$ $145 \mathrm{~N})$. Similar percentage pressure increases were noted for the maximum pressure 
values. For the parametric study as a whole, the overall maximum pressure was obtained for the RH-HF and $0.5 \mathrm{~mm}$ gap case.

\subsection{Discussion}

\subsubsection{Comparison of presently measured intramedullary pressures with cadaveric} data from the literature

Direct comparison of the present results to data from the literature is difficult because, to the author's knowledge, controlled hammering experiments of the type performed in the present study do not exist. Nevertheless, a number of studies do exist, in which the intramedullary pressure in a cadaveric femur was measured, for both reaming and insertion procedures. Comparison of the range of pressures measured in cadaveric studies with those measured in the present study is of interest, as it can be used to establish the performance of the presently utilized bone analogue. In the present study, overall, the pressure ranged from 263 to $2200 \mathrm{~mm} \mathrm{Hg}$. However, the $2200 \mathrm{~mm} \mathrm{Hg}$ was somewhat of an anomaly (Figure 4.7), resulting from a steel hammer strike of the implant, when it was very close to pressure transducer 1 . In reality, the majority of the pressures were between $800-1800 \mathrm{~mm} \mathrm{Hg}$.

While reaming cadaveric femurs, Hopf et al. ${ }^{53}$ measured pressures in the range of $20-750 \mathrm{~mm} \mathrm{Hg}$. Following the reaming procedure, the intramedullary device was inserted via a hammering procedure, resulting in pressures in the range of $48-1950 \mathrm{~mm}$ Hg. Similar studies from the literature ${ }^{7,24-30,54}$ gave similar approximate pressure ranges, with an overall range of $20-1950 \mathrm{~mm} \mathrm{Hg}$. The fact that the presently measured range of intramedullary pressures fall within the overall range of the cadaveric studies noted 
above (20-1950 $\mathrm{mmHg}$ ) lends credibility to the use of the present bone and marrow analogue system.

An analytical model was developed by Brown et al..$^{55}$ to approximate pressure build-up during reamer advancement with a small annular bone to reamer gap. The analysis is based on a combination of pressure driven and motion-entrained flow, also known as Hagen-Poiseuille and Couette Flow. The resulting expression for the pressure generated in the cylindrical geometry, $\Delta p$, can be approximated as follows, ${ }^{55}$

$$
\Delta p=\left(\frac{3 \mu L d_{m} \nu}{h^{3}}\right)\left(\frac{1}{1+\frac{3}{2} \varepsilon^{2}}\right)
$$

$\mu$ is the viscosity of the fluid, $L$ is the length of the implant, $d_{m}$ is the diameter of the intramedullary canal, $v$ is the (assumed constant) implant advancement velocity, $h$ is the implant to bone radial gap, and $\varepsilon$ is the eccentricity of the device (in the present case, assumed zero). While the analysis does not consider the porous nature of the bone, and assumes as steady rate of device advancement, Equation 4.1 can nevertheless be used to qualitatively evaluate the observed experimental trends in the following sections.

\subsubsection{Effect of operative parameters and clinical implications}

Tapered versus flat implant tips

Figures 4.5 and 4.6 demonstrate that only a slight pressure decrease can be obtained by changing the implant tip geometry from flat to tapered. The tapered geometry presumably allowed for a more gradual pressure build up in the vicinity of the implant tip facilitated funnelling of fluid into the gap and resulting in a slightly lowered mean pressure. However, since the frontal projected area of the two implants was identical for 
both implant tips, both the viscous drag force and the volume of fluid displaced by the advancing implant were also very close. This resulted in overall very small changes in intramedullary pressure and number of hammer strikes necessary for implant insertion (Figure 4.4). Use of a fluted implant might have led to lower pressures, but, in practice, such an implant would likely quickly become plugged with debris.

\section{Steel versus rubber hammer material}

Figure 4.4 shows that changing the hammer tip from rubber to steel, regardless of implant to bone gap, had very little effect on the number of hammer strikes necessary for insertion, despite the fact that the steel hammer produced an order of magnitude higher impact force (Table 4.1). This implies that the average distance the implant travelled per strike is similar for both steel and rubber hammer tips. On the other hand, Figure 4.9 clearly shows that, the number of strikes required for insertion (and thus the average distance the implant travelled per hit) changed significantly with impact force, when a rubber hammer tip was used, implying that the average distance the implant travels depends on the peak impact force. These seemingly contradictory results can be explained by noting that at a given level of force (i.e., LF or HF), both the steel and rubber tipped hammers were dropped from the same height on the pendulum apparatus. Because of the small difference in weight of the steel and rubber hammer tips, when compared to the weight of the pendulum arm and the hammer itself, the impact energies in both cases were thus similar. One would thus expect that the distance travelled per hit would be similar for both rubber and steel tips at the same level of impact energy, as implied by Figure 4.4. In effect, the higher impact force in the case of a steel hammer tip 
is balanced by the fact that there is a higher force pulse duration for the case of rubber tips. On the other hand, an increase in the pendulum drop height would have increased the impact energy, regardless of hammer tip, resulting in a higher implant travel per hit (less strikes for insertion), as shown when comparing LF to HF in both Figures 4.4 and 4.9 .

Figures 4.7 and 4.8 demonstrate that use of the steel hammer tip, which created a higher peak impact force than the rubber tip, also resulted in a higher pressure in the proximal portion of the bone analogue. The implant most likely accelerated very quickly in response to the very rapid rise in force associated with the steel hammer tip (Figure 4.2), resulting in very high pressure in the proximal part of the bone. This is consistent with previous investigations, which have found that the faster a reamer is advanced in an intramedullary canal, the higher the resulting pressure. ${ }^{27,28}$ Furthermore, the velocity appears in the numerator in Equation 4.1, implying that the pressure should increase with an increase in velocity. At distal locations (i.e., transducer 4), far downstream of the advancing reamer, the effect of the accelerating reamer is felt less, and the pressures for both rubber and steel hammer tips are similar.

The results of the present study thus suggest the use of a rubber, as opposed to a steel hammer for surgical procedures, at least during the initial insertion of the implant, as it will result in significantly lower intramedullary pressures. This in turn would appear to have the potential to reduce the risk of iatrogenically inducing clinical fat embolism syndrome without significantly compromising ultimate successful insertion of the implant. 


\section{Effect of peak impact force for a given hammer tip material}

Figures $4.4-4.10$ clearly show that an increase in peak impact force for a given hammer tip material always resulted in significantly increased intramedullary pressures and a decreased number of hammer strikes required for implant insertion, regardless of viscosity, implant to bone radial gap, and implant tip geometry. This is expected, given that Figures 4.1 and 4.2 show that, for a given hammer tip material, both the force duration and peak impact force increase when the pendulum drop height is increased. This increased impact energy not only leads to a higher implant travel per strike, but also a higher implant advancement rate, serving to increase the intramedullary pressure, as is also indicated by Equation 4.1.

The clinical implication is clear, a lower impact energy will result in significantly lower intramedullary pressures. Surgeons should therefore be advised to slow the cadence and reduce the swing amplitude when hammering an intramedullary implant into place. This could potentially result in an increased amount of time required to insert the implant; however, this would likely be minimal and should be balanced against the reduced FES risk to the patient.

\section{Effect of bone to implant gap}

Figures $4.5-4.10$ show that, all other parameters being equal, the intramedullary pressure and number of hammer strikes for implant insertion is significantly reduced for larger bone to implant radial gaps, regardless of viscosity, impact force and implant tip geometry. The reduced pressure is expected, given the smaller area of the implant tip acting to create a pressure lock between the tip and fluid. Equation 4.1, in which the gap 
parameter appears cubed in the denominator also predicts a sharp increase in pressure with decreasing gap.

It is not however possible to significantly alter operative technique such that the implant to bone gap is maximized (and the resulting intramedullary pressure minimized) as this could compromise the stability of the construct achieved and thereby the clinical outcome. Over reaming by $0.5-1.0 \mathrm{~mm}$ is generally advocated for insertion of intramedullary devices such as intramedullary nails or long femoral stems in total hip arthroplasty, though it should be noted that the reaming process itself also causes increased intramedullary pressure.

Effect of bone marrow viscosity

Figure 4.9 illustrates that the number of hammer strikes required for implant insertion increases significantly with increasing marrow viscosity, an expected result, given that a lower viscosity should provide a lower resistance to implant advance. However, Figure 4.10 shows that the intramedullary pressure downstream of the implant decreases with increasing viscosity, which contradicts the predictions of Equation 4.1, where the viscosity parameter is in the numerator. The likely explanation is that the implant advances more slowly in the more viscous fluid, which leads to lower intramedullary pressures, as discussed earlier.

This finding has clinical implications with regards to insertion of intramedullary devices into the distal portion of the femur, such as with retrograde nail insertion for fracture fixation or alignment rod insertion for total knee replacement. The marrow is known to be less viscous in this anatomic region, ${ }^{46}$ and the surgeon should be advised to 
reduce the force with which he/she strikes the implant, to ensure that the high pressures associated with low viscosity (Figure 4.10) are avoided.

\subsubsection{Limitations}

A number of simplifying assumptions were made in the present study, the most notable of which is the use of a simplified bone analogue to represent the shape of the femur. Nevertheless, great pains were taken to ensure that the porous plastic material used as the bone substitute had similar pore size and porosity as real cortical bone, and, as discussed in Section 4.1, the range of measured pressures in the present study was similar to that measured in similar studies utilizing cadaveric specimens. As shown in Table 3.2, the density and modulus of elasticity was lower than that of cortical bone. Nevertheless, these properties are expected to play as secondary role to fluid mechanics parameters such as porosity and pore size, which are much more important for the present experiments, which aim only to characterize fluid pressure. The density and modulus of elasticity would play a major role if the experimental runs included contact with the bone analogue, for example, reaming experiments.

In the present work, a constant synthetic bone marrow viscosity was used within the bone analogue. In reality, the bone marrow within the femur varies from the distal to the proximal location by as much as $90 \% .{ }^{46}$ Unfortunately, it proved very difficult to reproduce this fluid variation with a synthetic bone marrow within the bone analogue in a repeatable manner, due to the tendency of mixtures of different viscosities to combine into a single homogenous mixture once placed in the bone analogue. However, the conclusions drawn with respect to the trends associated with the effects of the various 
parameters are no less valid, only the pressure values themselves are. In other words, were it possible to perform experiments with varying viscosity (mimicking inter-patient variability), one would expect overall the same trends with respect to the effects of operative parameters on the mean pressures, though the pressure gradient along the length of the bone would be much larger (higher pressures distally, where the viscosity is low, and lower pressures proximally, where the viscosity is high).

In Section 3.1.2.1, it was mentioned that a Teflon tip was used on the implant to reduce the frictional force between the inner walls of the cylinder and the implant. This was done to eliminate a parameter that is, in any case, difficult to control in a clinical setting. In practice, there would likely be a significant friction at the implant bone interface when inserting an implant that does not require reaming. A larger hammering force would thus be required to advance the implant to a given depth, and it would advance at a slower rate. This would result in a somewhat reduced intramedullary pressure than those reported herein, but the parametric trends would likely be similar.

Figure 4.3 shows that the implant advanced by an approximately constant amount after each strike, as a result of the impact force being kept constant for each strike. A constant impact energy was used for the sake of simplicity, and to allow for easier interpretation of the effects of the various parameters, appropriate for the present study, which considers comparative rather than absolute pressures. It should, however, be noted that during orthopaedic procedures this is likely not to be the case, because surgeons are expected to use varying impact forces. The effect of this limitation is that the pressure variation would change depending on each strike, whereas during a controlled experiment this action is not considered. 


\section{Chapter 5}

\section{Numerical and Experimental Comparison}

One of the objectives of the thesis was to generate experimental data to compare to computational models developed by other independent research members. The hope is that these model can be used to study the effect of various operative parameters (rate of insertion, hammering force, orientation of bone, etc.), device geometry (prosthetic tip shape, diameter, etc.) and bone/marrow material properties (porosity, viscosity, etc.), so that the risk of FES in orthopaedic procedures can be reduced.

\subsection{Comparison of Experimental Results to Computational Fluid Dynamics Model of Implant Insertion}

\subsubsection{Experiments}

A number of experimental runs were performed in order to obtain a wide range of values that could be compared to the computational fluid dynamics (CFD) model. A similar experimental procedure to that described in Chapter 4 was used to generate these data. The experiments were performed with a fluid viscosity of $82.6 \mathrm{cP}$, a radial implant to bone analogue gap of $0.5 \mathrm{~mm}$, a flat implant tip geometry and the impact force was generated using the impulse hammer (Figure 3.7) with a steel tip, resulting in a peak force of approximately $1200 \mathrm{~N}$ (Figure 4.2). The experimental pressure results were 
obtained from the pressure transducers (Figure 3.6) after the hammer impacted the implant. The advancement rate of the implant was monitored with respect to time, by the potential displacement sensor (Figure 3.8). This resulted in one displacement profile for the implant, and four corresponding pressure values for all four pressure transducers. The experiment was repeated five times, and the maximum difference between the five experiment runs was minimal, approximately $1.9 \%$ for pressure, and $5.6 \%$ for displacement.

The CFD-FIDAP numerical model requires a very accurate description of the movement of the implant after the hammer strike is applied. With the present instrumentation, this proved very difficult to obtain, because of the design of the displacement sensor, which in reality was more applicable to reaming experiments that have a constant rate of intramedullary device advancement. The wire in the transducer unfortunately applied tension, making it difficult to attach to the implant without affecting the movement of the implant subsequent to it being struck. In other words, there was a tendency for the implant to retract out of the intramedullary canal under the action of the tension in the wire. Therefore, the response of the implant after the only the first strike was measured. This action did not affect the results in anyway, because after the hammer impacted the implant, a displacement profile was generated by the displacement sensor.

\subsubsection{CFD-FIDAP Model}

To duplicate the experimental data, a model of the cylinder and fluid was built in Gambit (Fluent, New Hampshire, U.S.A.) and analyzed in FIDAP (Fluent, New 
Hampshire, U.S.A.) by another member of the research team independently. For a more detailed explanation of the CFD-FIDAP model refer to the reference page. ${ }^{56}$

\subsubsection{Comparison of Experimental and CFD-FIDAP Results}

Figure 5.1 compares experimentally measured (the two runs, of the five performed, that gave the highest and lowest pressures), and numerically (CFD-FIDAP) predicted pressures during the insertion of the implant, with respect to the transducer number. Pressure transducer 1 was located at $75 \mathrm{~mm}$ from the front of the cylinder, whereas transducer 4 was located $300 \mathrm{~mm}$ from the front (see Figure 3.4). As can be seen by Table 5.1, the difference between experimental and numerical (CFD-FIDAP) values varied from $17 \%$ to $23 \%$.

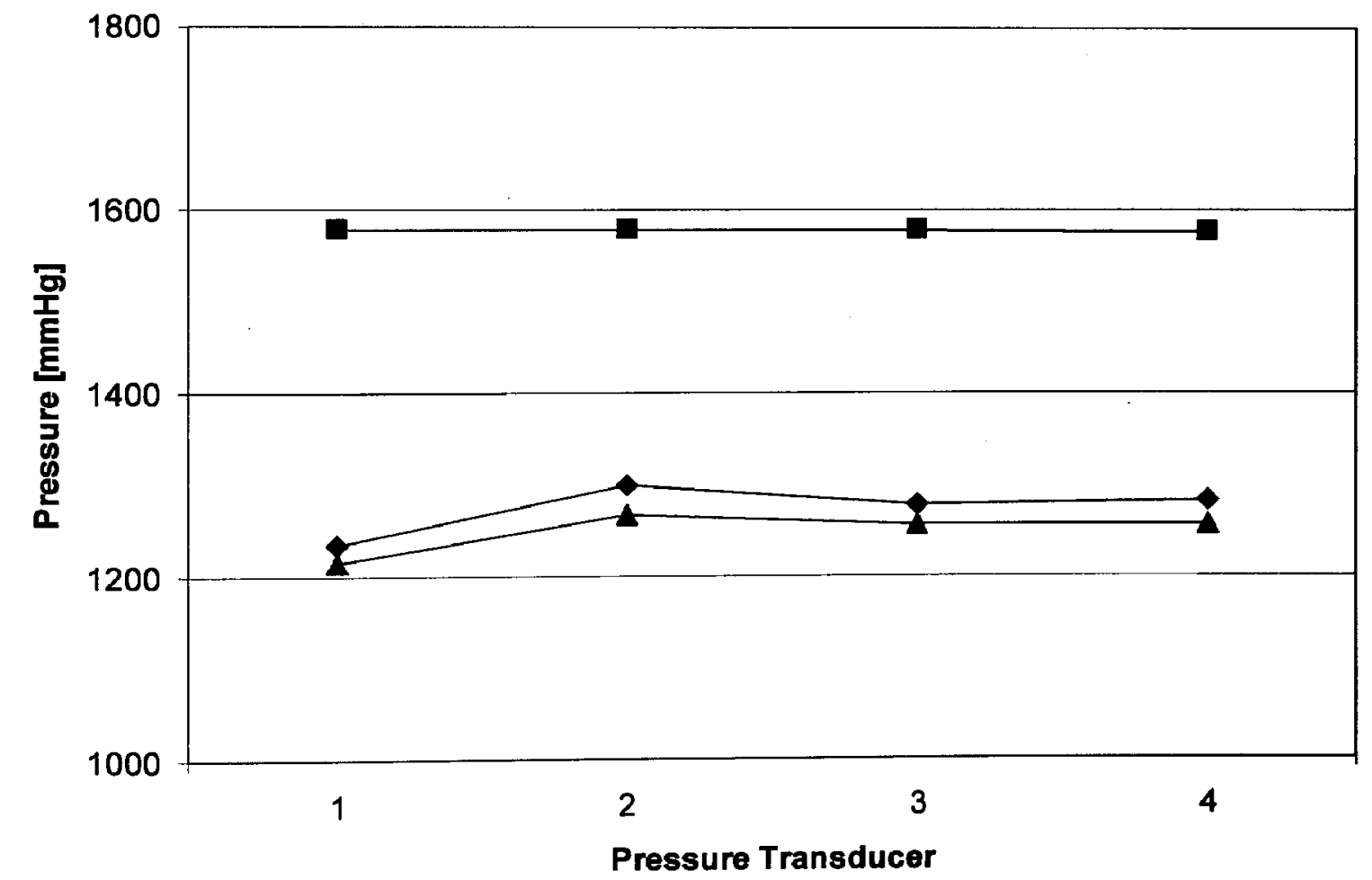

Figure 5.1: Experimental and numerical pressure values (FIDAP) - Numerical pressure results, $\mathbf{\Delta}$ - Experiment 1 pressure results, $\bullet-$ Experiment 2 pressure results 


\begin{tabular}{|l|c|c|c|c|}
\hline & $\begin{array}{c}\text { Pressure } \\
\text { Transducer 1 } \\
{[\%]}\end{array}$ & $\begin{array}{c}\text { Pressure } \\
\text { Transducer 2 } \\
{[\%]}\end{array}$ & $\begin{array}{c}\text { Pressure } \\
\text { Transducer 3 } \\
{[\%]}\end{array}$ & $\begin{array}{c}\text { Pressure } \\
\text { Transducer 4 } \\
{[\%]}\end{array}$ \\
\hline $\begin{array}{c}\text { Experiment 1 } \\
\text { (lower limit) }\end{array}$ & 22.955 & 19.610 & 20.326 & 20.320 \\
\hline $\begin{array}{l}\text { Experiment 2 } \\
\text { (upper limit) }\end{array}$ & 21.735 & 17.634 & 18.902 & 18.725 \\
\hline
\end{tabular}

Table 5.1: Experimental and numerical (CFD-FIDAP) comparison of pressure results.

\subsubsection{Discussion}

The reasonable (approx. $20 \%$ ) correlation between the two models shows that the use of CFD-FIDAP models to study intramedullary pressures resulting from insertion of a device into the intramedullary canal in long bones is possible. To the knowledge of the author, this is the first attempt to use CFD modeling to study a problem of this type.

The differences between experimental and numerical results are most probably due to the limitations and assumptions of the numerical model, together with the problems associated with obtaining an accurate implant velocity profile. As mentioned previously, the CFD-FIDAP numerical model requires a velocity profile of the implant following the impact strike of the hammer. This can be problematic, because of the need of an expensive sensor to measure the velocity with respect to time. Attempts were made to calculate the velocity of the implant using a high speed flash camera; however, the implant moved much slower than what the camera was able to capture. This is attributed to the cameras expose time of only 19 milliseconds. It is likely that an improved velocity measurement technique might have lead to improved results.

Secondly, the permeability of the plastic used in the experimental portion was unknown and had to be approximated for the computational model. Since the pore size and porosity of the plastic were similar to those of bone, the average permeability of 
cortical bone was used. This is a crude approximation due to the fact that permeability is not only a function of pore size or porosity, but also a function of pressure drop. For the model to fit experiments more closely, a more accurate determination of the permeability is likely required. In reality, this would be very difficult to measure accurately for the porous plastic. To measure the permeability of the porous plastic, Darcy's experimental apparatus would have to be constructed to calculate the pressure drop and flow rate for water to flow through the porous plastic material. Then Darcy's Law could be applied to calculate the permeability of the porous material. ${ }^{57}$

The computational model also does not take into consideration the clearance between the implant and the inner wall of the cylinder. In the present work, the smallest possible gap (i.e., $0.5 \mathrm{~mm}$ ) was used in the experiments to most closely match the capabilities of the model. Because the intramedullary pressure generally increases with decreasing gap, the CFD model, which cannot consider this gap, likely overestimates the pressure for the $0.5 \mathrm{~mm}$ gap experimental case. This appears to be borne out by the results shown in Figure 5.1.

\subsection{Comparison of Experimental Results to Finite Element Model of}

\section{Implant Insertion}

\subsubsection{Experiments}

Three experimental runs were carried out to compare to a finite element model developed by another member of the research team. The parameters that were varied during the experiment are summarized in Table 5.2. The parameters that were held constant during the experiment are: fluid viscosity $(82.6 \mathrm{cP})$, flat implant tip and rubber hammer tip. 


\begin{tabular}{|c|c|c|c|}
\hline $\begin{array}{c}\text { Test } \\
\text { Case }\end{array}$ & $\begin{array}{c}\text { Implant outer } \\
\text { diameter } \\
{[\mathrm{mm}]}\end{array}$ & $\begin{array}{c}\text { Gap between implant } \\
\text { and bone } \\
{[\mathrm{mm}]}\end{array}$ & $\begin{array}{c}\text { Peak force of } \\
\text { hammer strike } \\
{[\mathrm{N}]}\end{array}$ \\
\hline 1 & 14.43 & $\sim 1.5$ & 93.8 \\
\hline 2 & 14.94 & $\sim 1.0$ & 114.5 \\
\hline 3 & 15.49 & $\sim 0.5$ & 144.3 \\
\hline
\end{tabular}

Table 5.2: Experimental test cases

The experimental pressure results were obtained from the four individual pressure transducers (Figure 3.4) after the initial impact of the impulse hammer, and refer to only the first hammer strike, because multiple impacts would have taken too long to compute with the FE-ANSYS model.

\subsubsection{FE-ANSYS model}

Another member of the research team utilized commercially available finite element (FE) analysis software to develop a numerical (ANSYS/DYNA) model of the bone/implant/fluid system, which studied the movement of the implant in the bone analogue. The FE model was pre-processed in ANSYS (ANSYS Inc., Canonsburg, USA) and analyzed in LS-DYNA (Livermore Software Technology Corp., Livermore, USA). For a more detailed explanation of the FE-ANSYS model refer to the reference page. ${ }^{58}$

\subsubsection{Comparison of Experimental and FE-ANSYS Results}

Figure 5.2 through 5.4 illustrate the comparison between the experimental and FE pressure values obtained for the three cases in Table 5.2, and Table 5.3 summarizes the percentage differences. All figures display similar trends, with the smallest error 
occurring in the first transducer and growing towards the distal located transducers. The experimental numerical error between the two models varied between 3.2 and $29.2 \%$. The average error that occurred for the case 1 through 3 is $13.5,16.4$ and $21.0 \%$, respectively. The average comparison error for all cases was calculated to be $17.0 \%$.

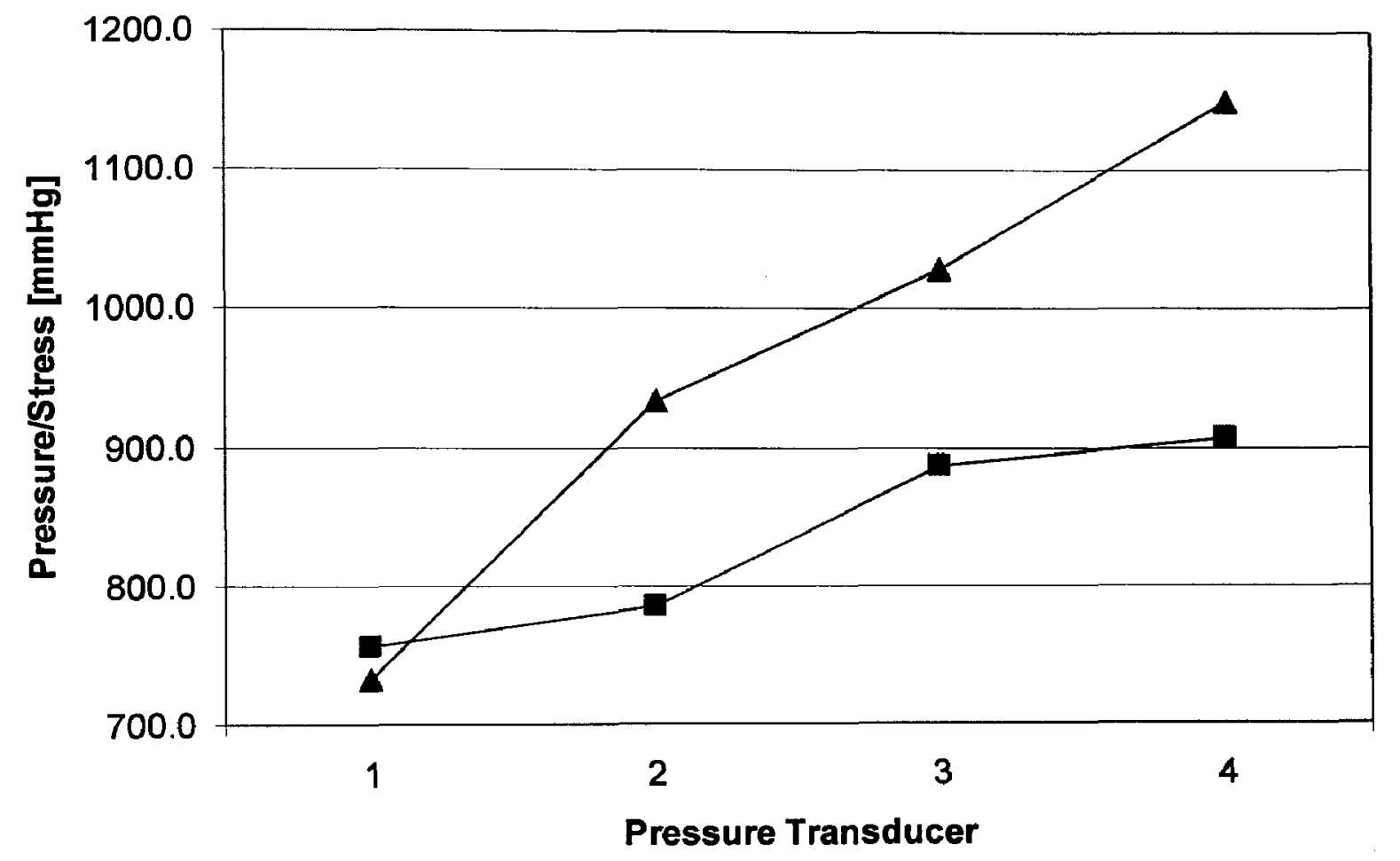

Figure 5.2: Experimental and numerical pressure values for test case 1 (FE-ANSYS) $\mathbf{\square}$ Numerical pressure results, $\mathbf{\Delta}$ - Experiment préssure results. 


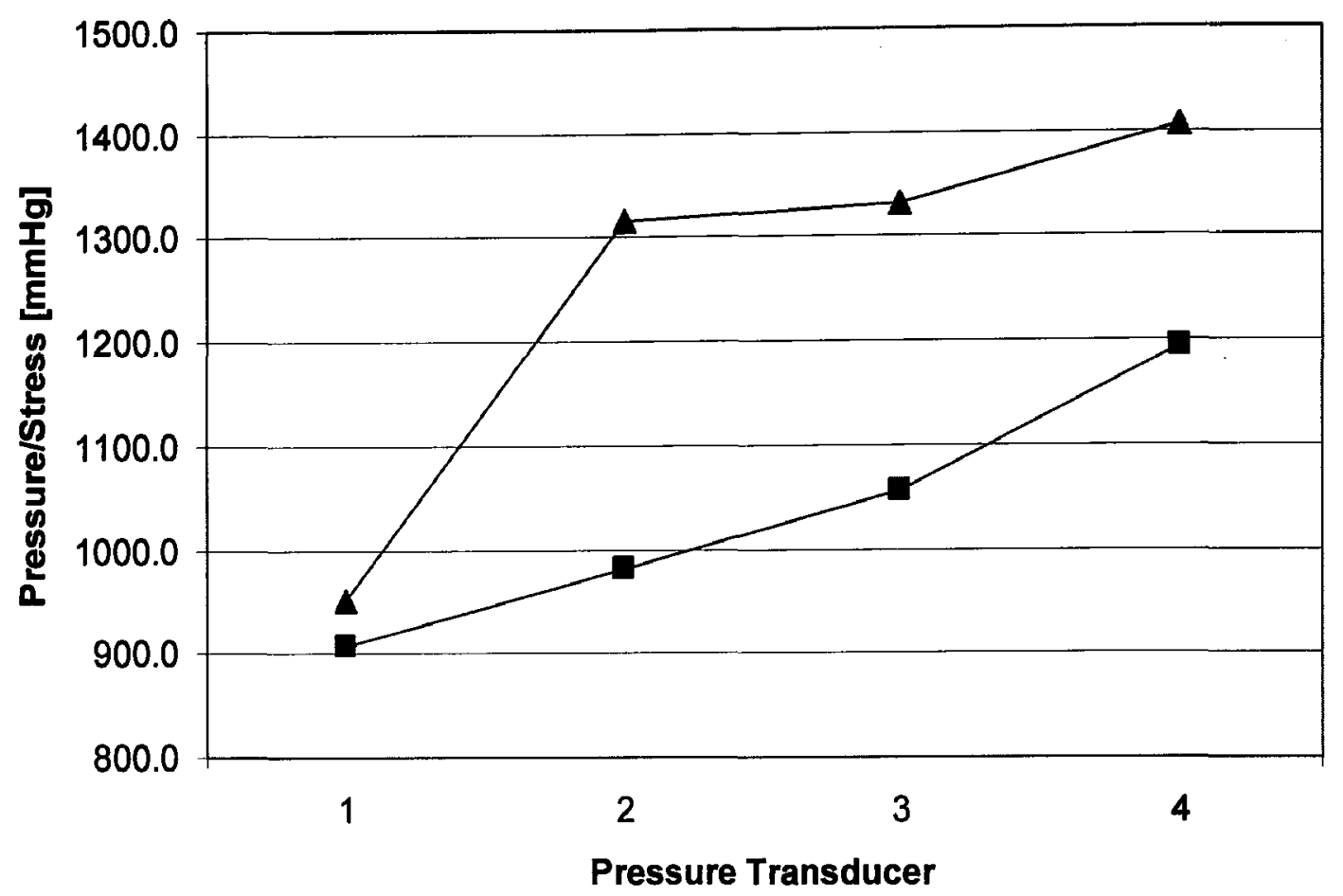

Figure 5.3: Experimental and numerical pressure values for test case 2 (FE-ANSYS) Numerical pressure results, $\boldsymbol{\Lambda}$ - Experiment pressure results.

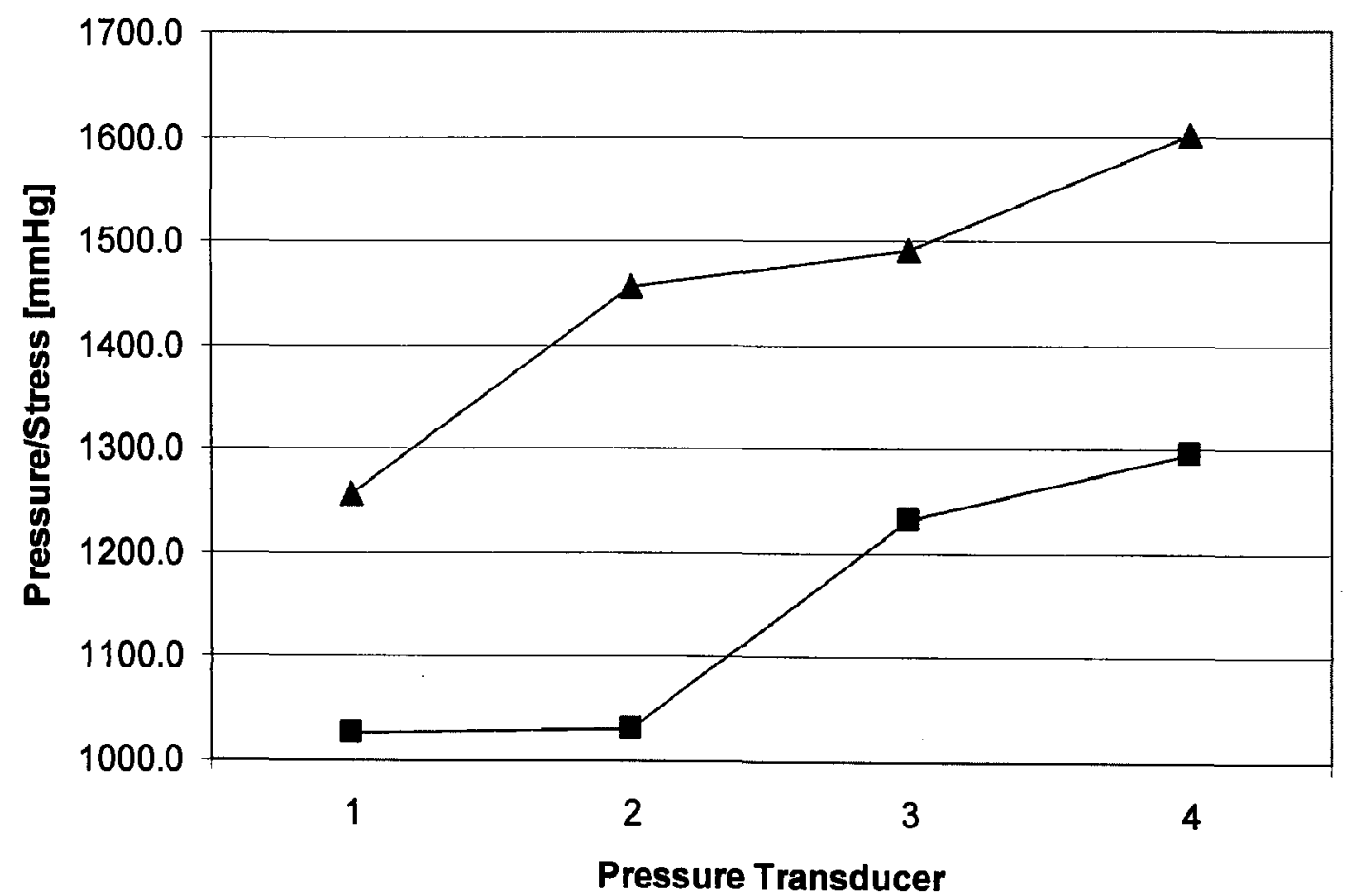

Figure 5.4: Experimental and numerical pressure values for test case 3 (FE-ANSYS) Numerical pressure results, $\mathbf{\Delta}$ - Experiment pressure results. 


\begin{tabular}{|c|c|c|c|c|}
\hline $\begin{array}{c}\text { Test } \\
\text { Case }\end{array}$ & Transducer & $\begin{array}{c}\text { Experimental } \\
\text { pressure } \\
{[\mathrm{mmHg}]}\end{array}$ & $\begin{array}{c}\text { FE-ANSYS } \\
\text { stress } \\
{[\mathrm{mmHg}]}\end{array}$ & $\begin{array}{c}\text { Percent } \\
\text { difference } \\
{[\%]}\end{array}$ \\
\hline \multirow{3}{*}{1} & 1 & 733 & 756 & 3.16 \\
\cline { 2 - 5 } & 2 & 934 & 785 & 15.98 \\
\cline { 2 - 5 } & 3 & 1029 & 886 & 13.90 \\
\hline \multirow{3}{*}{2} & 4 & 1150 & 907 & 21.11 \\
\cline { 2 - 5 } & 1 & 950 & 908 & 4.43 \\
\cline { 2 - 5 } & 2 & 1316 & 981 & 25.45 \\
\cline { 2 - 5 } & 3 & 1332 & 1057 & 20.66 \\
\hline 3 & 1 & 1405 & 1194 & 15.04 \\
\cline { 2 - 5 } & 2 & 1256 & 1026 & 18.32 \\
\cline { 2 - 5 } & 3 & 1457 & 1032 & 29.18 \\
\cline { 2 - 5 } & 4 & 1491 & 1233 & 17.27 \\
\hline
\end{tabular}

Table 5.3: Summary of experimental and numerical (FE-ANSYS) results

\subsubsection{Discussion}

In general, the FE-ANSYS model matched experiments reasonably well, underestimating the experimental results by an average of $17.0 \%$. Both the model and experimental results predict increasing pressure along the length of the bone. It is also noted that, in general, the model did a better job of predicting the pressure in the first transducer than those downstream of the implant. The reasons for this is, however, not clear. The differences between experimental and FE-ANSYS results are most likely due to the difficulty in obtaining an appropriate equation of state for the paraffin/petroleum jelly mixture, for use in the model. It is likely that a better experimental fit would have resulted, had it been possible to measure the parameters directly. There is also an error associated with the approximated Young's modulus value for the porous plastic material. The resources to calculate Young's modulus for the porous plastic were unfortunately not available. A better material property could have been obtained experimentally, if tensile testing was performed on the porous plastic material. 


\subsection{Use of Computational Models in Future Work}

The CFD-FIDAP model suffers from a number of drawbacks that might impede its usefulness in future work. It has only a very basic geometric modelling capability, and is therefore unsuitable for use in modelling bones of more complex geometry, and lacks the ability for creating a radial clearance for fluid escape between implant and interior cavity. Moreover, it requires a detailed description of the velocity of the implant as it advances, a very difficult parameter to measure.

The FE-ANSYS model, on the other hand, shows great promise, because it requires only the force versus time description as an input (along with the material properties), easily obtainable from inexpensive impulse hammer equipment. With a more accurate equation of state for the paraffin / petroleum jelly mixture, and a more accurate description of the material properties of the bone analogue, the FE-ANSYS model has great potential for simulating the hammering process. Changes in all the important parameters, i.e., implant tip geometry, impact force, fluid viscosity, and clearance gap can all be fairly easily accommodated. Moreover, commercial FE packages such as ANSYS/LS-DYNA can be used to model more complex geometry, such as that of a real femur, allowing for parametric studies to be more accurately matched to real orthopaedic procedures. Unfortunately, the complexity of larger models, coupled with the timedependent aspect of the problems, result in very long solving times, even with powerful computers. Nevertheless, as computers become faster, it should soon be possible to use such a model for parametric study of orthopaedic procedures leading to elevated intramedullary pressure. This would allow for redesign of operative technique and equipment that might lead to more drastic reductions in intramedullary pressure. 


\section{Chapter 6}

\section{Limitations, Recommendations and Conclusions}

\subsection{Summary}

In this thesis, an experimental procedure for analysis of the possible factors that lead to elevated intramedullary pressure, and thus the possible development of fat embolism syndrome, when inserting an intramedullary device into a femur, was proposed. The experimental model used a synthetic bone analogue, developed so that these factors could be examined in a controlled and repeatable manner, avoiding the specimen to specimen variability associated with cadaveric bones. The bone analogue, consisting of a porous plastic tube having similar porosity and pore size to that of real bone, was found to give a reasonable representation of simulated (paraffin wax/petroleum jelly mix) bone marrow flow through bone during intramedullary device hammering experiments. A controlled hammering procedure, mimicking that of a real orthopaedic procedure, was performed utilizing an experimental apparatus built by the author, and resulting intramedullary pressures were noted. Experimental data were also generated for comparison with numerical CFD-FIDAP and FE-ANSYS models. Finally, a parametric study was performed, which examined the effect of: hammering peak impact force, radial 
clearance gap between implant and bone analogue, implant tip geometry, bone marrow fluid viscosity and hammer tip material on resulting intramedullary pressure.

\subsection{Limitations of Approach}

The experimental approach utilized in this thesis assumed the following:

i. The synthetic bone analogue is assumed to have a constant porosity and pore size throughout the axi-symmetric geometry. The synthetic bone marrow which is composed of a paraffin / petroleum jelly mixture has a constant viscosity within the femoral canal of the synthetic bone analogue. A cadaveric femur would have a slight variation in porosity and pore size (depending on age), and the femoral cavity would have a variation in viscosity for the bone marrow (proximal to distal locations). Nevertheless, the results of the parametric study are useful for comparative study of the effects of the respective parameters.

ii. Friction at the bone/implant interface is negligible. In the present experiments, a Teflon tip was used to represent intramedullary devices during the hammering procedure, in order to reduce the friction force between the inner walls of the cylinder and the implant. During a orthopaedic procedure, there would likely be significant friction at the implant bone interface when inserting an implant that does not require reaming. This would likely lower the pressure, due to a slower advancement rate of the implant.

iii. A constant impact force was used during the experiments for the sake of simplicity, and to allow for the interpretation of the effects of various parameters. It 
should be noted that during orthopaedic procedures, surgeons actually apply a variety of impact forces and that different surgeons use different forces.

iv. The $25 \mathrm{mmHg}$ diastolic blood pressure was not considered during the experimental runs of the porous plastic bone analogue; however, this pressure would normally exist in orthopaedic procedures.

\subsection{Conclusions}

The most important conclusions of the thesis are summarized below:

i. A synthetic bone analogue can be used to mimic fluid flow characteristics in long bones, while avoiding the typical specimen to specimen variability associated with the use of cadaveric bones. The presently developed bone analogue resulted in measured pressures that matched the reported range for cadaveric studies in the literature.

ii. Tapered implant tips displayed minimal pressure reductions within the intramedullary cavity when compared to flat implant tips.

iii. The radical clearance gap and impact peak force both play a major role in the pressure reduction within the intramedullary cavity.

iv. The advancement rate of the implant within the cavity plays a greater role in the pressure gradient than the bone marrow viscosity. The implant advances more slowly in the more viscous fluid, which leads to lower intramedullary pressures.

v. Rubber hammer tips result in a pressure reduction in the proximal part of the femoral cavity when compared to a steel hammer tip; however, this relation is revered in 
the distal part of the femoral cavity, where the steel hammer tip shows lower pressure gradients.

vi. Numerical modeling shows great promise for analyzing hammering procedures for orthopaedic research into fat embolism syndrome.

\subsection{Recommendations for Future Work}

There are a number of areas that should be considered for future study:

i. Perform mechanical testing on the synthetic bone analogue to obtain more accurate mechanical properties (Young's Modulus, permeability). These could be used in more accurate numerical models of fluid flow in bone.

ii. Develop a more complex experimental apparatus that will be able to calculate the velocity and displacement of the implant as a function time, in response to hammering. This would allow for more accurate input into CFD models of flow, and might be accomplished via the use of an accelerometer.

iii. Study more complex implant geometries, looking into benefits of fluted or hollow implants that might provide an escape route for fluid.

iv. Develop more complex numerical models which can efficiently model multiple hammer strikes. Also, develop models with more complex geometries trying to more closely mimic femoral shape geometry. This, however, might be limited by manufacturability of the bone analogue materials. 


\section{References}

${ }^{1}$ Mellor A, Soni N. Fat embolism. Anaesthesia. 2001; 56:145-154.

${ }^{2}$ Woo R, Minster GJ, Fitzgerald RH, Mason LD, Lucas DR \& Smith FE. Pulmonary Fat Embolism in Revision Hip Arthroplasty. Clinical Orthopaedics and Related Research. 1995; 319:41-53.

${ }^{3}$ Bulger EM, Smith DG, Maier RV, Jurkovich GJ. Fat embolism syndrome. Archives of Surgery. 1997; 132:435-439.

${ }^{4}$ Hager CA, Brncick N. Fat embolism syndrome: A complication of orthopaedic trauma. Orthopaedic Nursing 1998; 17:41-46.

5 Peltier LF. Fat embolism: A current concept. Clinical Orthopaedics and Related Research.1969; 66:241-253.

${ }^{6}$ Gurd AR. Fat embolism: an aid to diagnosis. British Journal of Bone and Joint Surgery. 1970; 52B:732-737.

${ }^{7}$ Hofmann S, Hopf R, Mayr G, Schlag G, Salzar M. In vivo femoral intramedullary pressure during uncemented hip arthroplasty. Clinical Orthopaedics and Related Research. 1999; 360:136-146.

8 Schult M, Frerichmann U, Schiedel F, Brug E, Joist A. Pathophysiology of Fat Embolism after Intramedullary Reaming. European Journal of Trauma. 2003; 29:68-73.

${ }^{9}$ Nolte WJ, Olofsson T, Schersten T, Lewis DH. Evaluation of the Gurd test for fat embolism. British Journal of Bone and Joint Surgery. 1974; 56B:417-420.

${ }^{10}$ Lindeque BG, Schoeman HS, Dommisse GF, Boeyens MC, Vlok AL. Fat embolism and the fat embolism syndrome. A double-blind therapeutic study. British Journal of Bone and Joint Surgery. 1987; 69:128-130.

11 Pell AC, Christine J, Keating JF, Sutherland GR. The detection of fat embolism by transoesophageal echocardiography during reamed intramedullary nailings. A study of 24 patients with femoral and tibial fractures. British Journal of Bone and Joint Surgery. 1993; 75B:921-925.

12 Tronzo RG, Kallos T, Wyche MQ. Evaluation of intramedullary pressure when methylmethacrylate is inserted in total hip arthroplasty. Journal of Bone and Joint Surgery. 1974; 56A:714-718.

${ }^{13}$ Parvizi J, Holiday AD, Ereth MH, Lewallen DG. Sudden death during primary hip arthroplasty. Clinical Orthopaedics and Related Research. 1999; 369:39-48.

${ }^{14}$ Pitto RP, Koessler M, Kuehle JW. Comparison of Fixation of the Femoral Component without Cement and Fixation with Use of a Bone-Vacuum Cementing Technique for the 
Prevention of Fat Embolism During Total Hip Arthroplasty. The Journal of Bone and Joint Surgery. 1999; 81A:831-843.

${ }^{15}$ Shergill, G, Parmar H. Fat Embolism and The Fat Embolism Syndrome. Online posting.

Orthopaedics. 1 June 2004 <www.orthopaedics.com>

16 Papagelopoulos, P, Apostolou CD, Karachalios TS, Themistocleous GS, Giannakopoulos CK, Ioannidis TT. Pulmonary Fat Embolism After Total Hip and Total Knee Arthroplasty. Orthopedics. 2003; 26:523-527.

${ }^{17}$ Inadome T, Wall MC, Smith CL, Whiteside LA. Femoral intramedullary pressure during in vitro cemented and cementless total hip arthroplasty. Orthopaedic Trans. 1999; 22:154-155.

${ }^{18}$ Schmidt J, Sulk C, Weigand C, LaRosee K. Reduction of fat embolic risks in total hip arthroplasty using cannulated awls and rasps for the preparation of the femoral canal. Archives of Orthopaedic and Trauma Surgery. 2000; 120:100-102.

${ }^{19}$ Maharaj GR, Jamison RD. Intraoperative Impact: Characterization and Laboratory Simulation on Composite Hip Prostheses. Composite Materials for Implant Applications. 1993; 98-108.

${ }^{20}$ Ries MD, Rauscher LA, Hoskins S, Lott D, Richmann JA, Lynch F. Intramedullary Pressure and Pulmonary Function During Total Knee Arthroplasty. Clinical Orthopaedics and Related Research. 1998; 356:154-160.

${ }^{21}$ Collis DK. Cemented total hip replacement in patients who are less then fifty years old. J Bone Joint Surg. 1988; 66A:353-359.

22 Burrus, A. Wheeless Textbook of Orthopaedics_. Duke Health. 23 Aug. 2004 $<\mathrm{http}: / /$ www.wheelessonline.com/oa2/56.htm>

${ }^{23}$ Rommens PM, Claes P. Massive fat emboli syndrome after unsuccessful unreamed nailing of the tibia. Archives of Orthopaedic and Trauma Surgery. 1997; 116:184-186.

${ }^{24}$ Heim D, Chlegel U, Perren SM. Intramedullary pressure in reamed and unreamed nailing of the femur and tibia. Injury. 1994; 24(3):56-63.

${ }^{25}$ Kropfl A, Berger U, Neureiter H, Hertz H, Schlag G. Intramedullary pressure and bone marrow fat intravasation in unreamed femoral nailing. The Journal of Trauma: Injury, Infection and Critical Care 1997; 42:946-954.

${ }^{26}$ Muller C, McIff T, Rahn BA, Pfister U, Weller S. Intramedullary pressure, strain on the diaphysis and increase in cortical temperature when reaming the femoral medullary cavity. Injury. 1993; 24:22-30.

${ }^{27}$ Muller C, Mclff T, Rahn BA, Pfister U, Perren SM, Weller S. Influence of the compression force on the intramedullary pressure development in reaming of the femoral medullary cavity. Injury. 1993; 24:36-39.

${ }^{28}$ Johnson JA, Berkshire A, Leighton RK, Gross M, Chess DG, Petrie D. Some basic biomechanical characteristics of medullary pressure generation during reaming of the femur. Injury 1995; 26:451-454.

${ }^{29}$ Muller C, Frigg R, Pfister U. Effect of flexible drive diameter and reamed design on the increase of pressure in the medullary cavity during reaming. Injury. 1993; 24:40-47.

${ }^{30}$ Frolke JM, Bakker FC, Patka P, Haarman HJ. Intramedullary pressure in reamed femoral nailing with two different reamer designs. European Journal of Trauma. 2001; 235-240. 
${ }^{31}$ Martin R, Leighton RK, Petrie D, Ikejiani C, Smyth B. Effect of proximal and distal venting during intramedullary nailing. Clinical Orthopaedics and Related Research. $1996 ; 332: 80-89$.

${ }^{32}$ Heiner AD, Brown TD. Structural properties of a new design of composite replicate femurs and tibias. Journal of Biomechanics, 2001; 34:773-781.

33 Heiner AD, Brown TD. Structural properties of an improved redesign of composite replicate femurs and tibias. Proceedings of the 49th Annual Meeting of the Orthopaedic Research Society, New Orleans, USA, February 2003.

${ }^{34}$ Cristofolini L, Viceconti M, Cappello A, Toni A. Mechanical validation of whole bone composite femur models. Journal of Biomechanics. 1996; 29(4):525-35.

${ }^{35}$ Cristofolini L, Viceconti M. Mechanical validation of whole bone composite tibia models. Journal of Biomechanics. 2000; 33(3):279-288.

${ }^{36}$ Weiner S, Traub W. Bone structure: from angstroms to microns, The FASEB Journal, $1992 ; 6: 879-885$.

${ }^{37}$ Ascenzi A, Benvenuti A. Orientation of collagen fibers at the boundary between two successive osteonic lamellae and its mechanical interpretation, Journal of Biomechanics. 1986; 19:455-463.

${ }^{38}$ An YH, Draughn RA. Mechanical testing of bone and the bone-implant interface, CRC Press LLC. 2000; $42-44$.

${ }^{39}$ Schaffler MB, Burr DB. Stiffness of compact bone: Effects of porosity and density. Journal of Biomechanics. 1988; 21:13-16.

${ }^{40}$ Cowin SC, Van Buskirk WC, Ashman RB. Properties of Bone. Chapter 2 in Handbook of Engineering. Edited by Skalak R, Chien S. McGraw-Hill book Company, New York.

${ }_{41}$ Wang X, Qingwen N. Determination of cortical bone porosity and pore size distribution using a low field pulsed NMR approach. Journal of Orthopaedic Research. $2003 ; 21: 312-319$.

${ }^{42}$ Le Huec JC, Schaeverbeke T, Clement D, Faber J, Le Rebeller A. Influence of porosity on the mechanical resistance of hydroxyapatite ceramics under compressive stress. Biomaterials. 1995; 18:113-118.

${ }^{43}$ An YH, Draughn RA. Mechanical testing of bone and the bone-implant interface, CRC Press LLC. 2000; 43.

${ }^{44}$ de Bruyn PPH, Breen PC, Thomas TB. The microcirculation of the bone marrow. Anatomical Record. 1970, 168:55-68.

${ }^{45}$ Draenert K, Draenert Y. The Vascular System of Bone Marrow. Scanning Electron Microscopy. 1980; 113-121.

${ }^{46}$ Bryant JD, David T, Gaskell PH, King S, Lond G. Rheology of bovine bone marrow. Proceedings of the Institution of Mechanical Engineers. 1989; 203:71-75.

47 Eugene F. Du Bois, The Many Different Temperatures of the Human Body and Its Parts, Western Journal of Surgery. 1951; 59:476-490.

48 Petrakis NL. Temperature of human bone marrow. Journal of Applied Physiology. 1952; 4:549-553.

${ }^{49}$ Gogolewski S. Nonmetallic materials for bone substitutes. European Cells and Materials. 2001; 2:54-55.

${ }^{50}$ Bredbenner TL, Haug RH. Substitutes for human cadaveric bone in maxillofacial rigid fixation research. Oral Surgersy Oral Medicine Oral Pathology. 2000; 90:574-580. 
${ }^{51}$ Mousavi M, David R, Ehteshami J, Pajenda G, Vecsei V. Pressure changes during reaming with different parameters and reamer designs. Clinical Orthopaedics and Related Research, 1999; 373:295-303.

${ }^{52}$ Dobrjanski D, Gaber O, Saghir Z, Behdinan K, Zalzal P, de Beer J, Papini M. The pressure generated during the insertion of an intramedullary device: experiments and numerical modeling. Biomedicine 2005 Conference, Bologna, Italy. 2005

${ }^{53}$ Hopf $\mathrm{T}$, Gleitz M, Hess T, Intramedullary pressure during reaming and nailing of the femur with modern compression interlocking nails: a potential cause of fat embolism? Unfallchirurg, 1994; 38:899.

${ }^{54}$ Wenda K, Runkel M, Degreif J, et al. Pathogenesis and clinical relevance of bone marrow embolism in medullary nailing demonstrated by intraoperative echocardiography. Injury, 1993; 24:73.

${ }^{55}$ Brown GA, Kyle RF. Biofluids mechanics of intramedullary reaming, Bioengineering Conference ASME 1997. 1997; 35:581-582.

${ }_{57}^{56}$ Gaber O. MASc. Thesis, Ryerson University. 2005.

${ }^{57}$ White FM. Fluid Mechanics. 4th ed. McGraw-Hill, Toronto, 1999.

${ }^{58}$ Saadetian P. MASc. Thesis, Ryerson University. 2005. 
Appendix A

\section{Pressure Profiles}




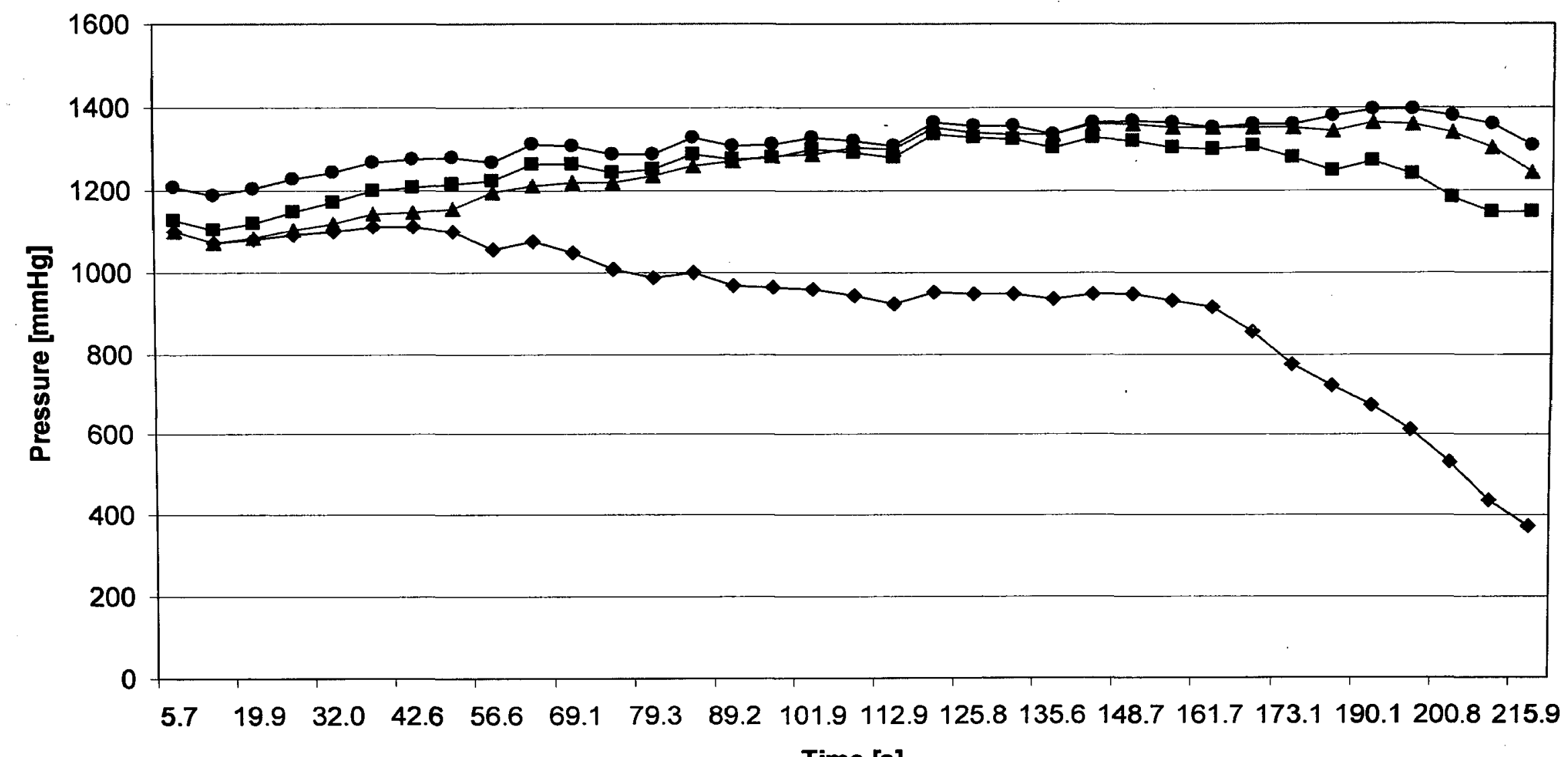

Time [s]

$\multimap$ Pressure $1 \rightarrow$ Pressure $2 \rightarrow$ Pressure $3 \rightarrow$ Pressure 4

Figure A.1: Pressure variation using rubber hammer tip, flat implant tip geometry, $0.5 \mathrm{~mm}$ bone to implant radial gap, $59.4 \mathrm{cP}$ synthetic bone marrow viscosity and a $90 \mathrm{~N}$ peak impact force. 


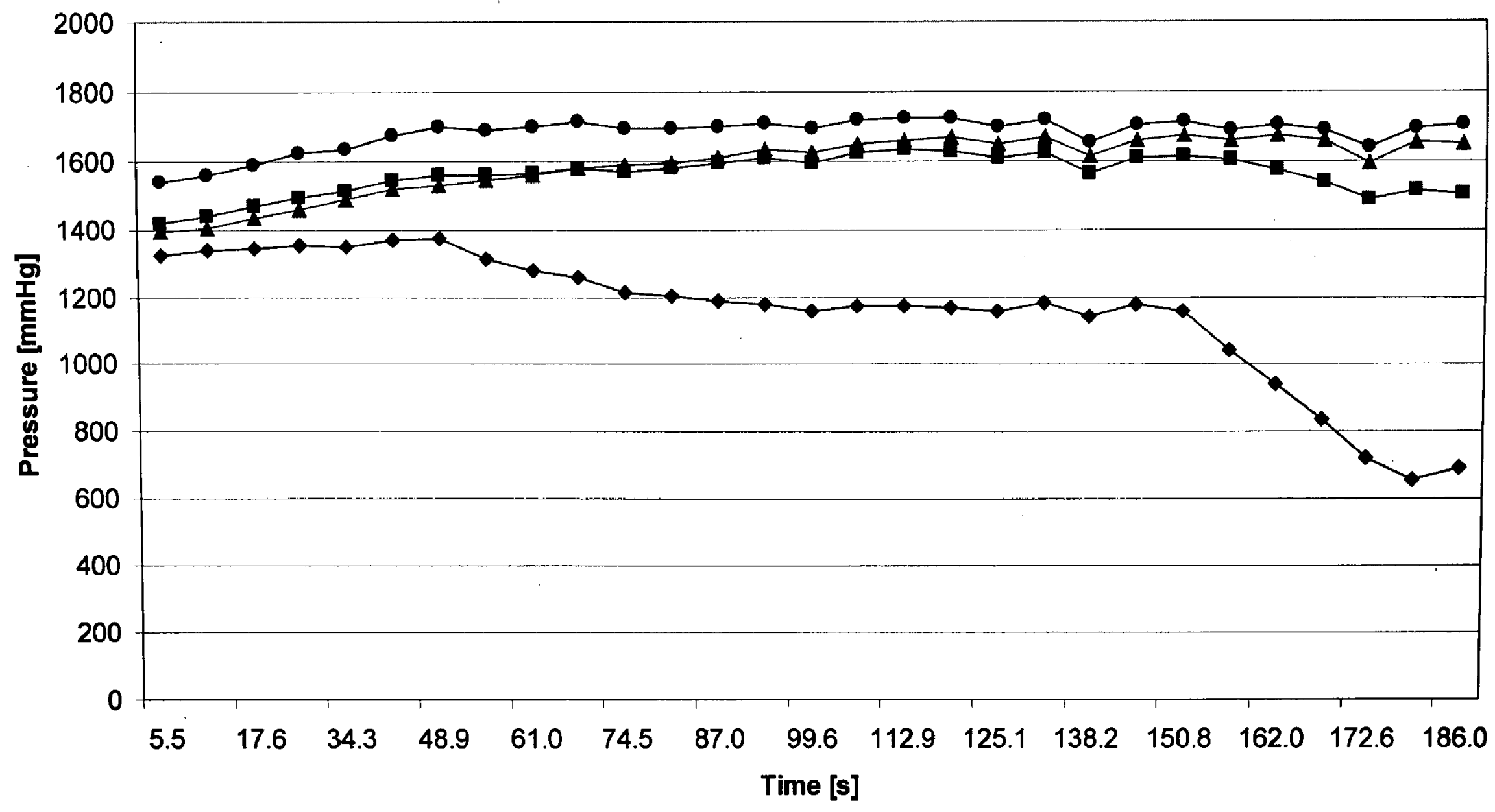

$\multimap$ Pressure $1 \rightarrow$-Pressure $2 \multimap$ Pressure $3 \multimap$ Pressure 4

Figure A.2: Pressure variation using rubber hammer tip, flat implant tip geometry, $0.5 \mathrm{~mm}$ bone to implant radial gap, $59.4 \mathrm{cP}$ synthetic bone marrow viscosity and a $110 \mathrm{~N}$ peak impact force. 


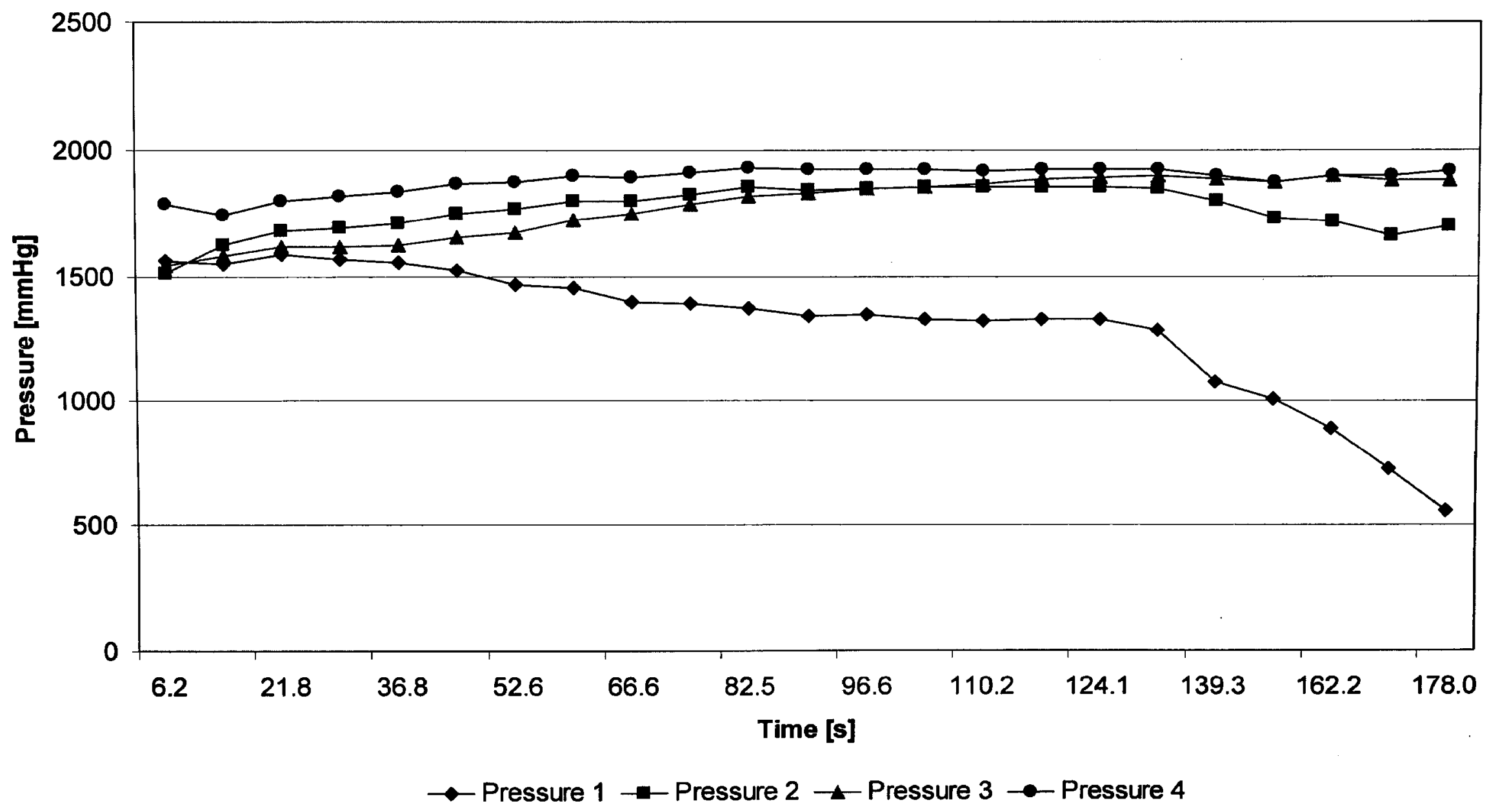

Figure A.3: Pressure variation using rubber hammer tip, flat implant tip geometry, $0.5 \mathrm{~mm}$ bone to implant radial gap, $59.4 \mathrm{cP}$ synthetic bone marrow viscosity and a $145 \mathrm{~N}$ peak impact force. 


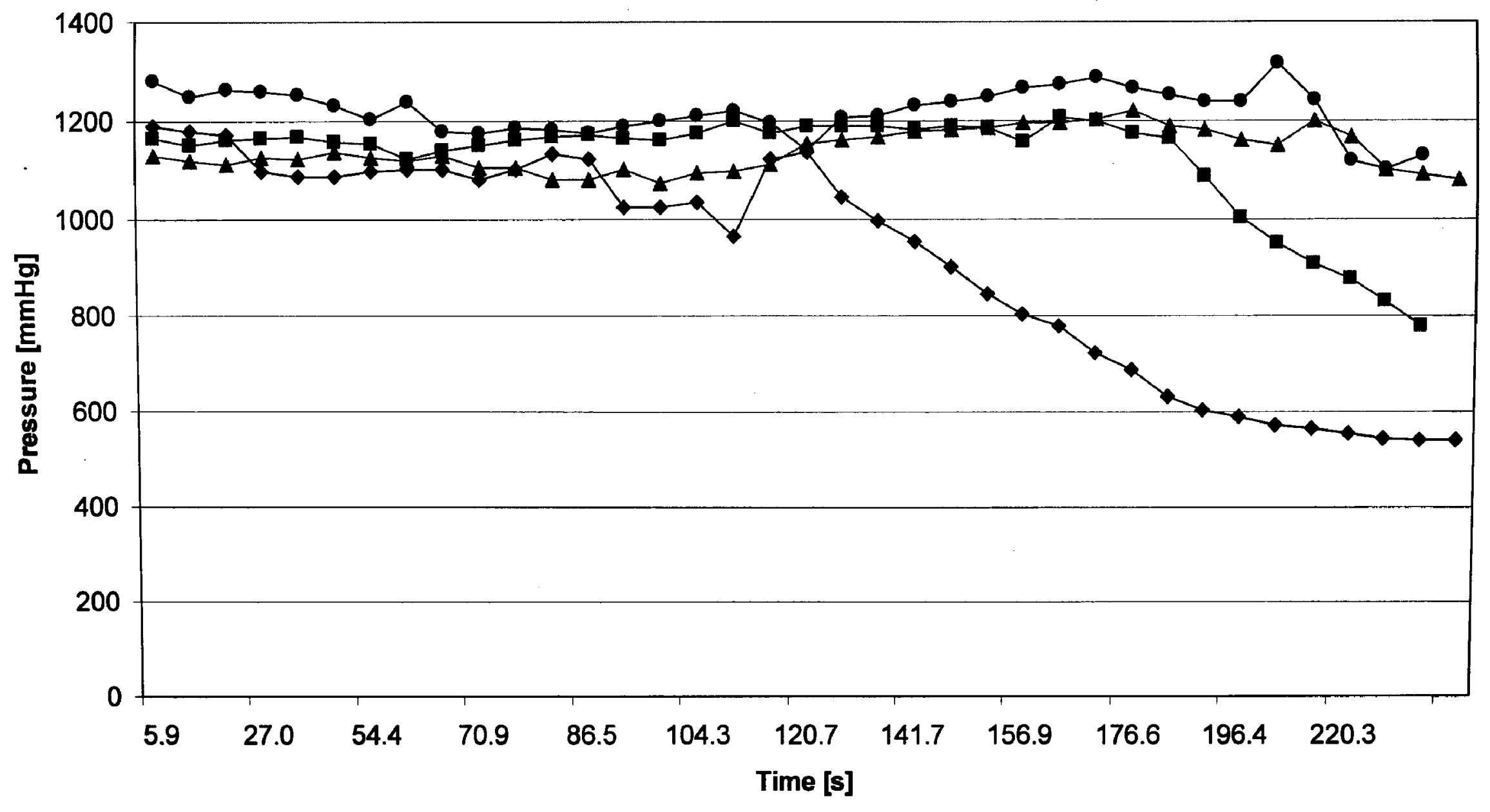

$\multimap$ Pressure $1 \rightarrow$ Pressure $2 \rightarrow$ Pressure $3 \rightarrow$ Pressure 4

Figure A.4: Pressure variation using rubber hammer tip, flat implant tip geometry, $0.5 \mathrm{~mm}$ bone to implant radial gap, $82.6 \mathrm{cP}$ synthetic bone marrow viscosity and a $90 \mathrm{~N}$ peak impact force. 


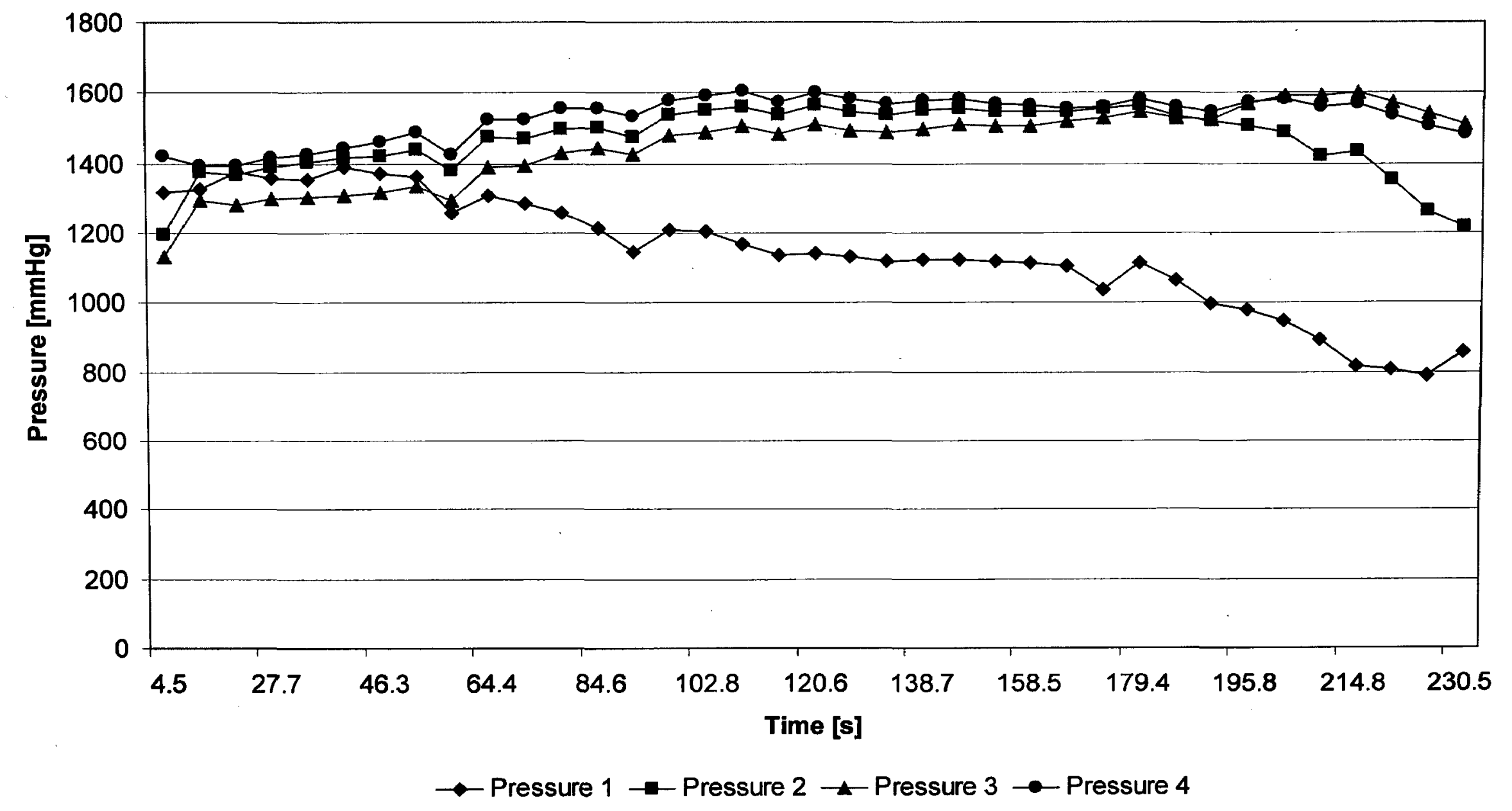

Figure A.5: Pressure variation using rubber hammer tip, flat implant tip geometry, $0.5 \mathrm{~mm}$ bone to implant radial gap, $82.6 \mathrm{cP}$ synthetic bone marrow viscosity and a $110 \mathrm{~N}$ peak impact force. 


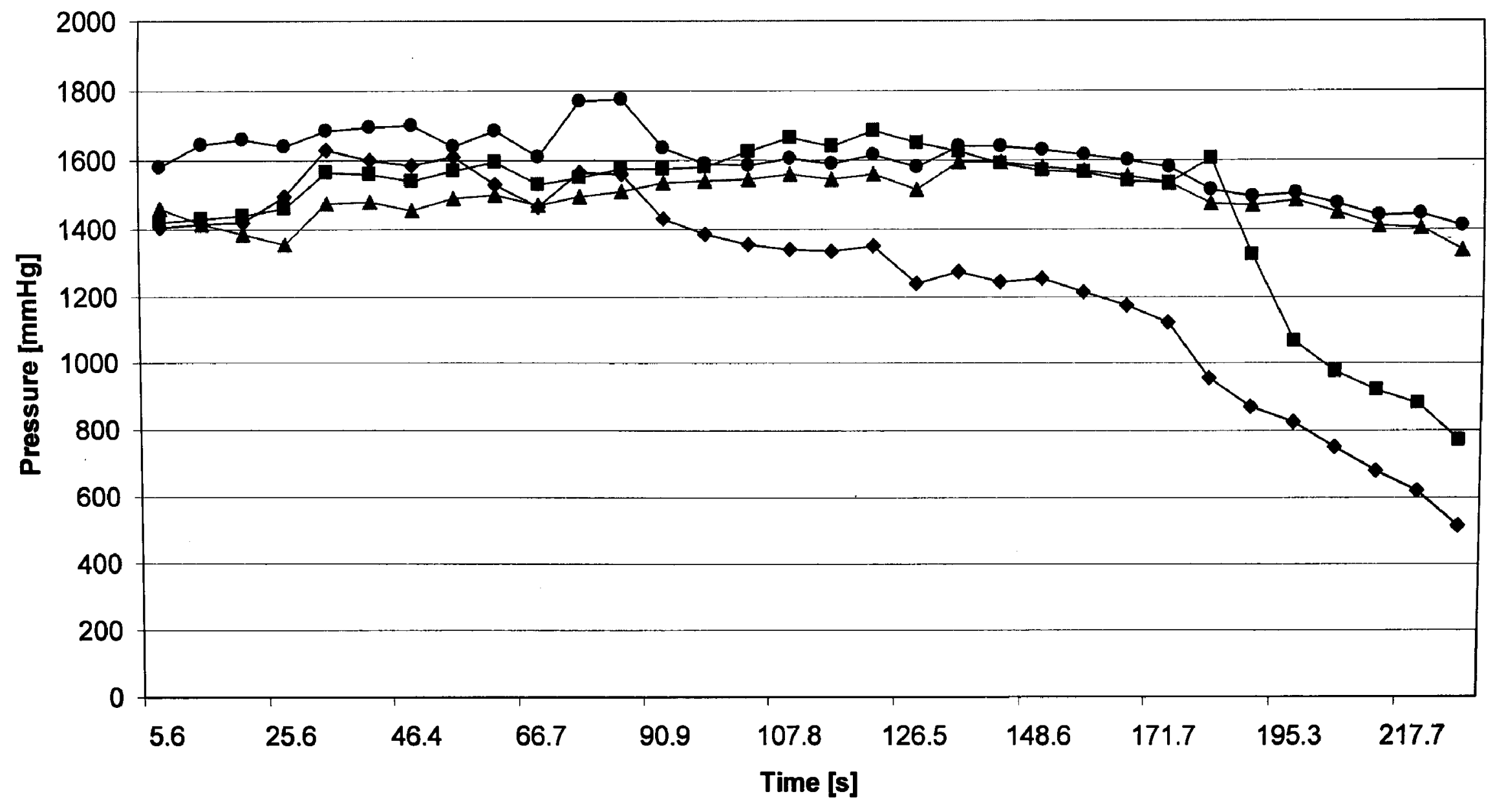

$\rightarrow$ Pressure $1 \rightarrow$-Pressure $2 \multimap$ Pressure $3 \rightarrow$ Pressure 4

Figure A.6: Pressure variation using rubber hammer tip, flat implant tip geometry, $0.5 \mathrm{~mm}$ bone to implant radial gap, $82.6 \mathrm{cP}$ synthetic bone marrow viscosity and a 145 N peak impact force. 


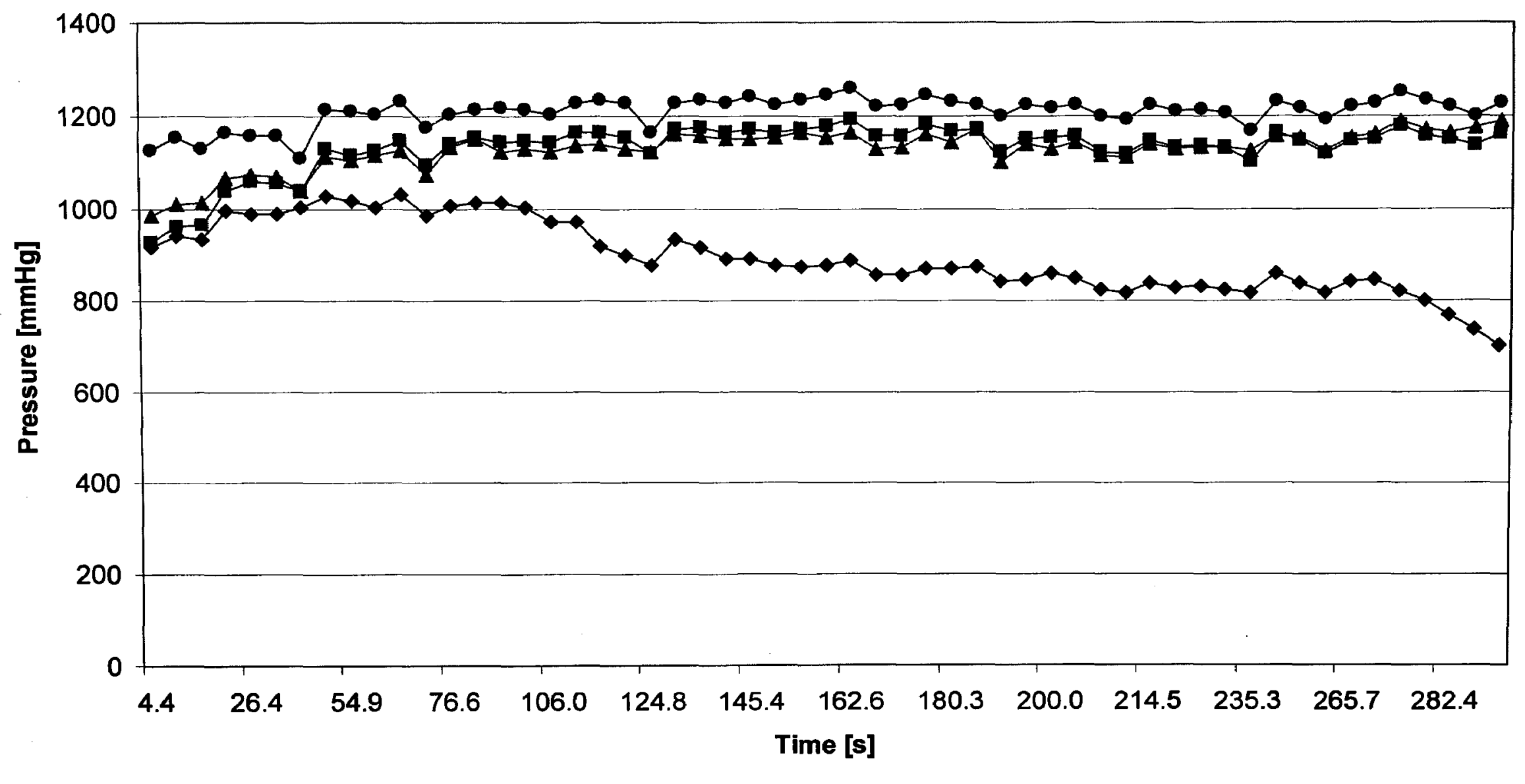

$\multimap$ Pressure $1 \rightarrow$ Pressure $2 \multimap$ Pressure $3 \multimap$ Pressure 4

Figure A.7: Pressure variation using rubber hammer tip, flat implant tip geometry, $0.5 \mathrm{~mm}$ bone to implant radial gap, $146.4 \mathrm{cP}$ synthetic bone marrow viscosity and a $90 \mathrm{~N}$ peak impact force. 


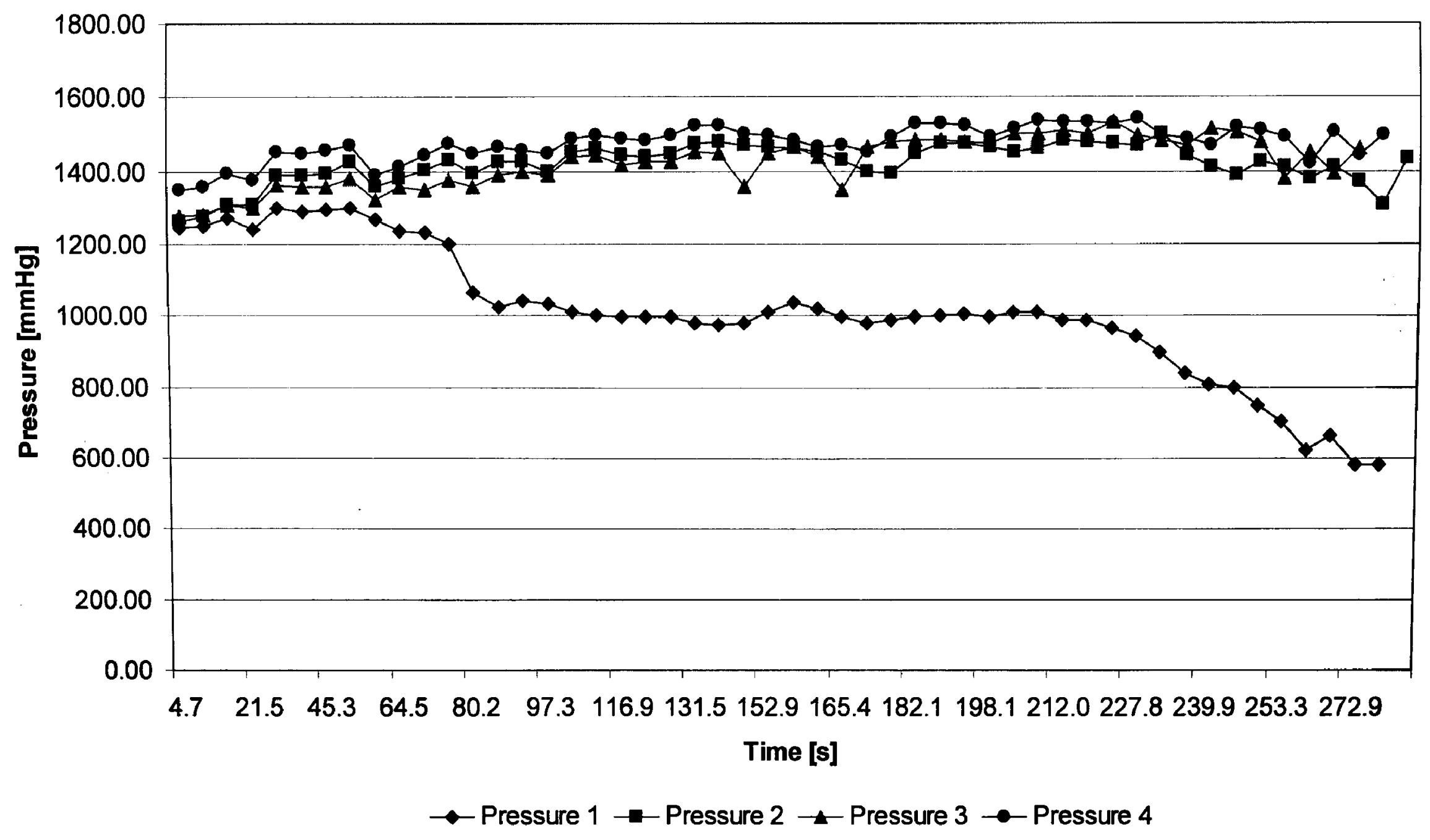

Figure A.8: Pressure variation using rubber hammer tip, flat implant tip geometry, $0.5 \mathrm{~mm}$ bone to implant radial gap, $146.4 \mathrm{cP}$ synthetic bone marrow viscosity and a $110 \mathrm{~N}$ peak impact force. 


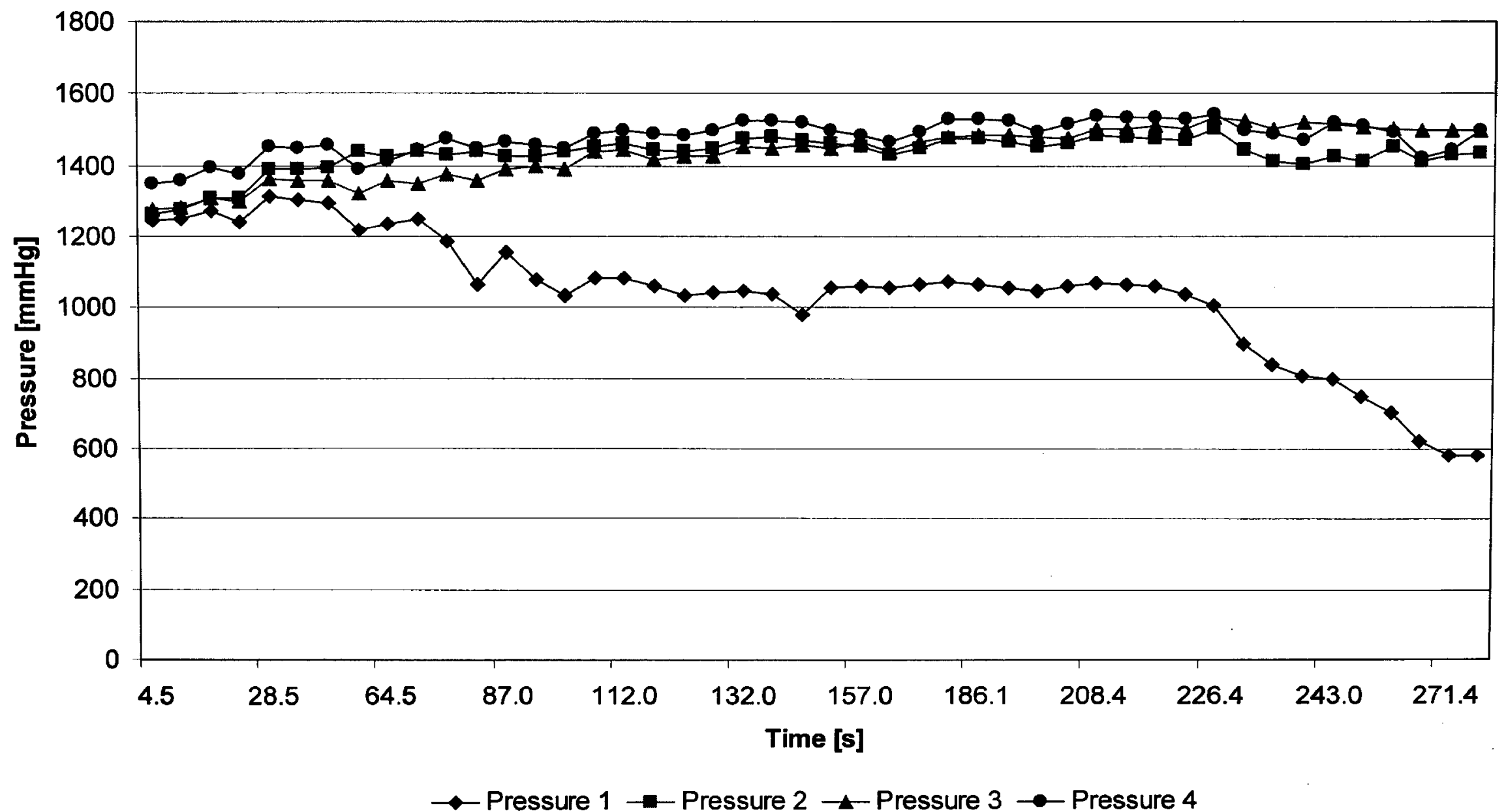

Figure A.9: Pressure variation using rubber hammer tip, flat implant tip geometry, $0.5 \mathrm{~mm}$ bone to implant radial gap, $146.4 \mathrm{cP}$ synthetic bone marrow viscosity and a $145 \mathrm{~N}$ peak impact force. 


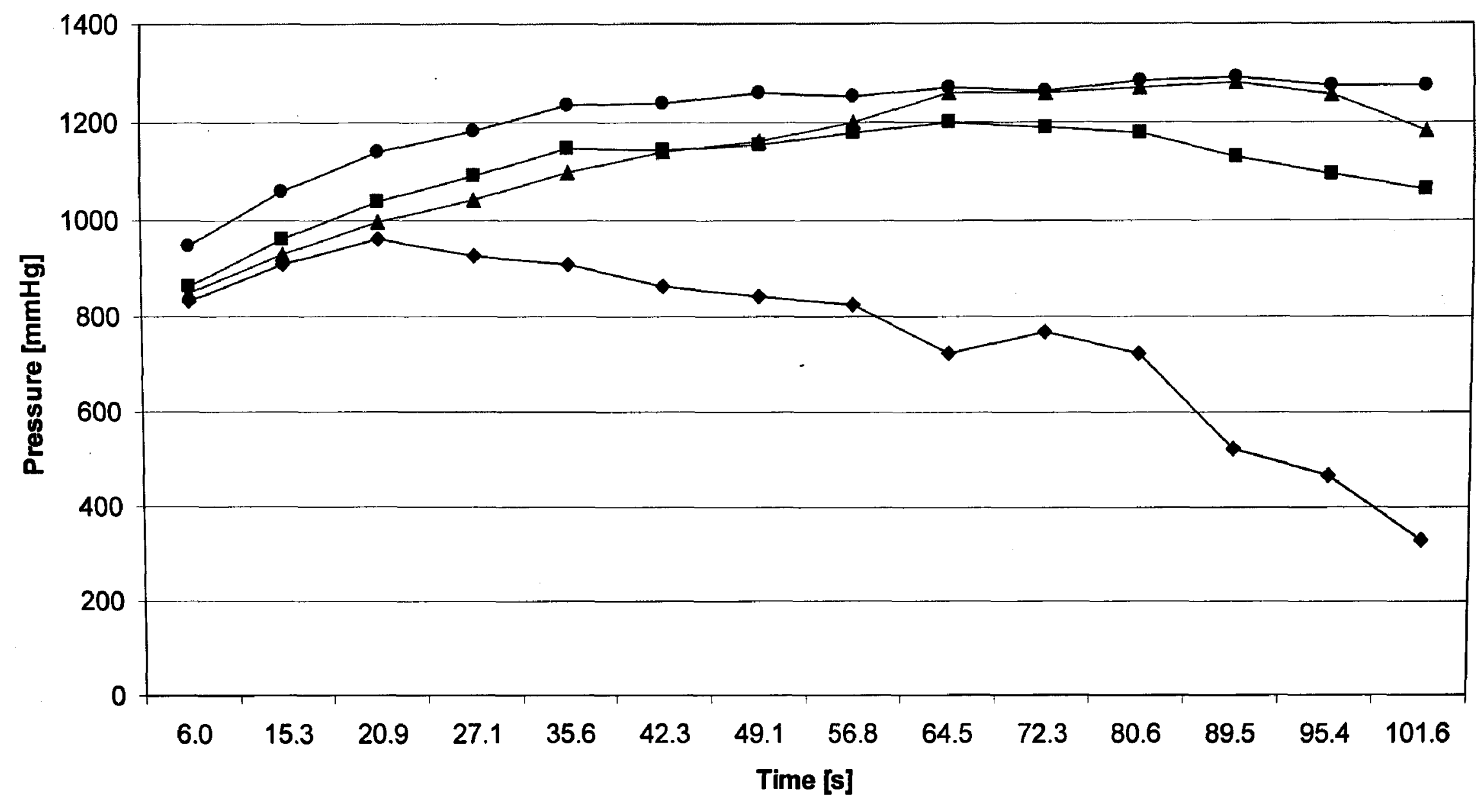

$\neg$ Pressure $1 \rightarrow$-Pressure $2 \rightarrow$ Pressure $3 \rightarrow$ Pressure 4

Figure A.10: Pressure variation using rubber hammer tip, flat implant tip geometry, $1.0 \mathrm{~mm}$ bone to implant radial gap, $59.4 \mathrm{cP}$ synthetic bone marrow viscosity and a $90 \mathrm{~N}$ peak impact force. 


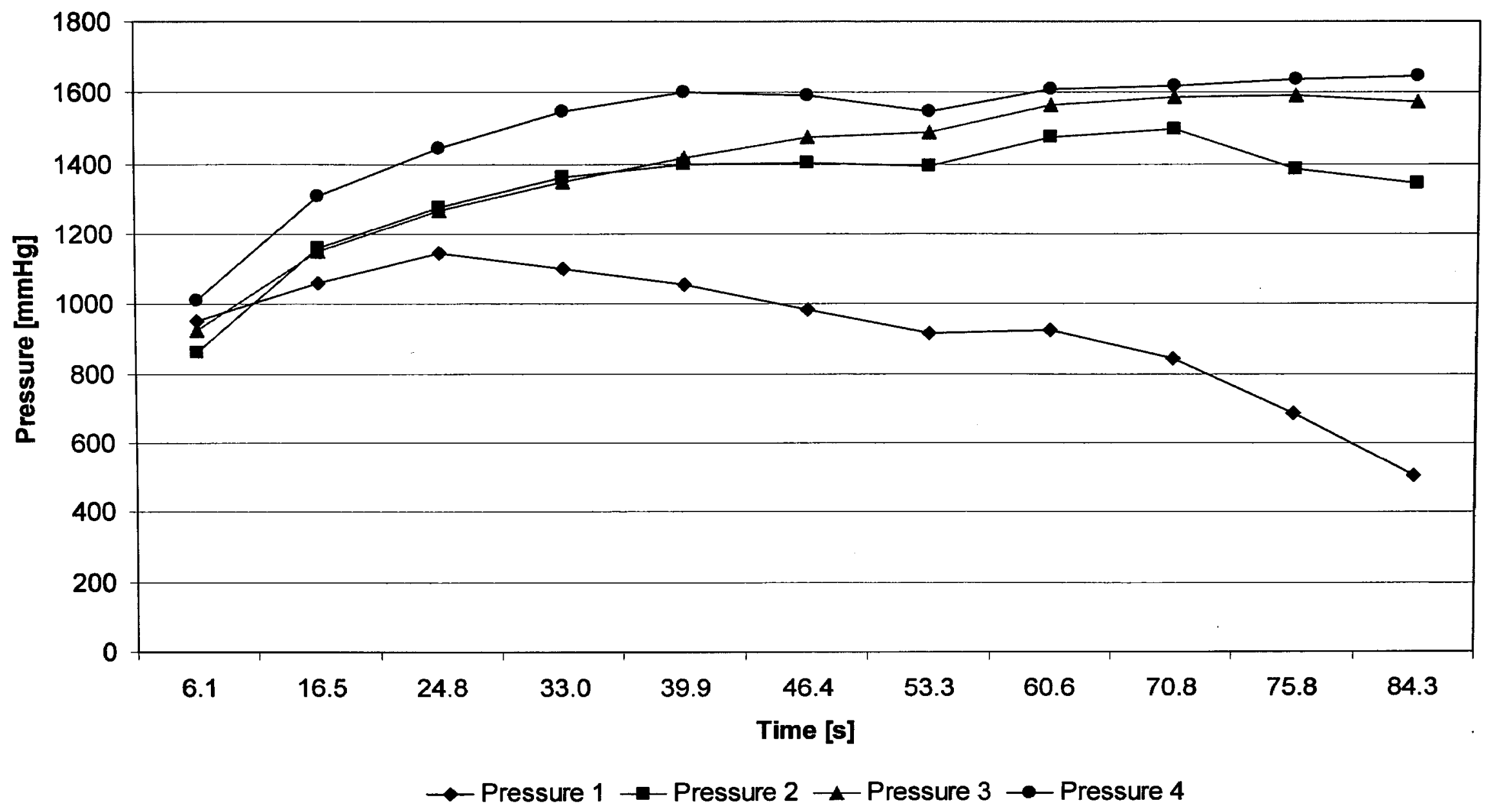

Figure A.11: Pressure variation using rubber hammer tip, flat implant tip geometry, $1.0 \mathrm{~mm}$ bone to implant radial gap, $59.4 \mathrm{cP}$ synthetic bone marrow viscosity and a $110 \mathrm{~N}$ peak impact force. 


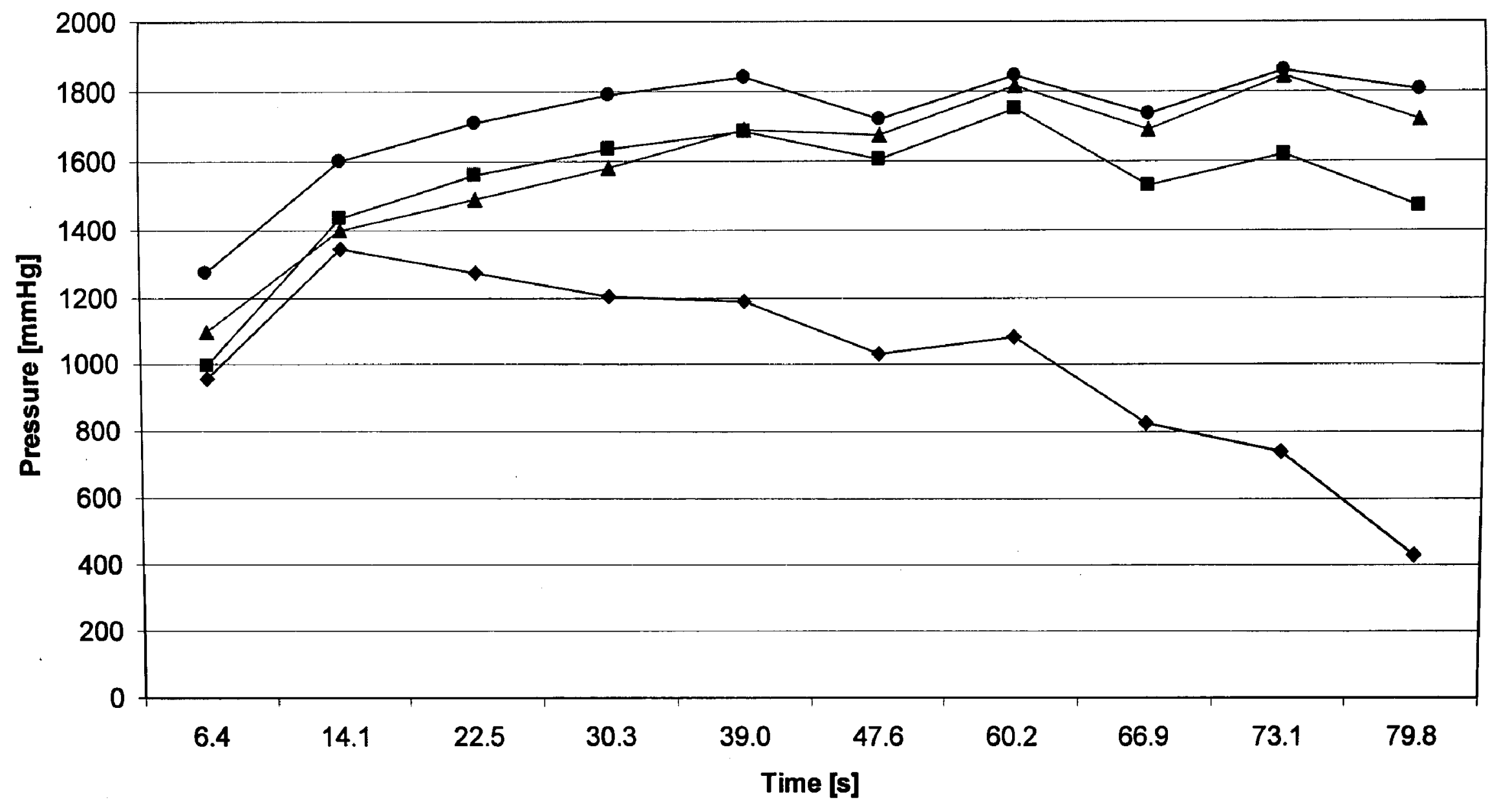

$\rightarrow$ Pressure $1 \rightarrow$-Pressure $2 \multimap$ Pressure $3 \rightarrow$ Pressure 4

Figure A.12: Pressure variation using rubber hammer tip, flat implant tip geometry, $1.0 \mathrm{~mm}$ bone to implant radial gap, $59.4 \mathrm{cP}$ synthetic bone marrow viscosity and a $145 \mathrm{~N}$ peak impact force. 


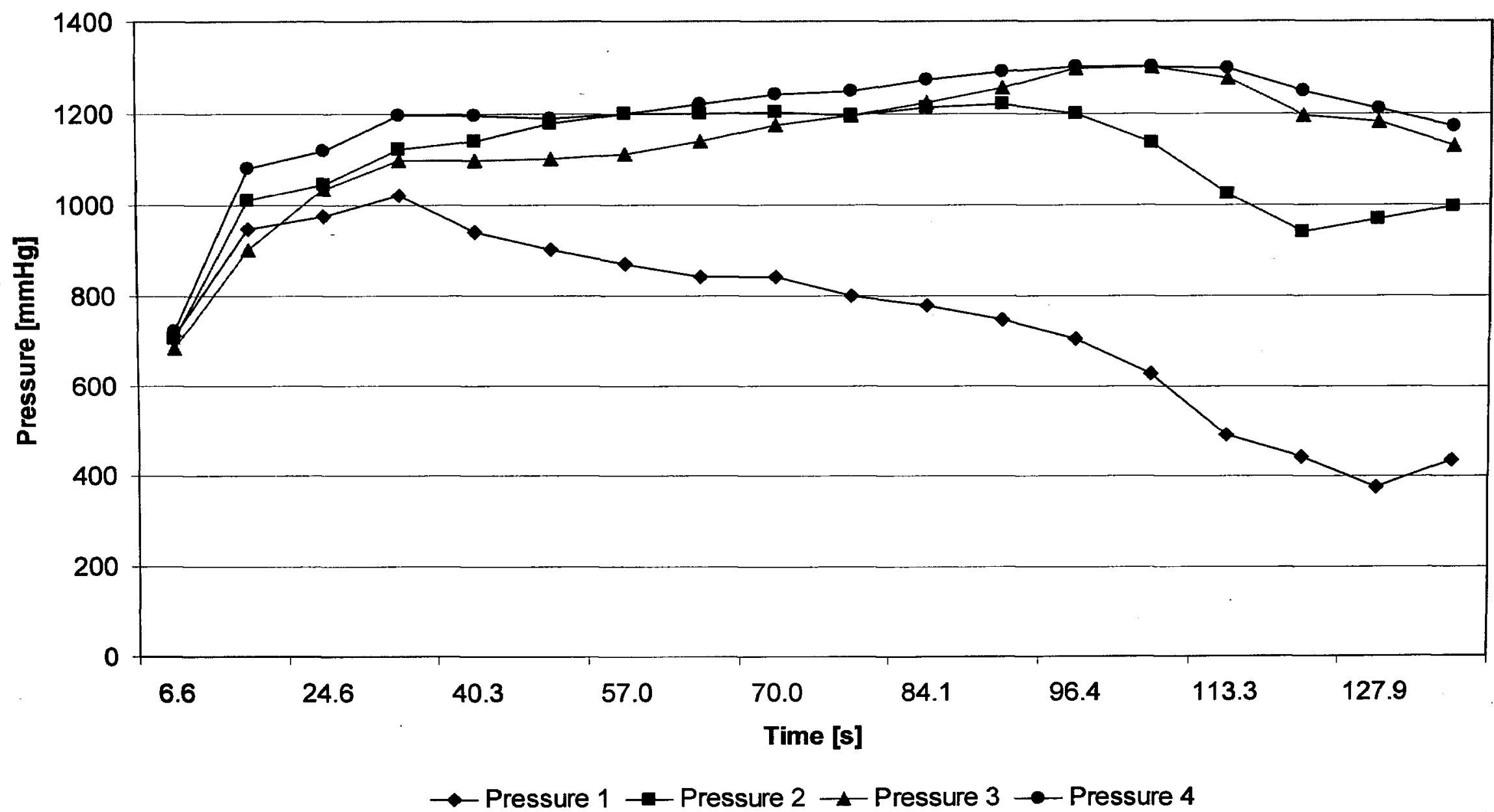

Figure A.13: Pressure variation using rubber hammer tip, flat implant tip geometry, $1.0 \mathrm{~mm}$ bone to implant radial gap, $82.6 \mathrm{cP}$ synthetic bone marrow viscosity and a $90 \mathrm{~N}$ peak impact force. 


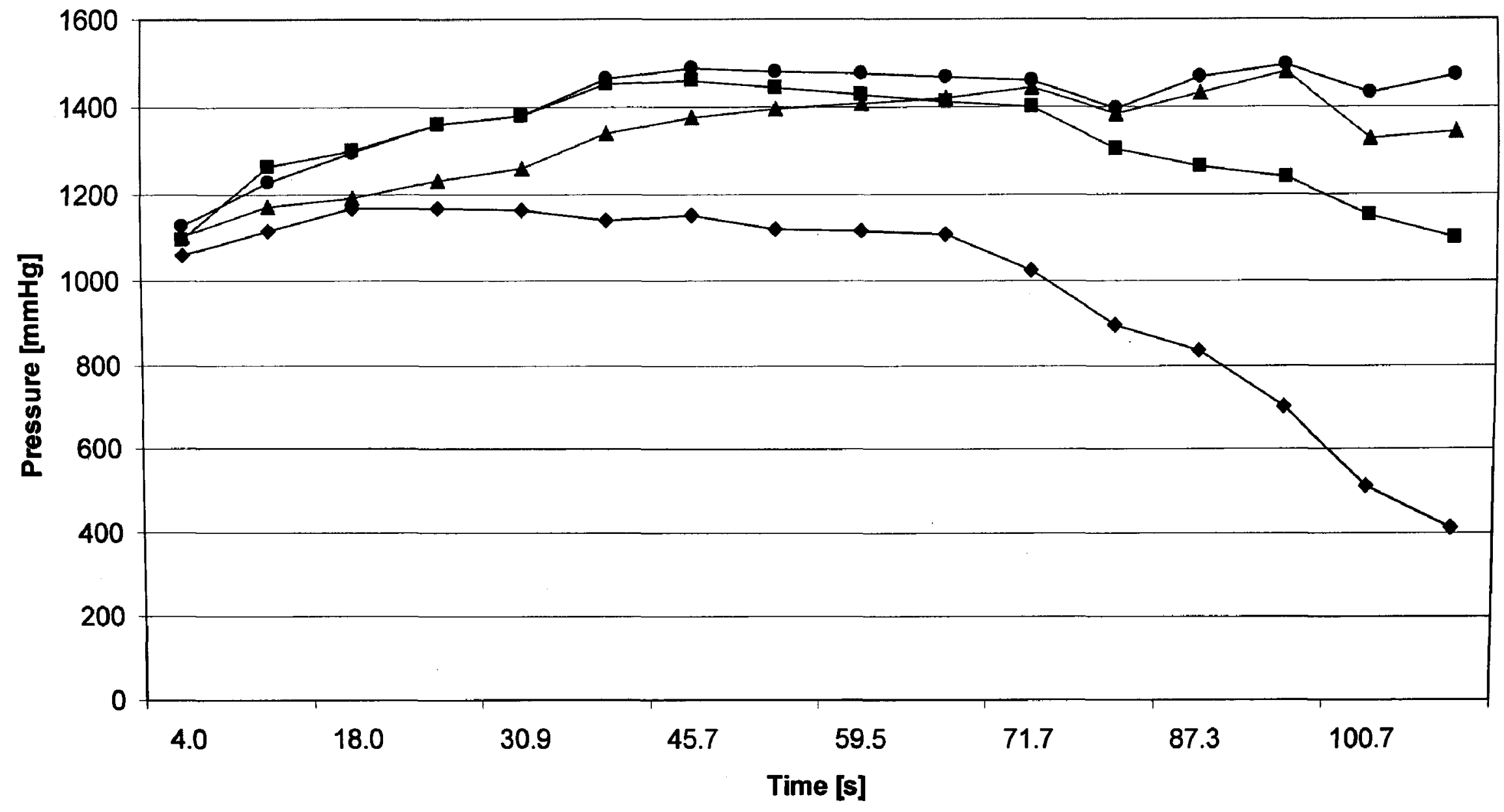

$\rightarrow$ Pressure $1 \rightarrow$-Pressure $2 \multimap$ Pressure $3 \rightarrow$ Pressure 4

Figure A.14: Pressure variation using rubber hammer tip, flat implant tip geometry, $1.0 \mathrm{~mm}$ bone to implant radial gap, $82.6 \mathrm{cP}$ synthetic bone marrow viscosity and a $110 \mathrm{~N}$ peak impact force. 


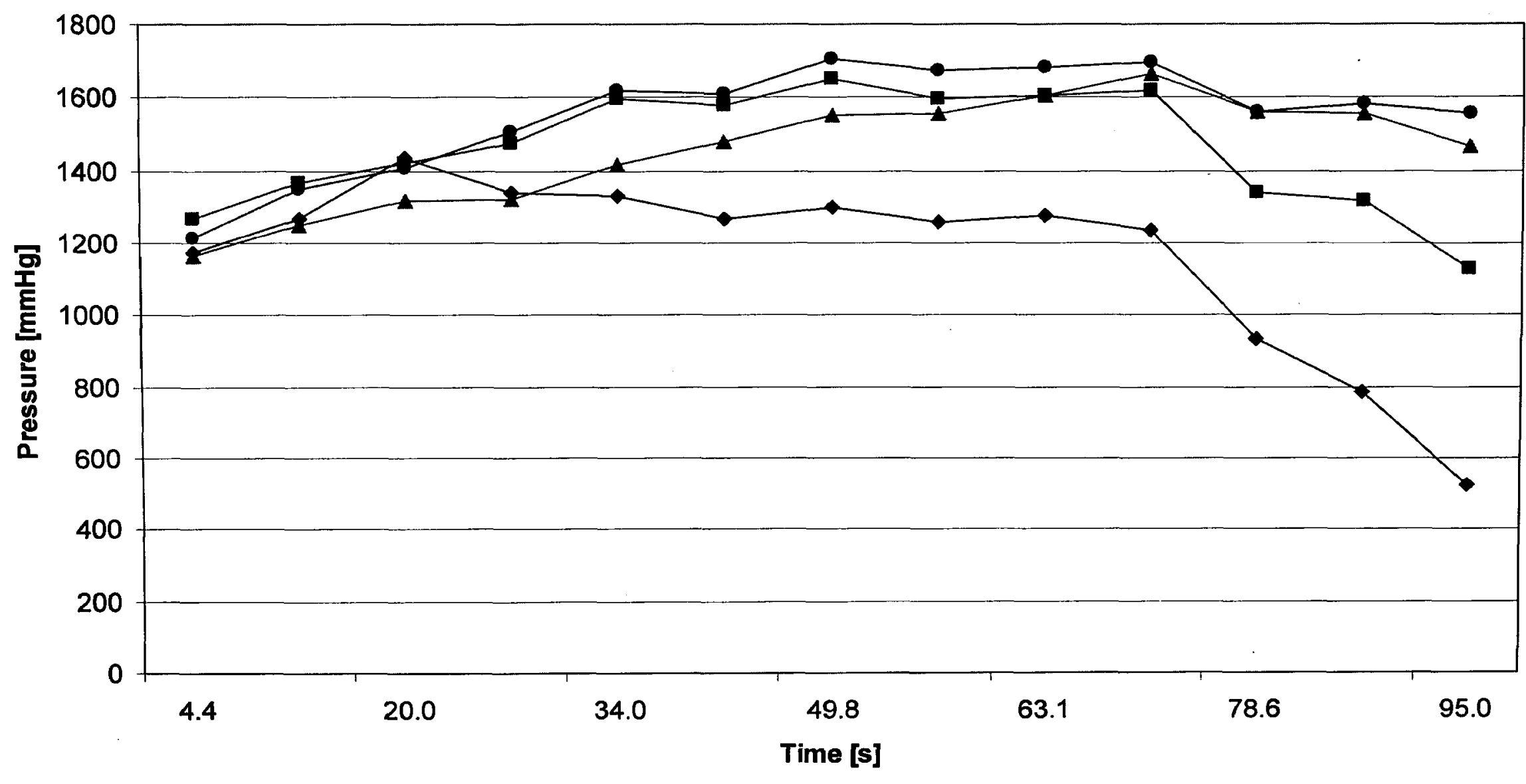

$\rightarrow$ Pressure $1 \rightarrow$ Pressure $2 \multimap$ Pressure $3 \rightarrow$ Pressure 4

Figure A.15: Pressure variation using rubber hammer tip, flat implant tip geometry, $1.0 \mathrm{~mm}$ bane to implant radial gap, 82.6 cP synthetic bone marrow viscosity and a $145 \mathrm{~N}$ peak impact force. 


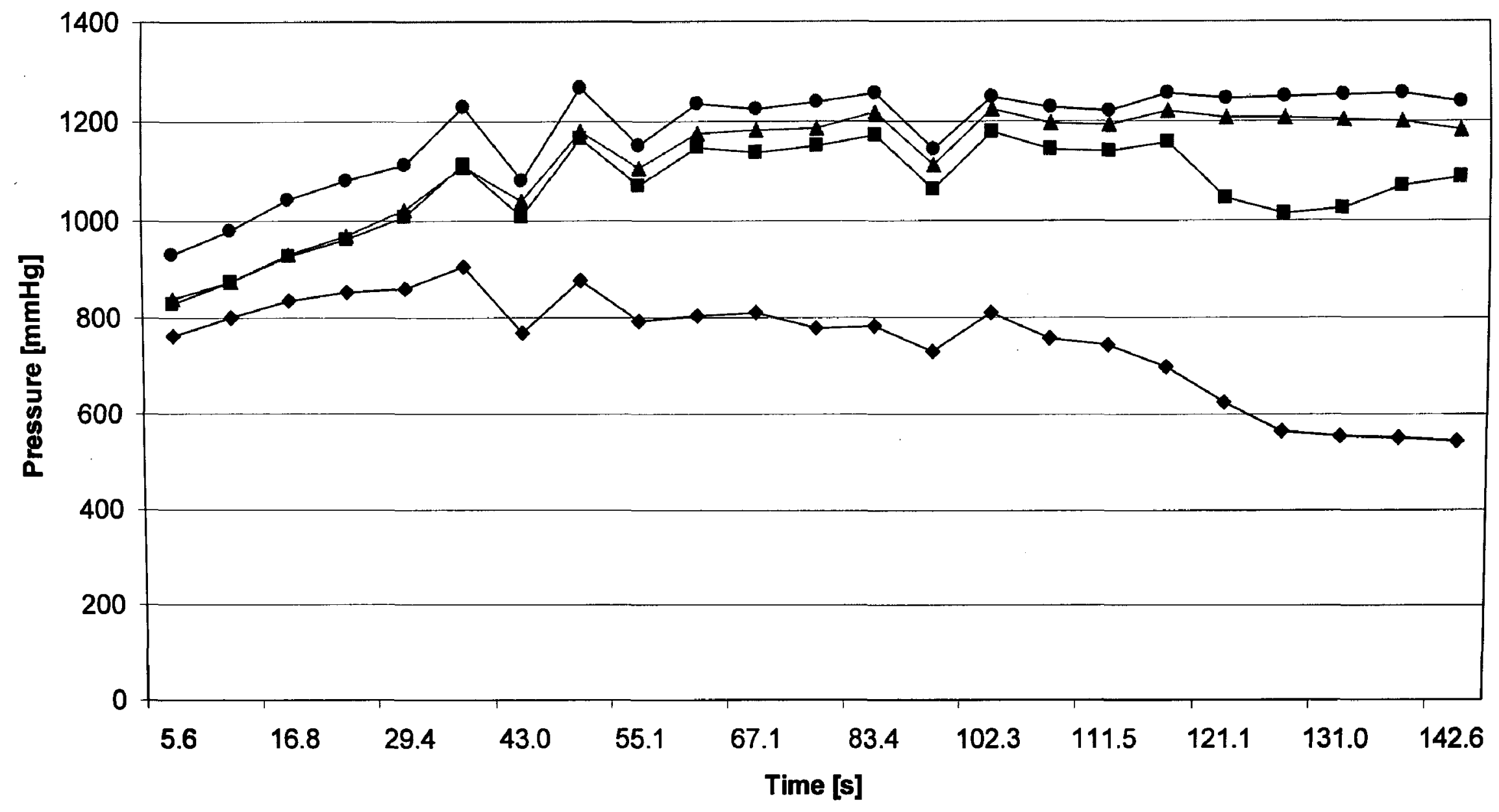

$\multimap$ Pressure $1 \multimap$ Pressure $2 \multimap$ Pressure $3 \multimap$ Pressure 4

Figure A.16: Pressure variation using rubber hammer tip, flat implant tip geometry, $1.0 \mathrm{~mm}$ bone to implant radial gap, $146.4 \mathrm{cP}$ synthetic bone marrow viscosity and a $90 \mathrm{~N}$ peak impact force. 


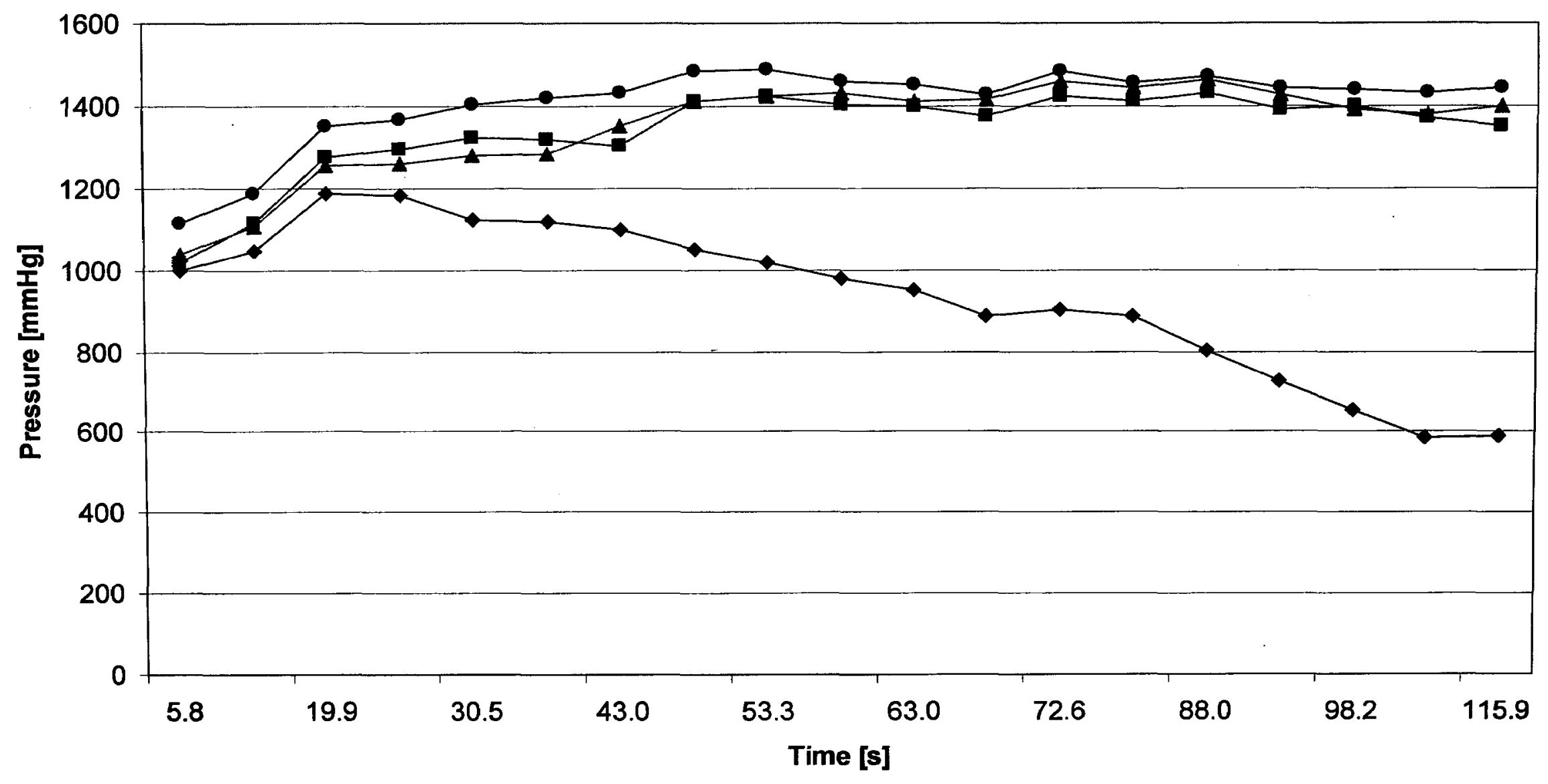

$\rightarrow$ Pressure $1 \rightarrow$ Pressure $2 \multimap$ Pressure $3 \multimap$ Pressure 4

Figure A.17: Pressure variation using rubber hammer tip, flat implant tip geometry, $1.0 \mathrm{~mm}$ bone to implant radial gap, $146.4 \mathrm{cP}$ synthetic bone marrow viscosity and a $110 \mathrm{~N}$ peak impact force. 


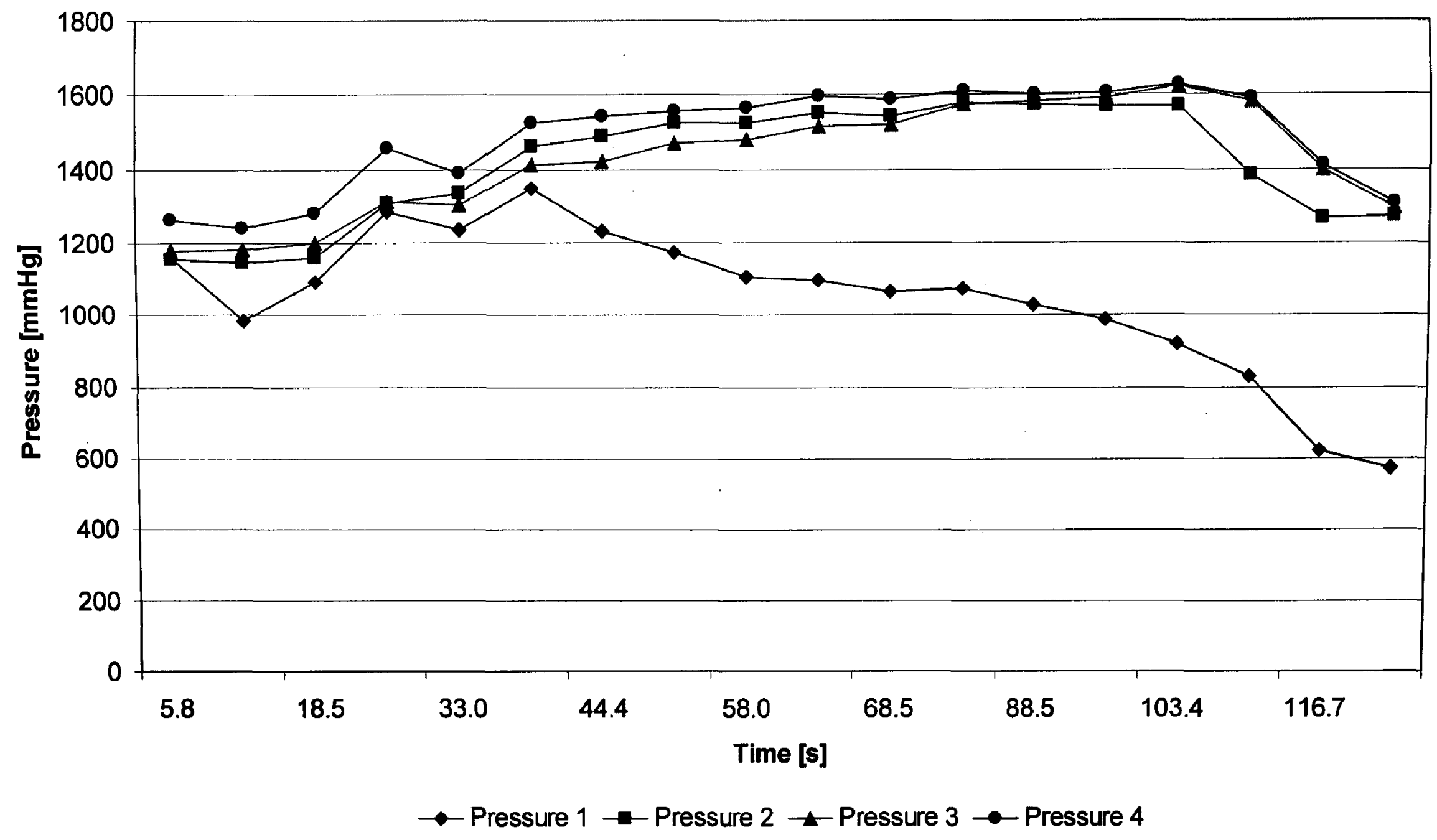

Figure A.18: Pressure variation using rubber hammer tip, flat implant tip geometry, $1.0 \mathrm{~mm}$ bone to implant radial gap, $146.4 \mathrm{cP}$ synthetic bone marrow viscosity and a $145 \mathrm{~N}$ peak impact force. 


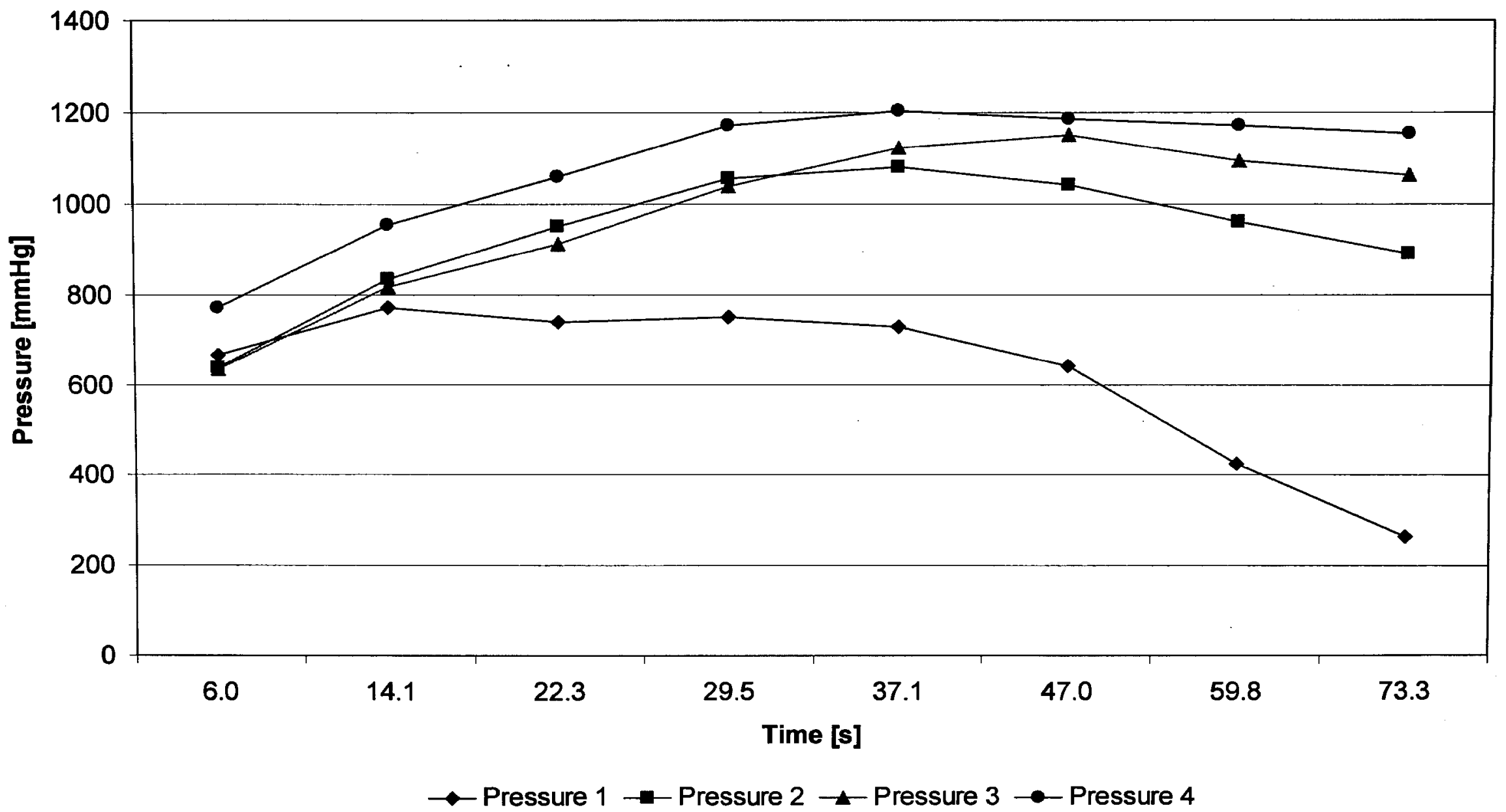

Figure A.19: Pressure variation using rubber hammer tip, flat implant tip geometry, $1.5 \mathrm{~mm}$ bone to implant radial gap, $59.4 \mathrm{cP}$ synthetic bone marrow viscosity and a 90 N peak impact force. 


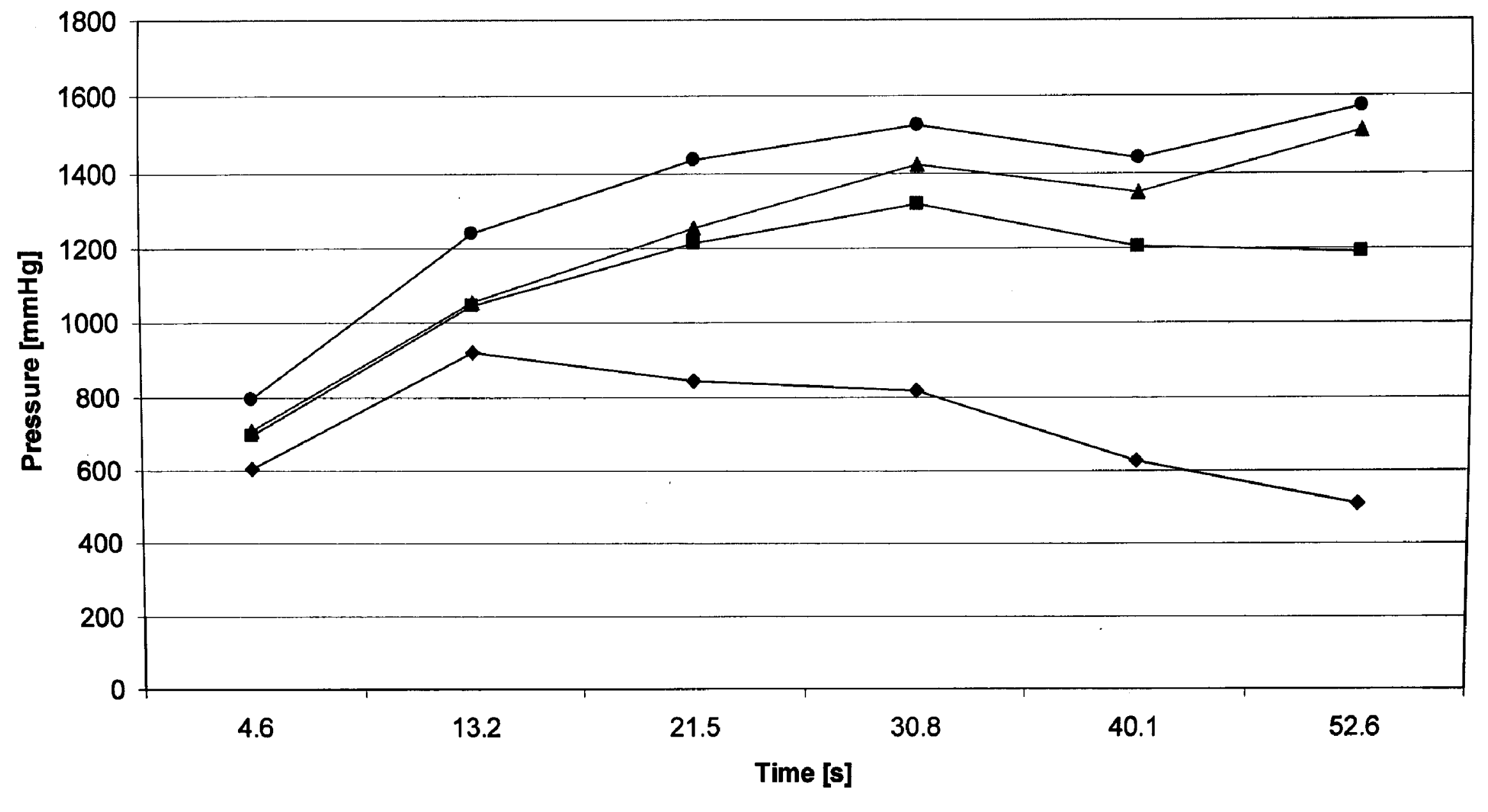

$\multimap$ Pressure $1 \rightarrow$-Pressure $2 \multimap$ Pressure $3 \multimap$ Pressure 4

Figure A.20: Pressure variation using rubber hammer tip, flat implant tip geometry, $1.5 \mathrm{~mm}$ bone to implant radial gap, $59.4 \mathrm{cP}$ synthetic bone marrow viscosity and a $110 \mathrm{~N}$ peak impact force. 


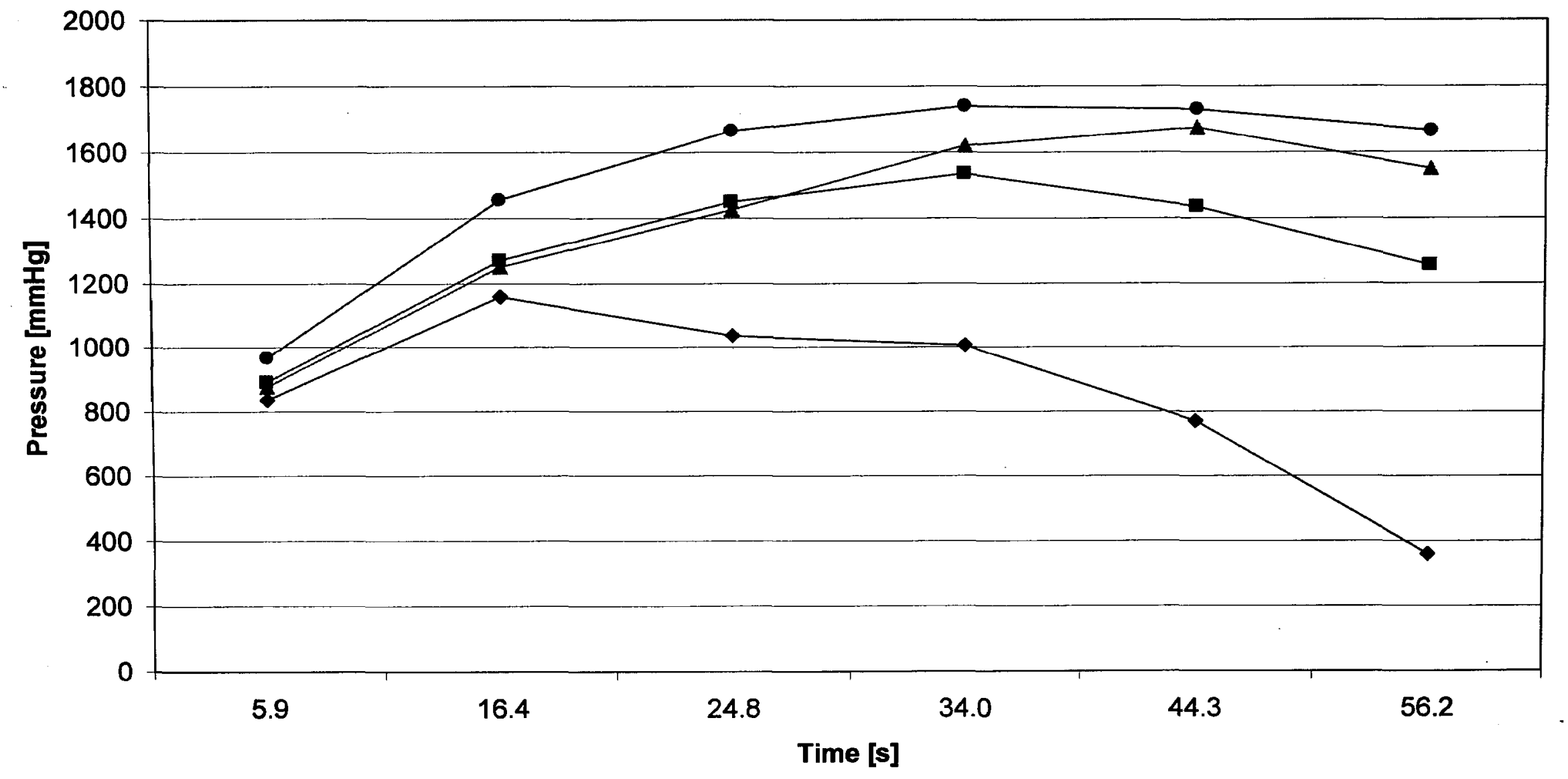

$\multimap$ Pressure $1 \rightarrow$-Pressure $2 \rightarrow$ Pressure $3 \rightarrow-$ Pressure 4

Figure A.21: Pressure variation using rubber hammer tip, flat implant tip geometry, $1.5 \mathrm{~mm}$ bone to implant radial gap, $59.4 \mathrm{cP}$ synthetic bone marrow viscosity and a $145 \mathrm{~N}$ peak impact force. 


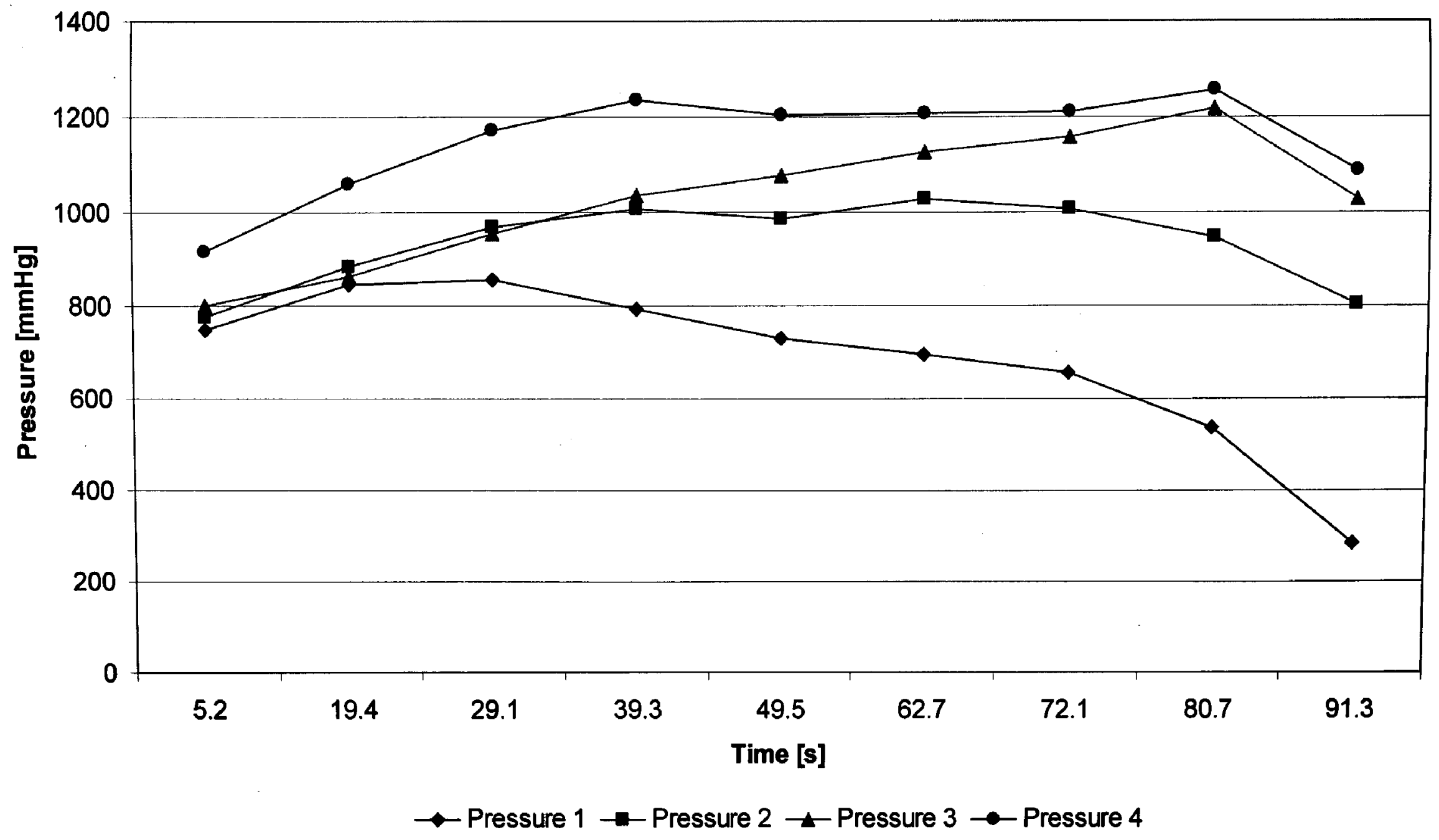

Figure A.22: Pressure variation using rubber hammer tip, flat implant tip geometry, $1.5 \mathrm{~mm}$ bone to implant radial gap, $82.6 \mathrm{cP}$ synthetic bone marrow viscosity and a 90 N peak impact force. 


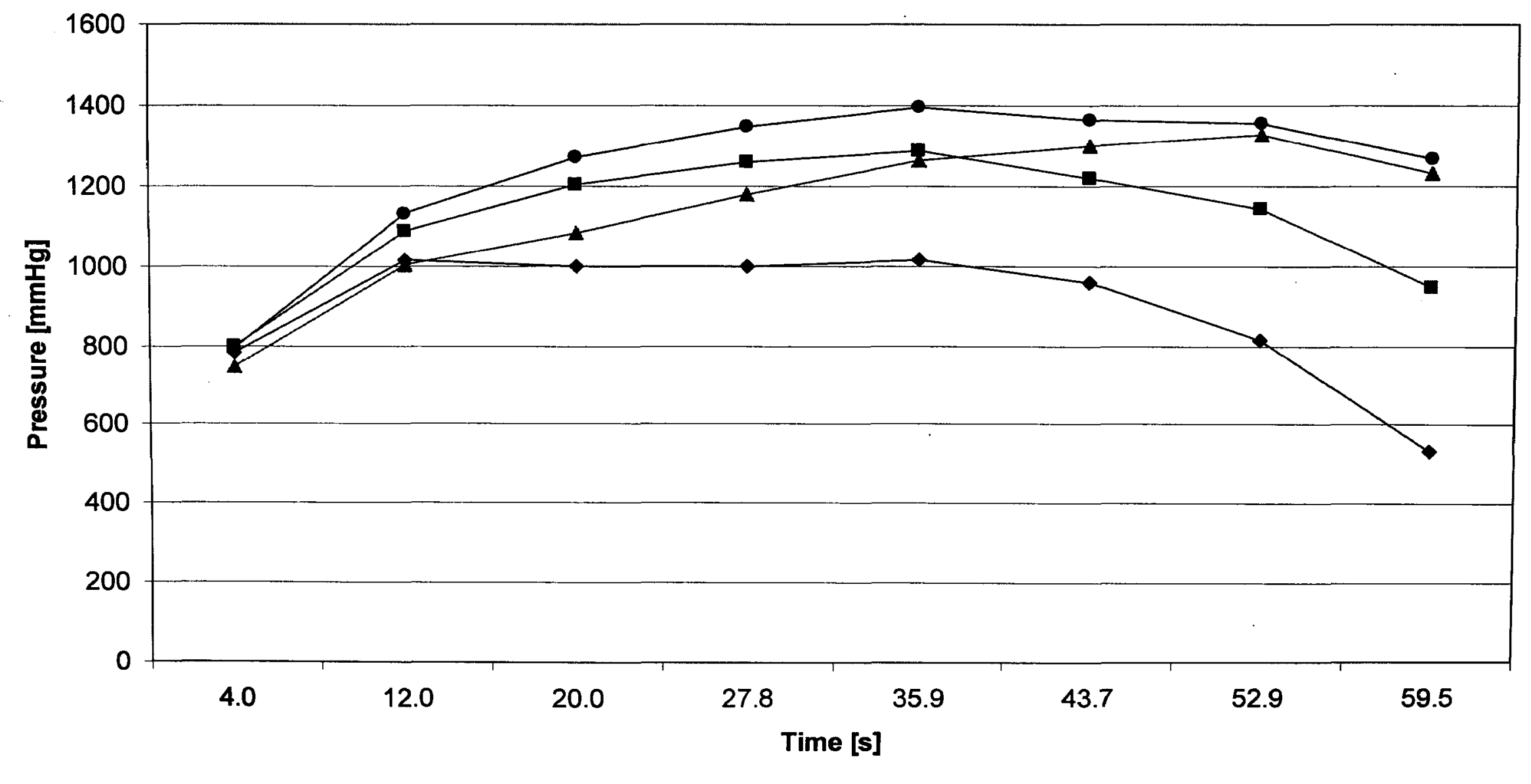

$\rightarrow$ Pressure $1 \rightarrow$ Pressure $2 \multimap$ Pressure $3 \rightarrow$ Pressure 4

Figure A.23: Pressure variation using rubber hammer tip, flat implant tip geometry, $1.5 \mathrm{~mm}$ bone to implant radial gap, $82.6 \mathrm{cP}$ synthetic bone marrow viscosity and a $110 \mathrm{~N}$ peak impact force. 


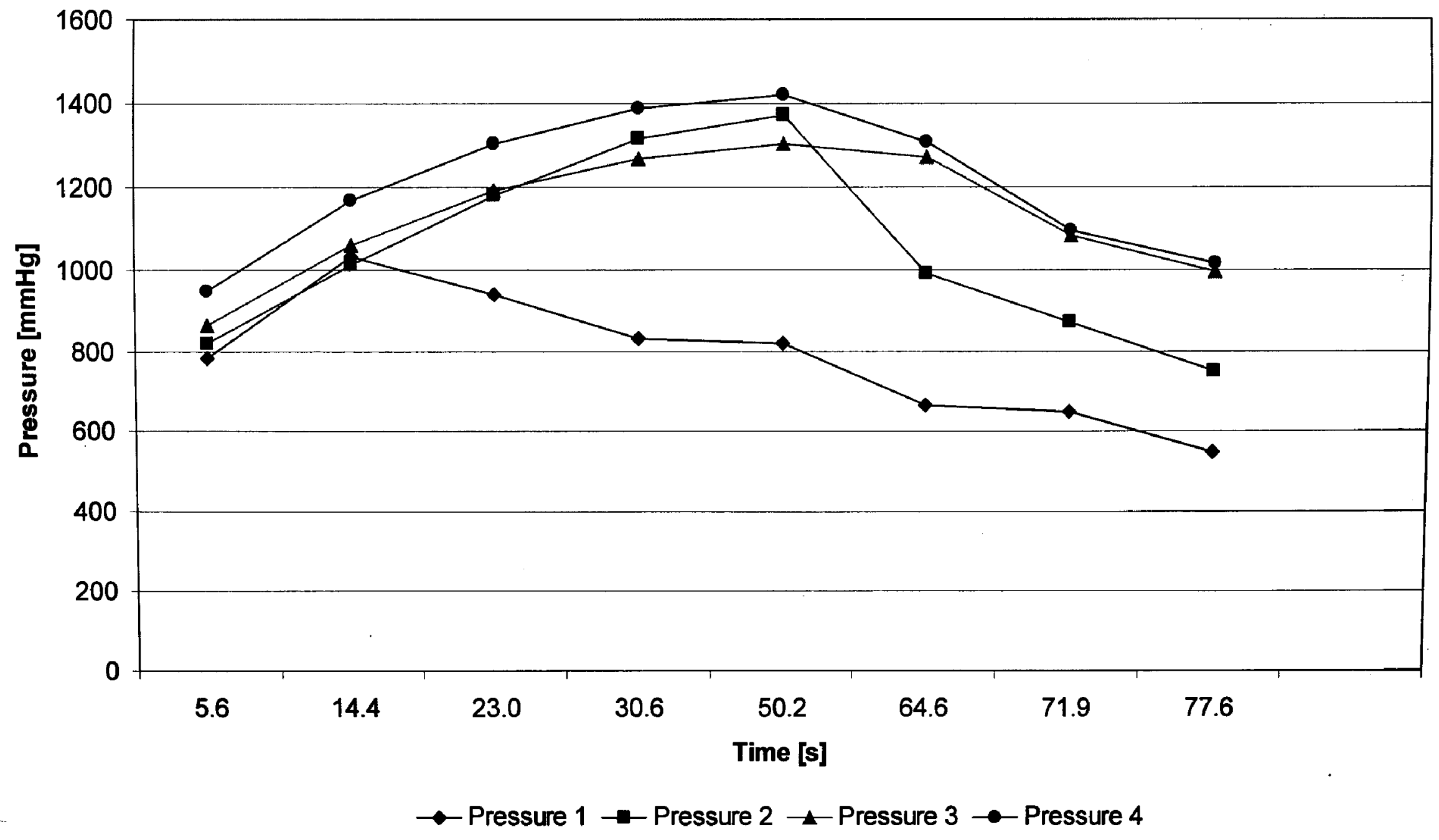

Figure A.24: Pressure variation using rubber hammer tip, flat implant tip geometry, $1.5 \mathrm{~mm}$ bone to implant radial gap, $82.6 \mathrm{cP}$ synthetic bone marrow viscosity and a $145 \mathrm{~N}$ peak impact force. 


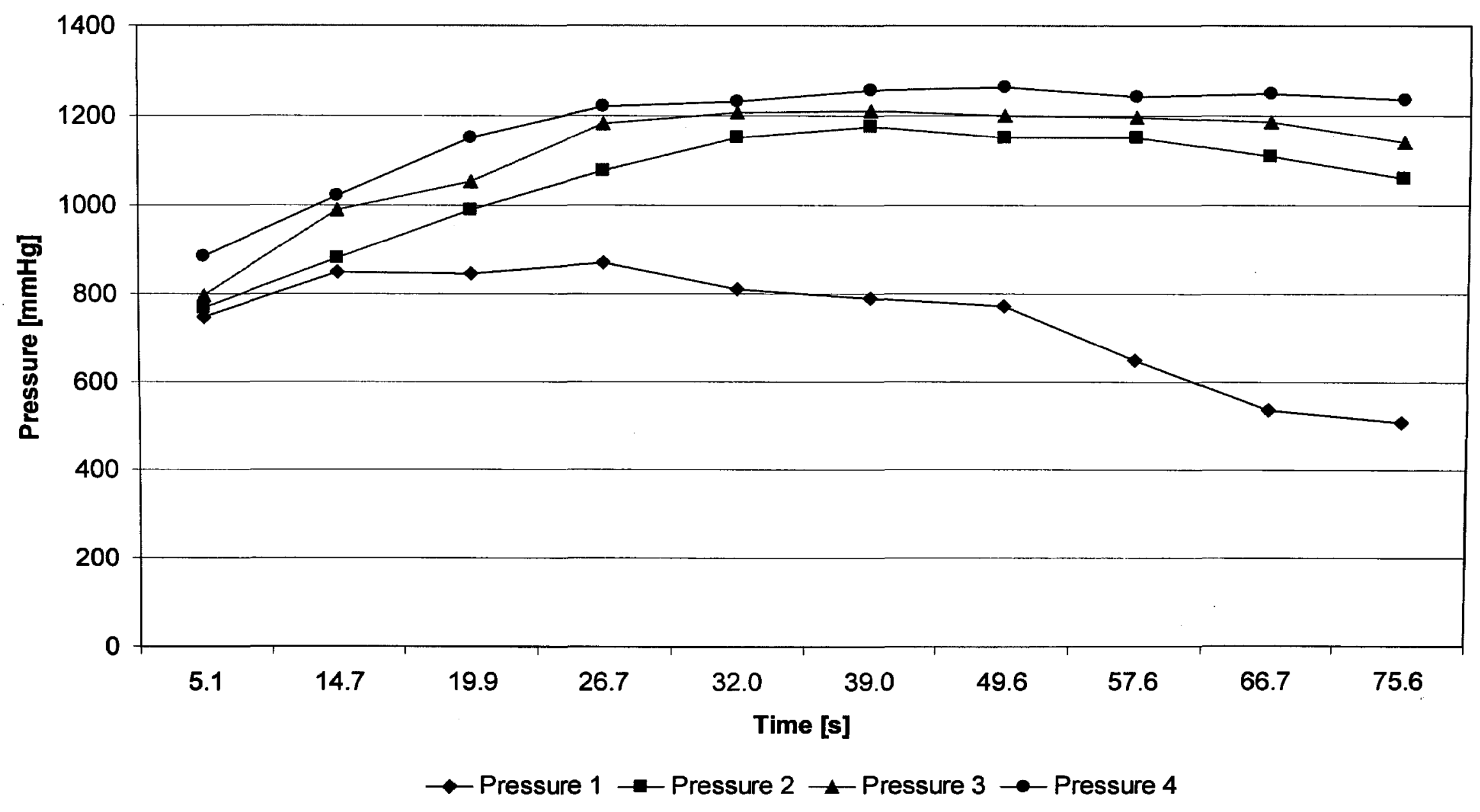

Figure A.25: Pressure variation using rubber hammer tip, flat implant tip geometry, $1.5 \mathrm{~mm}$ bone to implant radial gap, $146.4 \mathrm{cP}$ synthetic bone marrow viscosity and a $90 \mathrm{~N}$ peak impact force. 


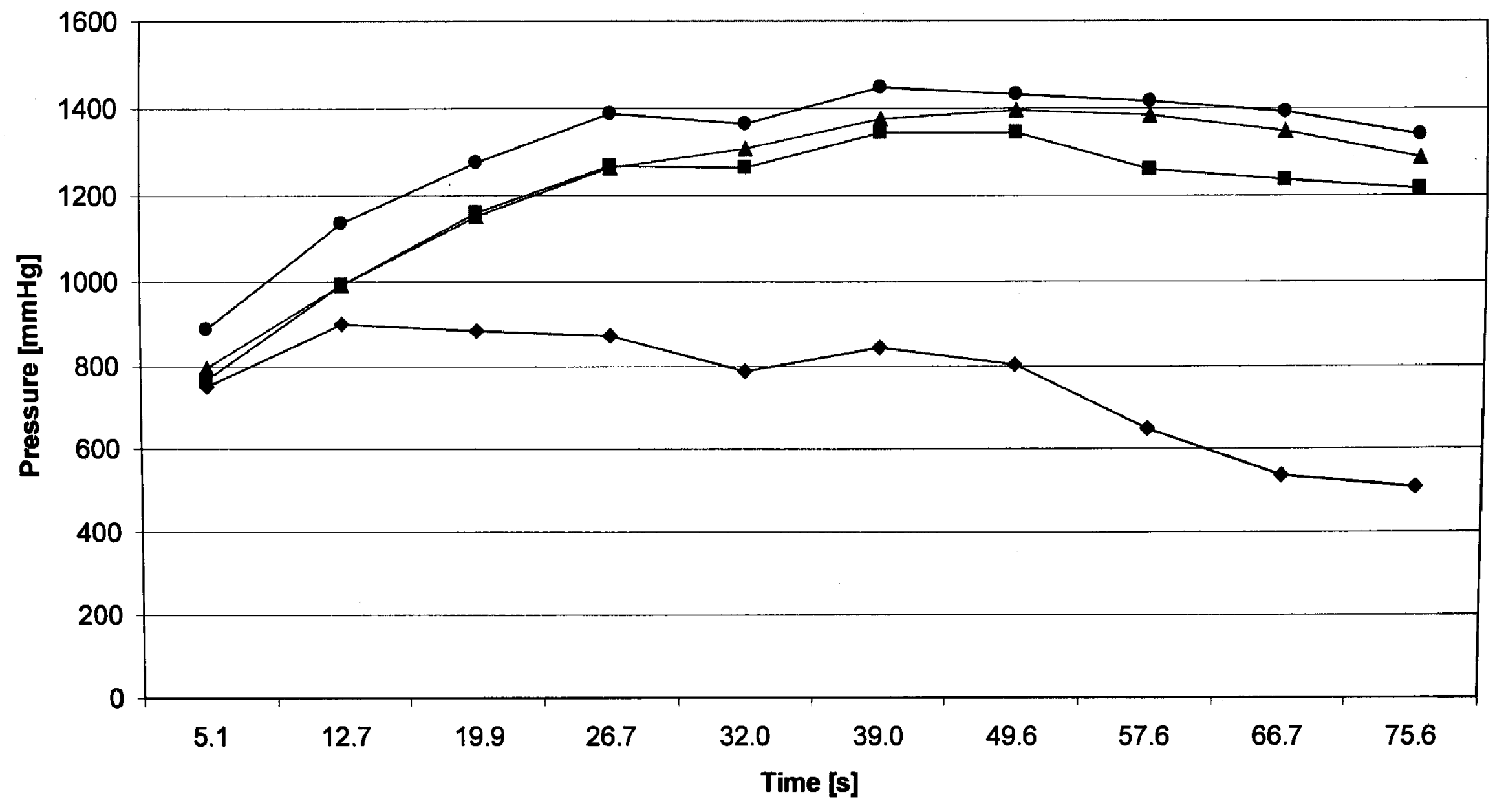

$\multimap$ Pressure $1 \rightarrow$ Pressure $2 \rightarrow$ Pressure $3 \rightarrow$ Pressure 4

Figure A.26: Pressure variation using rubber hammer tip, flat implant tip geometry, $1.5 \mathrm{~mm}$ bone to implant radial gap, $146.4 \mathrm{cP}$ synthetic bone marrow viscosity and a $110 \mathrm{~N}$ peak impact force. 


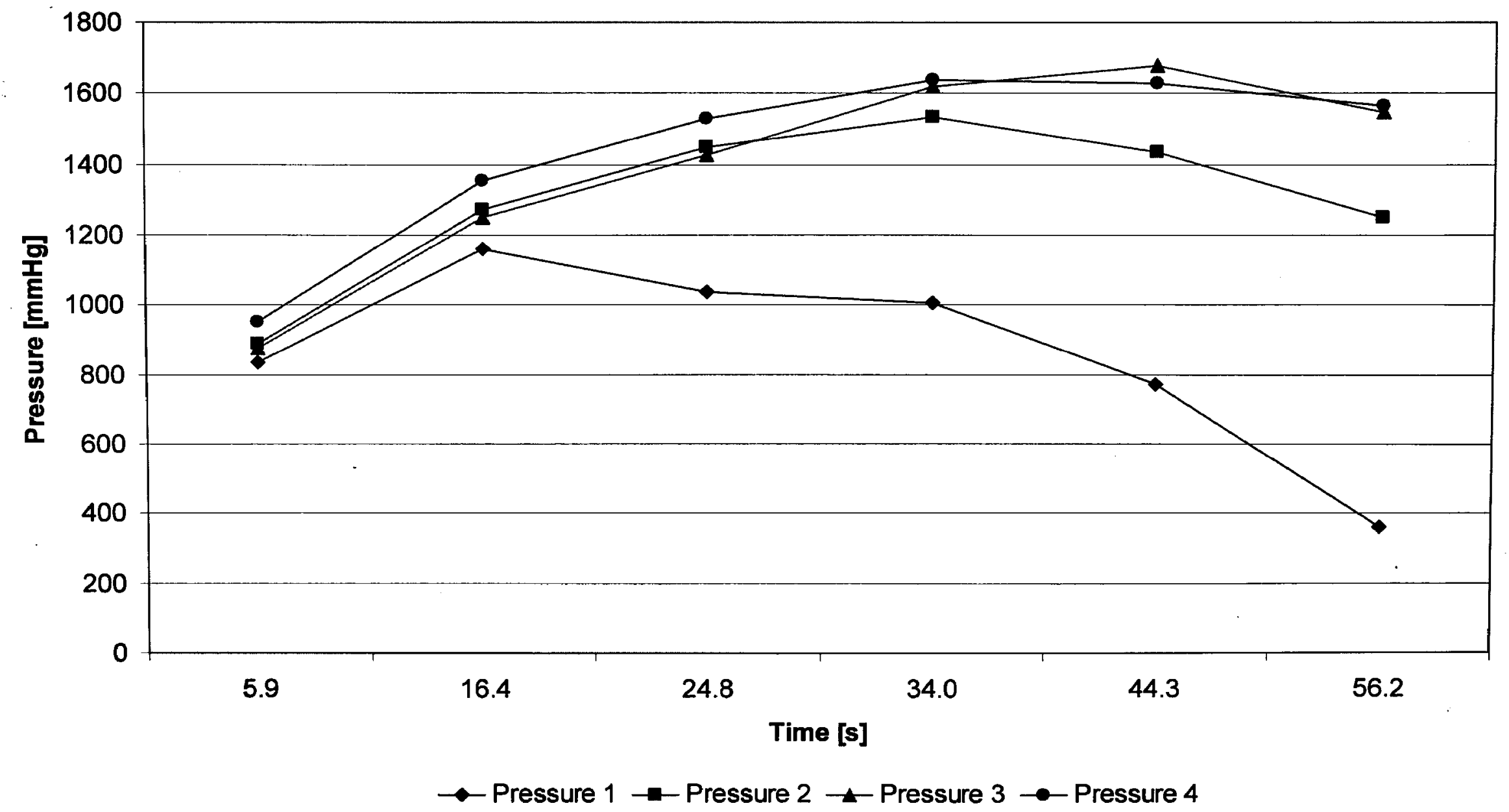

Figure A.27: Pressure variation using rubber hammer tip, flat implant tip geometry, 1.5 mm bone to implant radial gap, 146.4 cP synthetic bone marrow viscosity and a $145 \mathrm{~N}$ peak impact force. 


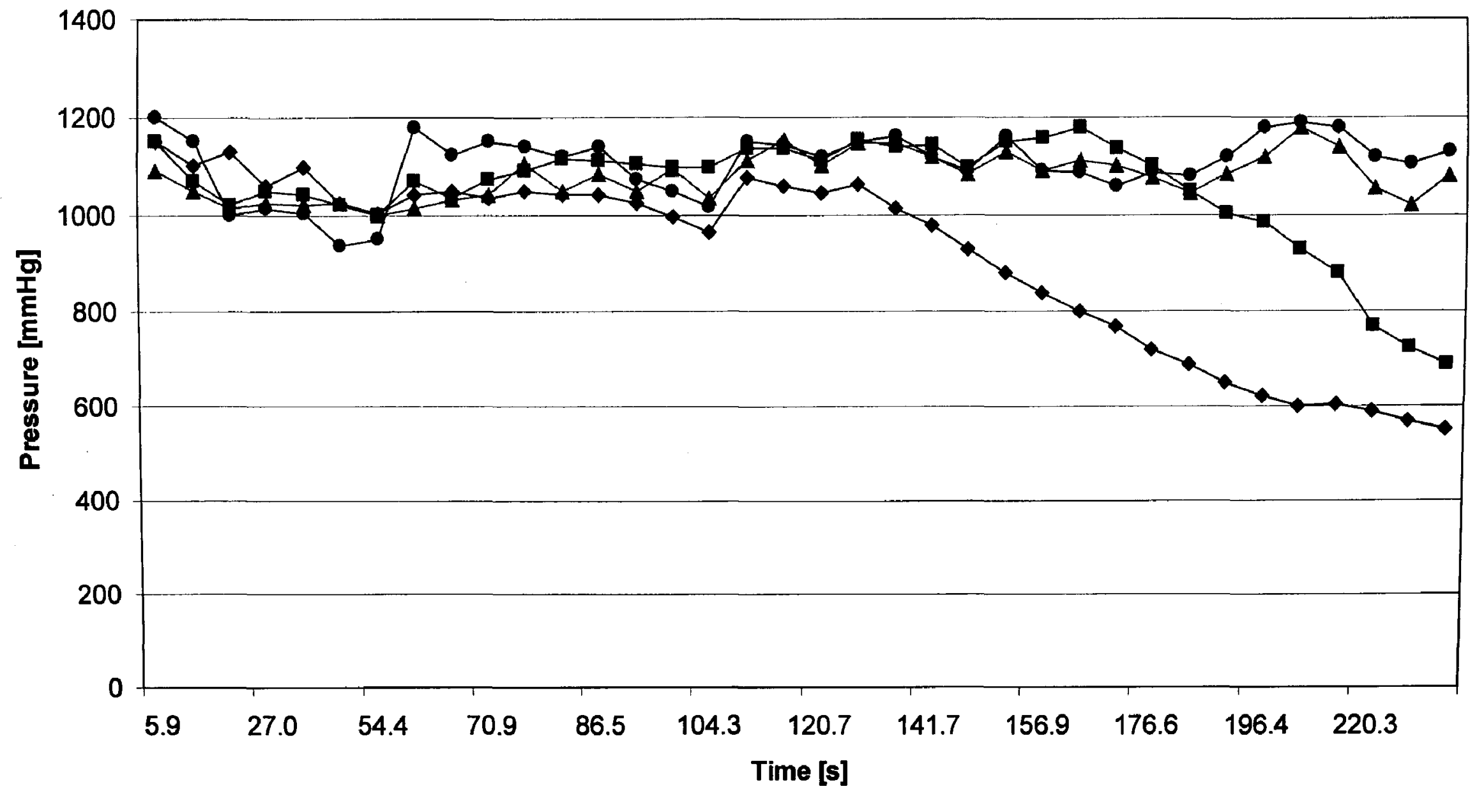

$\rightarrow$ Pressure $1 \rightarrow$ Pressure $2 \multimap$ Pressure $3 \rightarrow$ Pressure 4

Figure A.28: Pressure variation using rubber hammer tip, tapered implant tip geometry, $0.5 \mathrm{~mm}$ bone to implant radial gap, $82.6 \mathrm{cP}$ synthetic bone marrow viscosity and a 90 N peak impact force. 


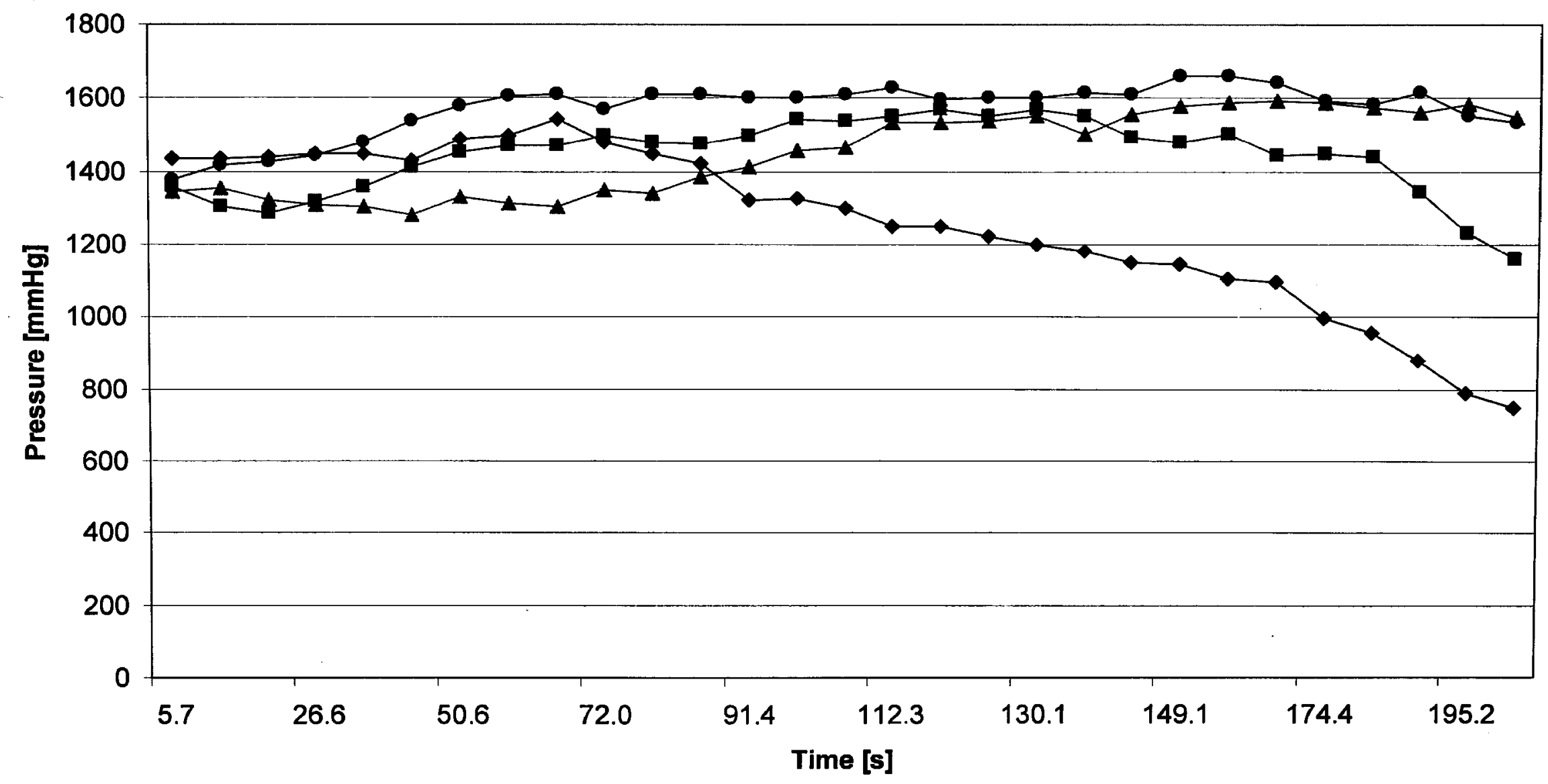

$\rightarrow-$ Pressure $1 \rightarrow$ Pressure $2 \rightarrow$ Pressure $3 \rightarrow$ Pressure 4

Figure A.29: Pressure variation using rubber hammer tip, tapered implant tip geometry, 0.5 mm bone to implant radial gap, 82.6 cP synthetic bone marrow viscosity and a 145 Neak impact force. 


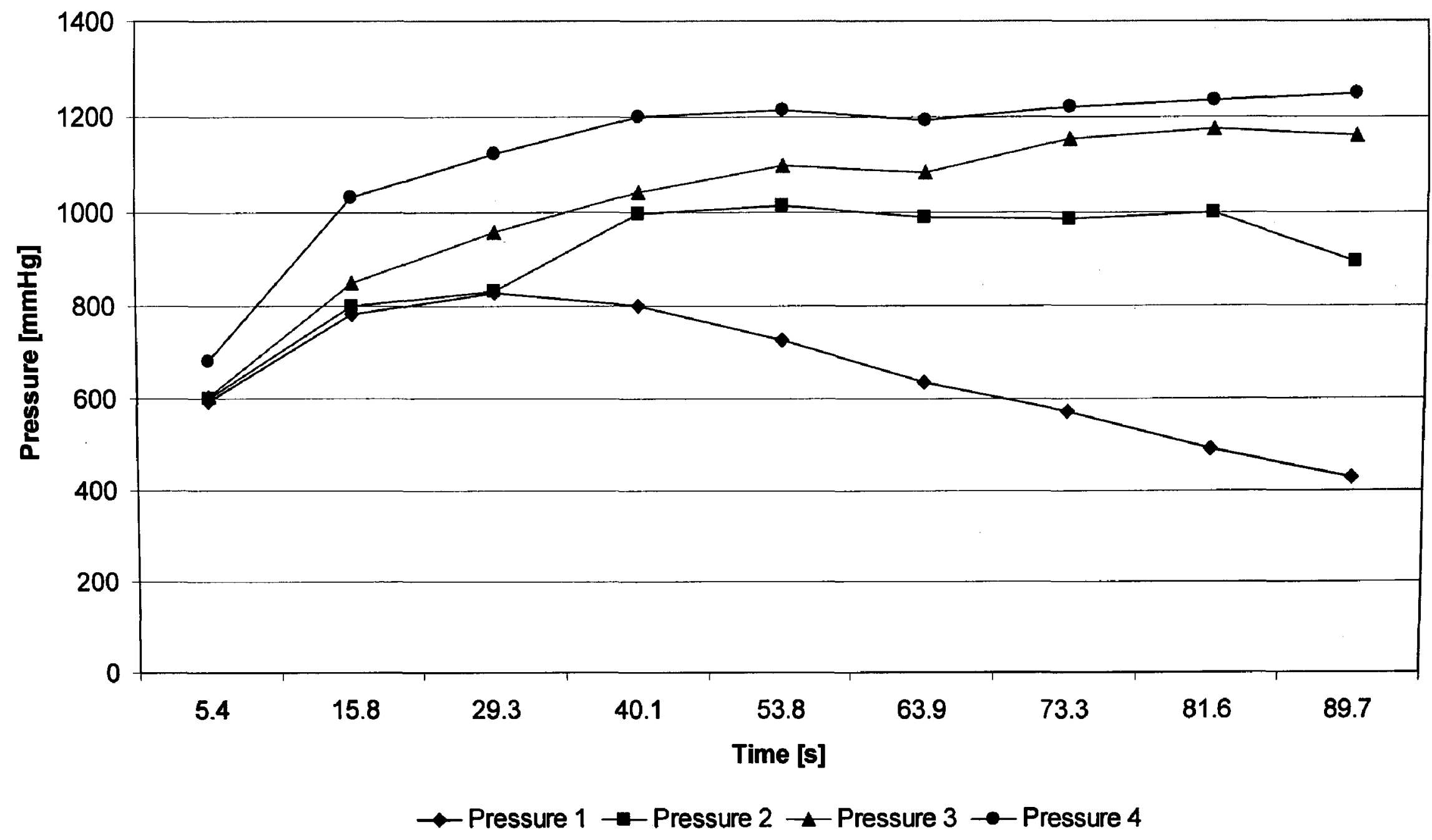

Figure A.30: Pressure variation using rubber hammer tip, tapered implant tip geometry, $1.5 \mathrm{~mm}$ bone to implant radial gap, $82.6 c P$ synthetic bone marrow viscosity and a $90 \mathrm{~N}$ peak impact force. 


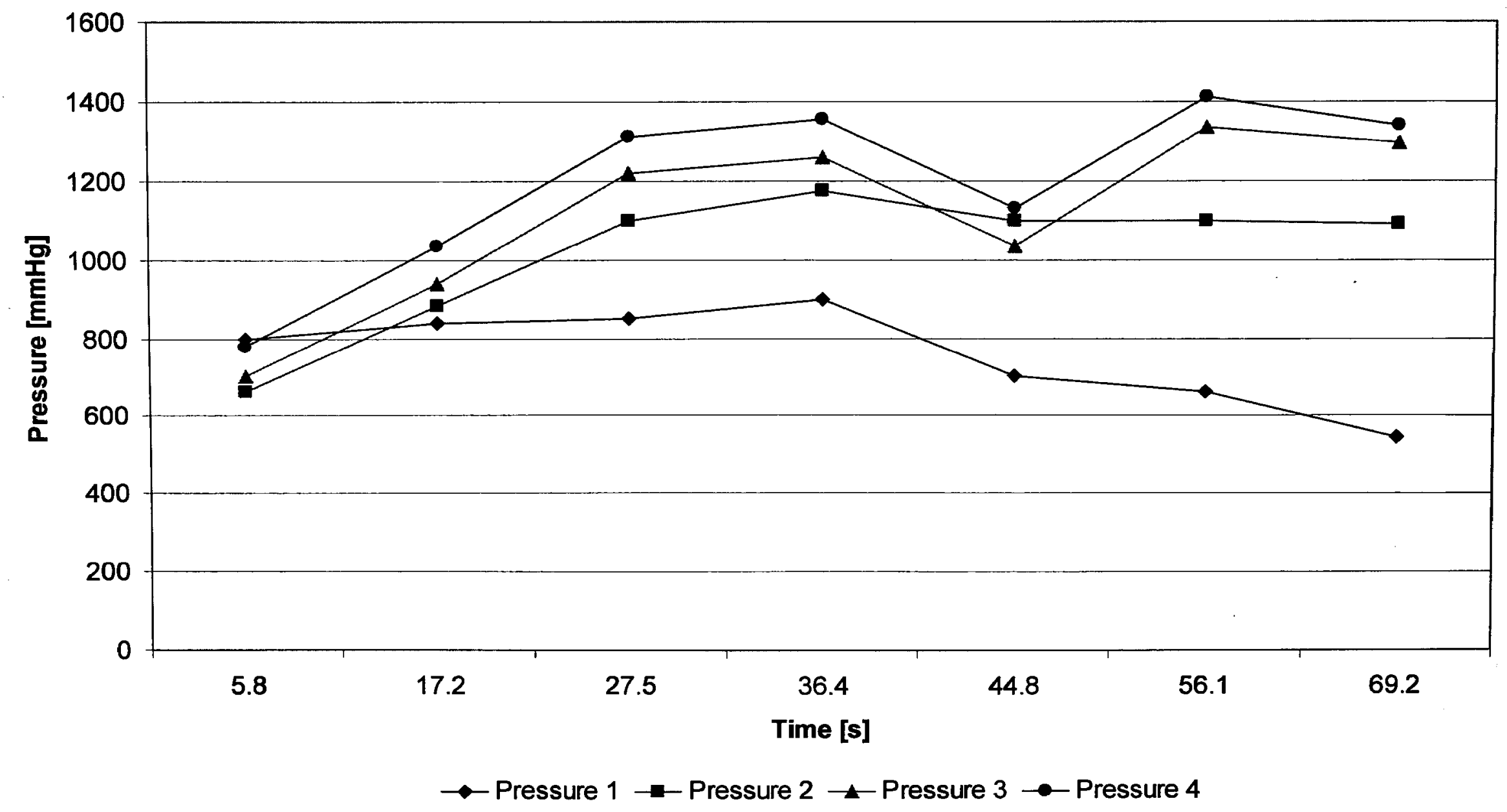

Figure A.31: Pressure variation using rubber hammer tip, tapered implant tip geometry, $1.5 \mathrm{~mm}$ bone to implant radial gap, $82.6 \mathrm{cP}$ synthetic bone marrow viscosity and a $145 \mathrm{~N}$ peak impact force. 


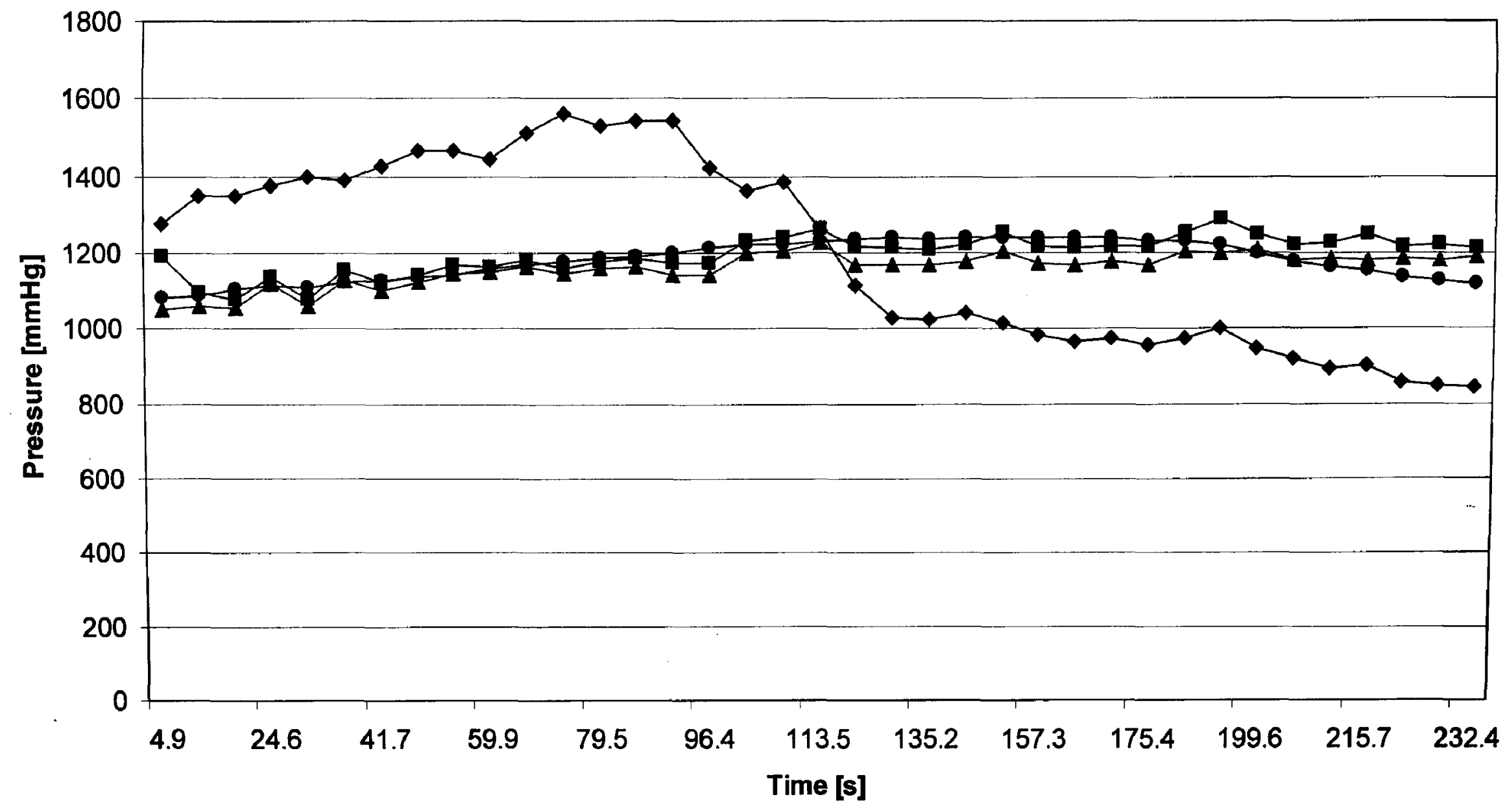

$\multimap$ Pressure $1 \rightarrow$-Pressure $2 \multimap$ Pressure $3 \multimap$ Pressure 4

Figure A.32: Pressure variation using steel hammer tip, flat implant tip geometry, $0.5 \mathrm{~mm}$ bone to implant radial gap, $82.6 \mathrm{cP}$ synthetic bone marrow viscosity and a $90 \mathrm{~N}$ peak impact force. 


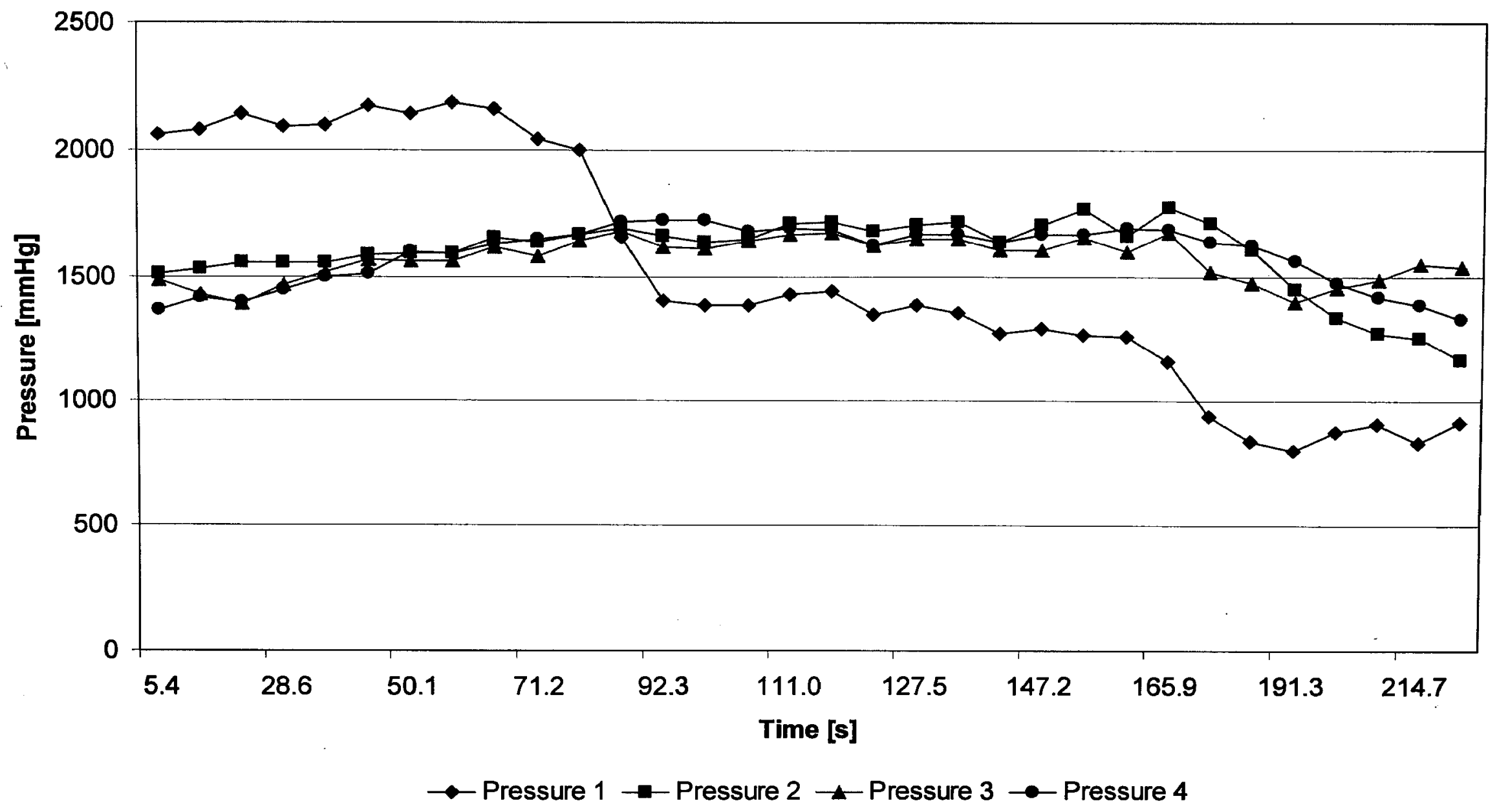

Figure A.33: Pressure variation using steel hammer tip, flat implant tip geometry, $0.5 \mathrm{~mm}$ bone to implant radial gap, $82.6 \mathrm{cP}$ synthetic bone marrow viscosity and a 145 N peak impact force. 


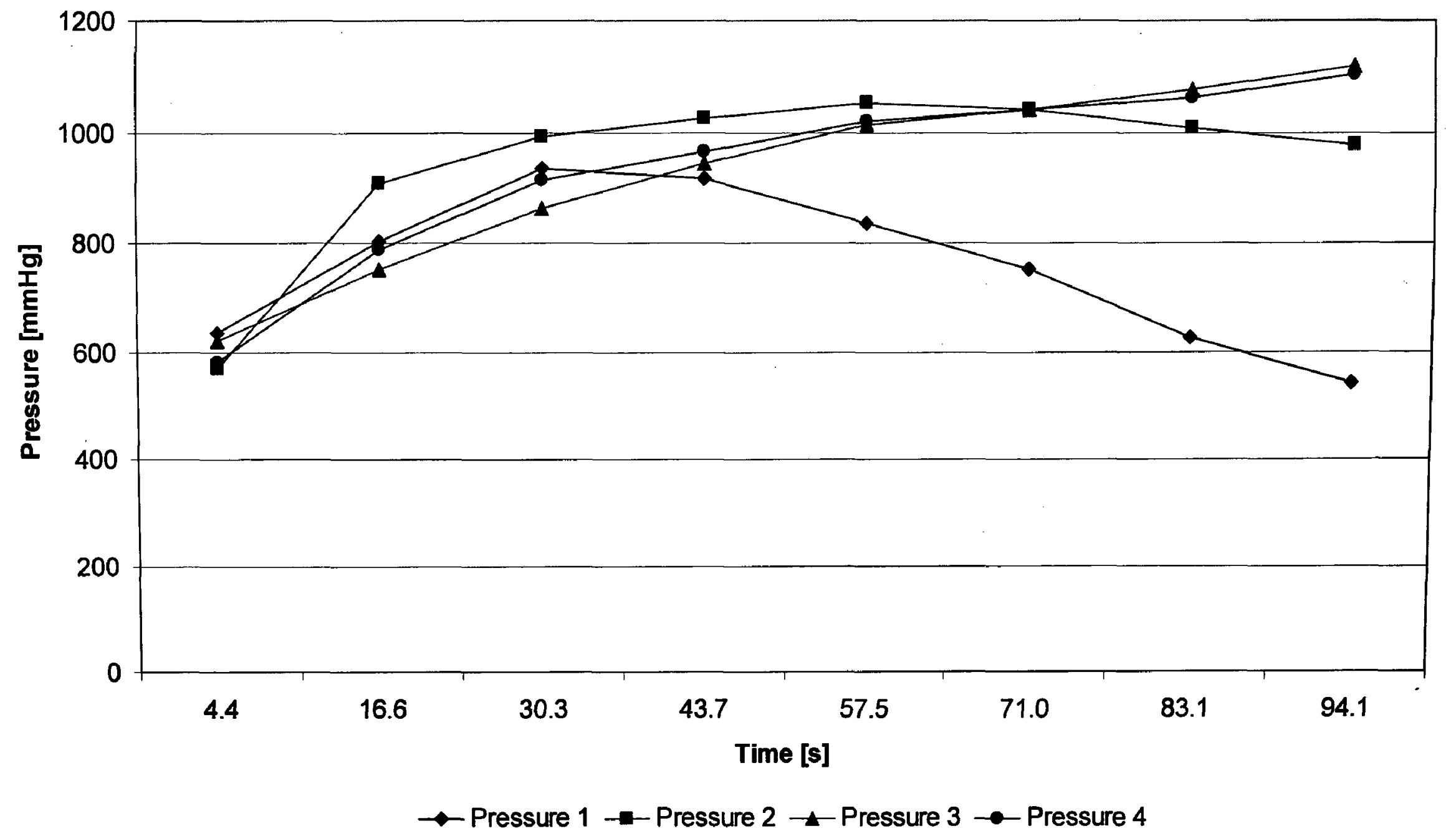

Figure A.34: Pressure variation using steel hammer tip, flat implant tip geometry, $1.5 \mathrm{~mm}$ bone to implant radial gap, $82.6 \mathrm{cP}$ synthetic bone marrow viscosity and a $90 \mathrm{~N}$ peak impact force. 


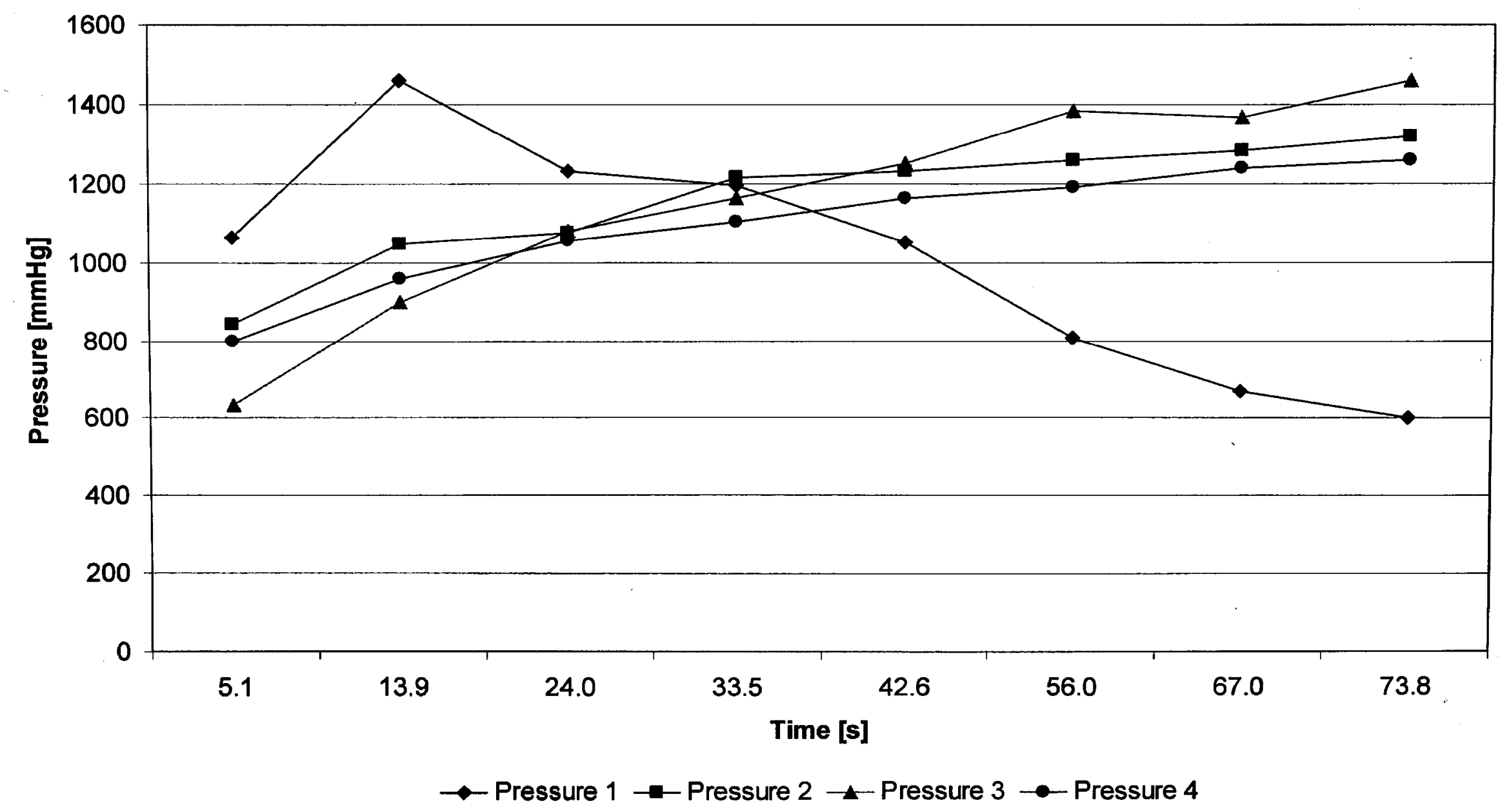

Figure A.35: Pressure variation using steel hammer tip, flat implant tip geometry, $1.5 \mathrm{~mm}$ bone to implant radial gap, $82.6 \mathrm{cP}$ synthetic bone marrow viscosity and a $145 \mathrm{~N}$ peak impact force. 


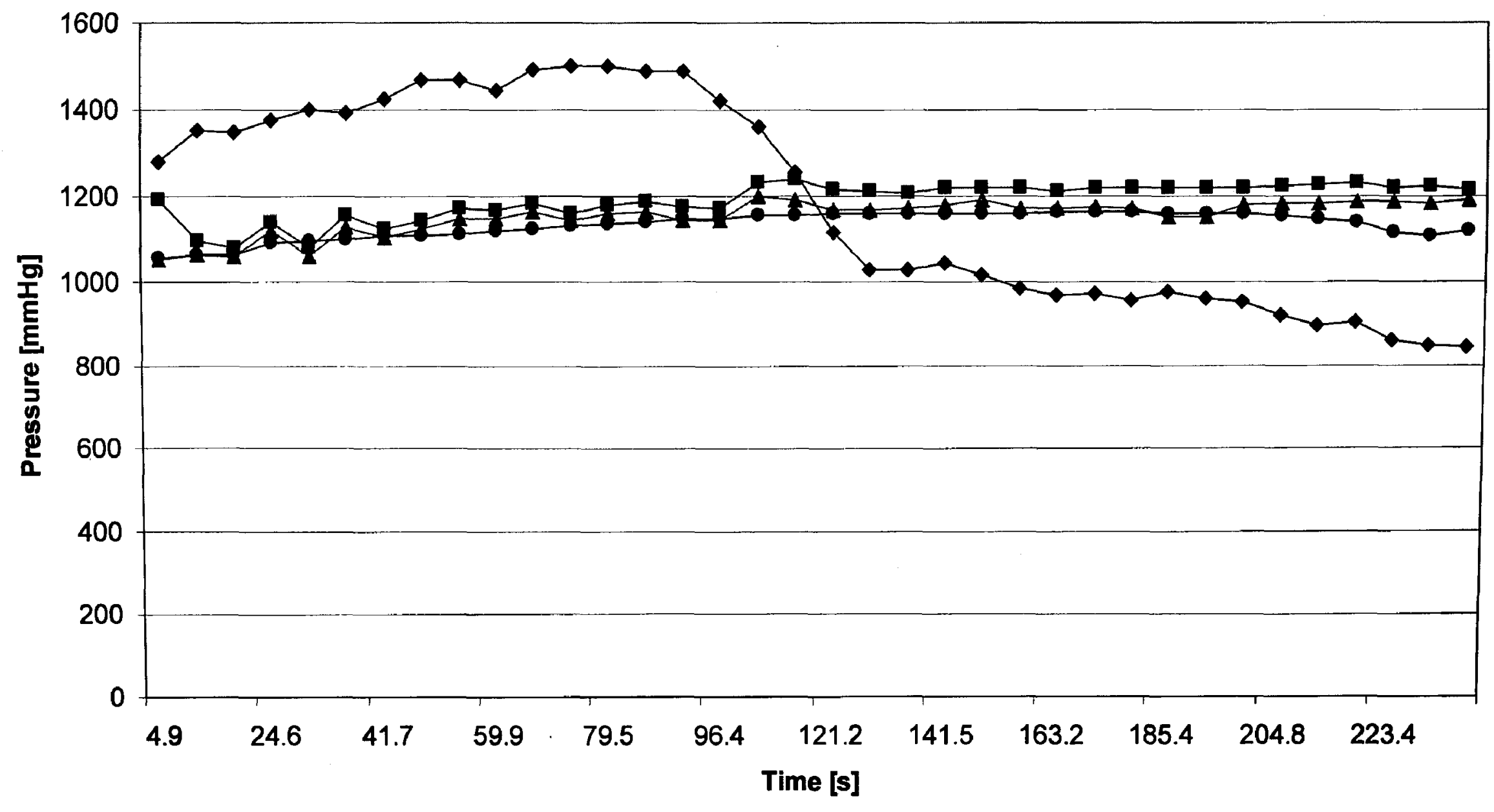

$\rightarrow$ Pressure $1 \rightarrow$ Pressure $2 \rightarrow$ Pressure $3 \rightarrow$ Pressure 4

Figure A.36: Pressure variation using steel hammer tip, tapered implant tip geometry, $0.5 \mathrm{~mm}$ bone to implant radial gap, $82.6 \mathrm{cP}$ synthetic bone marrow viscosity and a $90 \mathrm{~N}$ peak impact force. 


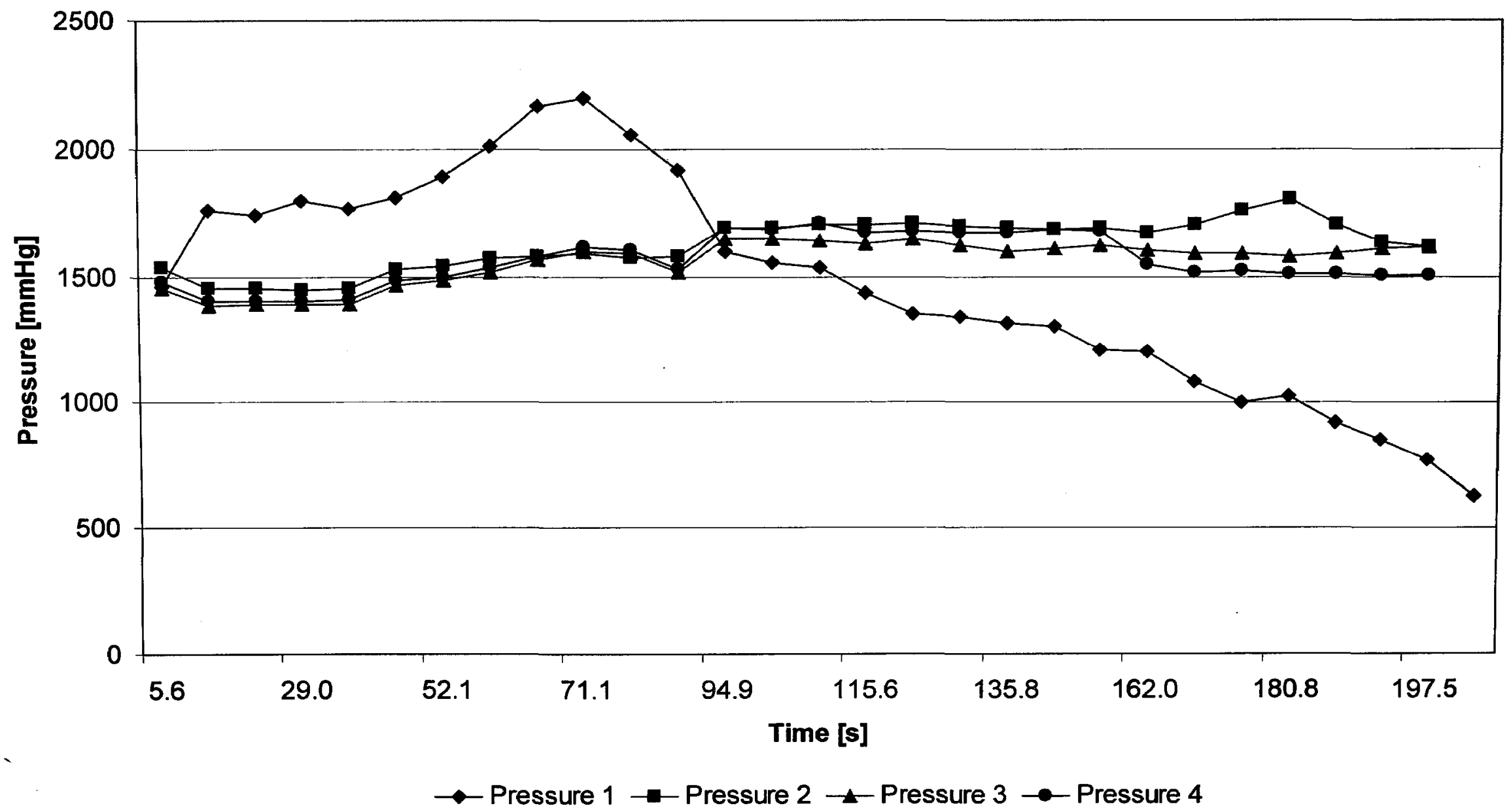

Figure A.37: Pressure variation using steel hammer tip, tapered implant tip geometry, $0.5 \mathrm{~mm}$ bone to implant radial gap, $82.6 \mathrm{cP}$ synthetic bone marrow viscosity and a $145 \mathrm{~N}$ peak impact force. 


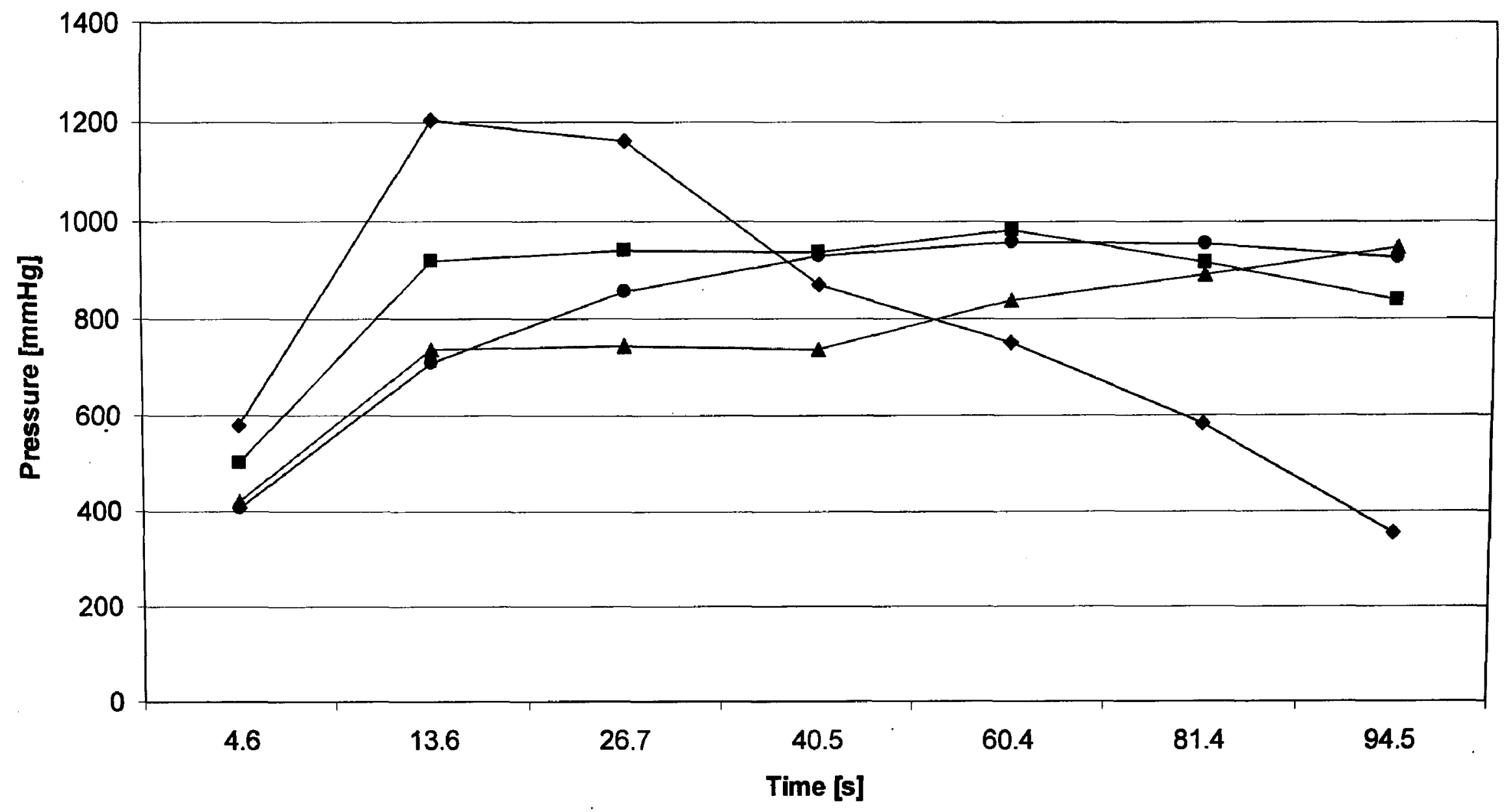

$\multimap$ Pressure $1 \rightarrow-$ Pressure $2 \multimap$ Pressure $3 \rightarrow$ Pressure 4

. Figure A.38: Pressure variation using steel hammer tip, tapered implant tip geometry, $1.5 \mathrm{~mm}$ bone to implant radial gap, $82.6 \mathrm{cP}$ synthetic bone marrow viscosity and a 90 N peak impact force. 


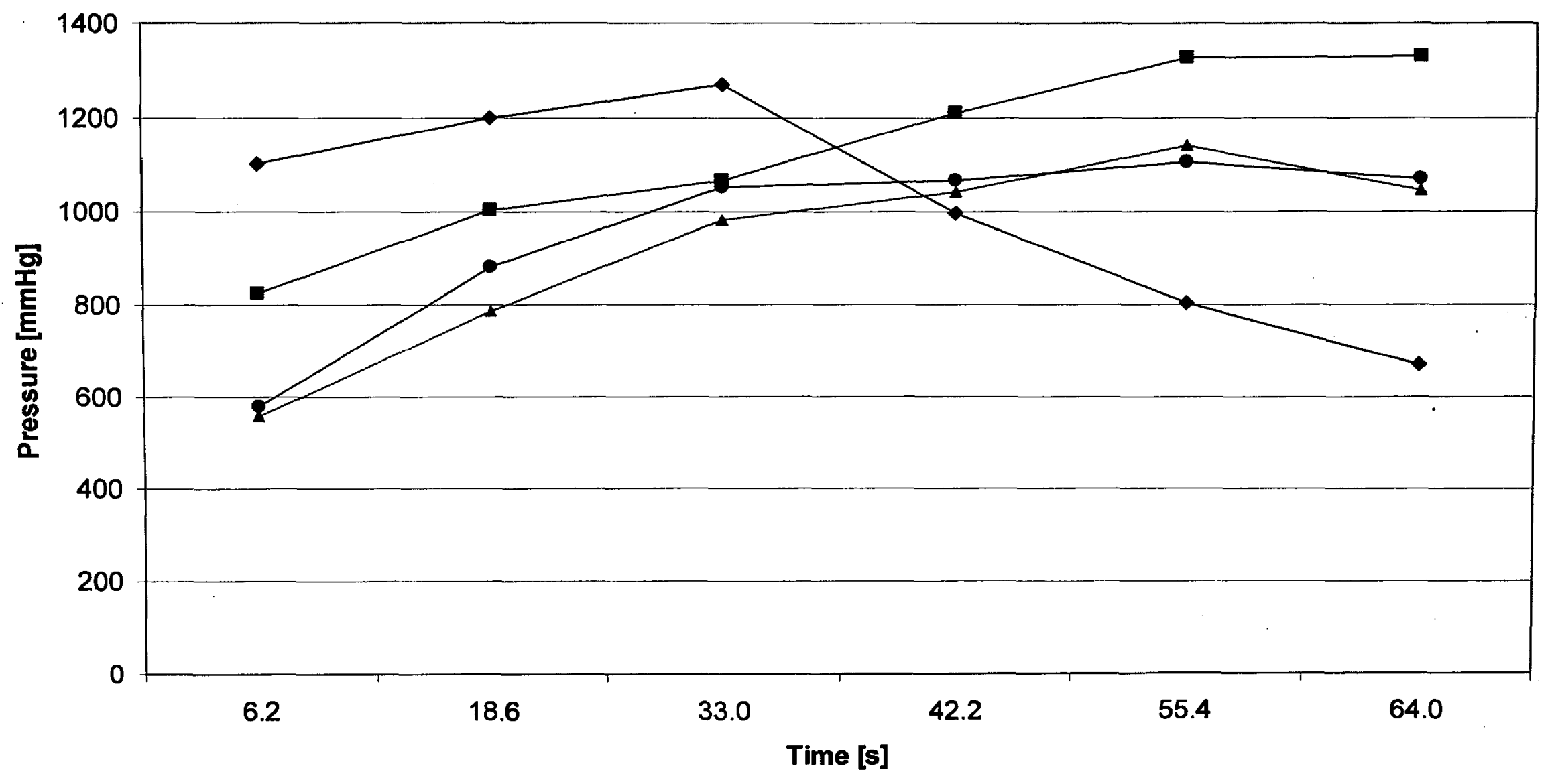

$\rightarrow$ Pressure $1 \rightarrow$ Pressure $2 \rightarrow$ Pressure $3 \rightarrow$ Pressure 4

Figure A.39: Pressure variation using steel hammer tip, tapered implant tip geometry, $1.5 \mathrm{~mm}$ bone to implant radial gap, $82.6 \mathrm{cP}$ synthetic bone marrow viscosity and a $145 \mathrm{~N}$ peak impact force. 
Appendix B

\section{Experimental Data}




\begin{tabular}{|l|c|c|c|c|c|}
\hline \multicolumn{6}{|c|}{ All values in mmHg } \\
\hline \multicolumn{1}{|c|}{$\begin{array}{c}\text { Clearance Gap } \\
\text { Stem Tip Geometry }\end{array}$} & $\begin{array}{c}\text { Flat } \\
\text { P1 }\end{array}$ & $\begin{array}{c}1.5 \mathrm{~mm} \\
\text { Flat }\end{array}$ & $\begin{array}{c}\text { Tapered } \\
\text { Tapered }\end{array}$ & $1.5 \mathrm{~mm}$ \\
\hline $45^{\circ}$ Release & P2 & 1122 & 934 & 1051 & 901 \\
\hline $90 \mathrm{~N}$ Impulse & P3 & 1139 & 1029 & 1079 & 1014 \\
\hline & P4 & 1220 & 1150 & 1105 & 1127 \\
\hline & P1 & 1198 & 756 & 1186 & 786 \\
\hline $45^{\circ}$ Release & P2 & 1196 & 946 & 1189 & 863 \\
\hline $900 \mathrm{~N}$ Impulse & P3 & 1158 & 929 & 1152 & 758 \\
\hline & P4 & 1180 & 934 & 1132 & 820 \\
\hline $75^{\circ}$ Release & P1 & 1256 & 783 & 1257 & 757 \\
\hline 145 N Impulse & P2 & 1457 & 1038 & 1441 & 1016 \\
\hline & P3 & 1491 & 1129 & 1451 & 1111 \\
\hline & P4 & 1601 & 1205 & 1571 & 1195 \\
\hline $75^{\circ}$ Release & P2 & 1591 & 1160 & 1624 & 1126 \\
\hline $1100 \mathrm{~N}$ Impulse & P3 & 1568 & 1154 & 1557 & 925 \\
\hline & P4 & 1584 & 1096 & 1561 & 959 \\
\hline
\end{tabular}

Table B.1: Pressure Values (MEAN) for Parametric Study 1 


\begin{tabular}{|l|c|c|c|c|c|}
\hline \multicolumn{6}{|c|}{ All values in mmHg } \\
\hline \multicolumn{2}{|c|}{$\begin{array}{c}\text { Clearance Gap } \\
\text { Stem Tip Geometry }\end{array}$} & $\begin{array}{c}0.5 \mathrm{~mm} \\
\text { Flat }\end{array}$ & $\begin{array}{c}1.5 \mathrm{~mm} \\
\text { Flat }\end{array}$ & $\begin{array}{c}0.5 \mathrm{~mm} \\
\text { Tapered }\end{array}$ & $\begin{array}{c}1.5 \mathrm{~mm} \\
\text { Tapered }\end{array}$ \\
\hline & P1 & 544 & 284 & 552 & 427 \\
\hline $45^{\circ}$ Release & P2 & 779 & 776 & 689 & 599 \\
\hline 90 N Impulse & P3 & 1073 & 801 & 1000 & 602 \\
\hline & P4 & 1101 & 918 & 938 & 679 \\
\hline & P1 & 844 & 542 & 844 & 353 \\
\hline $45^{\circ}$ Release & P2 & 1078 & 569 & 1078 & 502 \\
\hline 900 N Impulse & P3 & 1052 & 619 & 1052 & 420 \\
\hline & P4 & 1084 & 579 & 1055 & 409 \\
\hline $75^{\circ}$ Release & P1 & 516 & 551 & 751 & 546 \\
\hline 145 N Impulse & P3 & 773 & 749 & 1160 & 663 \\
\hline & P4 & 1337 & 862 & 1280 & 700 \\
\hline & P1 & 801 & 601 & 623 & 670 \\
\hline $75^{\circ}$ Release & P2 & 1168 & 844 & 1450 & 824 \\
\hline 1100 N Impulse & P3 & 1397 & 632 & 1388 & 557 \\
\hline & P4 & 1329 & 800 & 1402 & 580 \\
\hline
\end{tabular}

Table B.2: Pressure Valuès (MIN) for Parametric Study 1 


\begin{tabular}{|l|c|c|c|c|c|}
\hline \multicolumn{6}{|c|}{ All values in mmHg } \\
\hline \multicolumn{2}{|c|}{ Clearance Gap } & $0.5 \mathrm{~mm}$ & $1.5 \mathrm{~mm}$ & $0.5 \mathrm{~mm}$ & $1.5 \mathrm{~mm}$ \\
Stem Tip Geometry & Flat & Flat & Tapered & Tapered \\
\hline & P1 & 1191 & 857 & 1151 & 828 \\
\hline $45^{\circ}$ Release & P2 & 1208 & 1027 & 1179 & 1013 \\
\hline $90 \mathrm{~N}$ Impulse & P3 & 1221 & 1216 & 1181 & 1175 \\
\hline & P4 & 1317 & 1258 & 1200 & 1248 \\
\hline & P1 & 1563 & 936 & 1500 & 1202 \\
\hline $45^{\circ}$ Release & P2 & 1291 & 1053 & 1241 & 984 \\
\hline 900 N Impulse & P3 & 1228 & 1120 & 1199 & 946 \\
\hline & P4 & 1243 & 1104 & 1163 & 958 \\
\hline & P1 & 1628 & 1029 & 1542 & 900 \\
\hline $75^{\circ}$ Release & P2 & 1684 & 1372 & 1572 & 1173 \\
\hline 145 N Impulse & P3 & 1594 & 1303 & 1593 & 1334 \\
\hline & P4 & 1773 & 1421 & 1661 & 1411 \\
\hline & P1 & 2188 & 1461 & 2200 & 1269 \\
\hline $75^{\circ}$ Release & P2 & 1773 & 1320 & 1803 & 1328 \\
\hline 1100 N Impulse & P3 & 1677 & 1461 & 1651 & 1141 \\
\hline & P4 & 1720 & 1261 & 1709 & 1106 \\
\hline
\end{tabular}

Table B.3: Pressure Values (MAX) for Parametric Study 1 


\begin{tabular}{|l|c|c|c|c|c|c|c|c|c|c|}
\hline \multicolumn{10}{|c|}{ All values in mmHg } \\
\hline Clearance Gap & $0.5 \mathrm{~mm}$ & $0.5 \mathrm{~mm}$ & $0.5 \mathrm{~mm}$ & $1.0 \mathrm{~mm}$ & $1.0 \mathrm{~mm}$ & $1.0 \mathrm{~mm}$ & $1.5 \mathrm{~mm}$ & $1.5 \mathrm{~mm}$ & $1.5 \mathrm{~mm}$ \\
Marrow Viscosity & $59 \mathrm{cP}$ & $83 \mathrm{cP}$ & $146 \mathrm{cP}$ & $59 \mathrm{cP}$ & $83 \mathrm{cP}$ & $146 \mathrm{cP}$ & $59 \mathrm{cP}$ & $83 \mathrm{cP}$ & $146 \mathrm{cP}$ \\
\hline & $\mathrm{P} 1$ & 919 & 912 & 902 & 757 & 747 & 748 & 675 & 733 & 738 \\
\hline $45^{\circ}$ Release & $\mathrm{P} 2$ & 1246 & 1122 & 1131 & 1103 & 1095 & 1065 & 932 & 934 & 1051 \\
\hline $90 \mathrm{~N}$ Impulse & P3 & 1261 & 1139 & 1128 & 1138 & 1134 & 1121 & 980 & 1029 & 1116 \\
\hline & $\mathrm{P} 4$ & 1315 & 1220 & 1209 & 1212 & 1196 & 1181 & 1084 & 1150 & 1175 \\
\hline & $\mathrm{P} 1$ & 1154 & 1144 & 1008 & 925 & 950 & 936 & 837 & 811 & 753 \\
\hline $60^{\circ}$ Release & $\mathrm{P} 2$ & 1559 & 1391 & 1391 & 1324 & 1315 & 1339 & 1111 & 1118 & 1184 \\
\hline $115 \mathrm{~N}$ Impulse & $\mathrm{P} 3$ & 1589 & 1453 & 1401 & 1400 & 1332 & 1349 & 1217 & 1141 & 1229 \\
\hline & $\mathrm{P} 4$ & 1679 & 1530 & 1456 & 1507 & 1405 & 1408 & 1334 & 1240 & 1307 \\
\hline & $\mathrm{P} 1$ & 1302 & 1256 & 1090 & 1008 & 1052 & 1022 & 961 & 943 & 863 \\
\hline $75^{\circ}$ Release & P2 & 1763 & 1457 & 1451 & 1527 & 1459 & 1383 & 1304 & 1268 & 1292 \\
\hline $145 \mathrm{~N}$ Impulse & P3 & 1777 & 1491 & 1468 & 1600 & 1455 & 1392 & 1399 & 1299 & 1299 \\
\hline & $\mathrm{P} 4$ & 1882 & 1601 & 1499 & 1717 & 1551 & 1451 & 1536 & 1457 & 1410 \\
\hline
\end{tabular}

Table B.4: Pressure Values (MEAN) for Parametric Study 2 


\begin{tabular}{|c|c|c|c|c|c|c|c|c|c|c|}
\hline \multicolumn{10}{|c|}{ All values in mmHg } \\
\hline Clearance Gap & $0.5 \mathrm{~mm}$ & $0.5 \mathrm{~mm}$ & $0.5 \mathrm{~mm}$ & $1.0 \mathrm{~mm}$ & $1.0 \mathrm{~mm}$ & $1.0 \mathrm{~mm}$ & $1.5 \mathrm{~mm}$ & $1.5 \mathrm{~mm}$ & $1.5 \mathrm{~mm}$ \\
Marrow Viscosity & $59 \mathrm{cP}$ & $83 \mathrm{cP}$ & $146 \mathrm{cP}$ & $59 \mathrm{cP}$ & $83 \mathrm{cP}$ & $146 \mathrm{cP}$ & $59 \mathrm{cP}$ & $83 \mathrm{cP}$ & $146 \mathrm{cP}$ \\
\hline & $\mathrm{P} 1$ & 0 & 543 & 702 & 331 & 375 & 543 & 263 & 284 & 748 \\
\hline $45^{\circ}$ Release & P2 & 0 & 779 & 926 & 863 & 705 & 827 & 637 & 776 & 768 \\
\hline 90 N Impulse & P3 & 0 & 1073 & 984 & 850 & 684 & 838 & 637 & 801 & 796 \\
\hline & P4 & 0 & 1101 & 1107 & 946 & 723 & 932 & 773 & 918 & 885 \\
\hline & P1 & 1375 & 788 & 580 & 505 & 413 & 585 & 512 & 532 & 508 \\
\hline $60^{\circ}$ Release & P2 & 1633 & 1193 & 1262 & 860 & 1095 & 1019 & 693 & 797 & 768 \\
\hline 115 N Impulse & P3 & 1677 & 1131 & 0 & 925 & 1103 & 1041 & 709 & 747 & 796 \\
\hline & P4 & 1727 & 1393 & 1349 & 1011 & 1127 & 1113 & 795 & 795 & 885 \\
\hline & P1 & 0 & 516 & 580 & 432 & 524 & 571 & 363 & 551 & 363 \\
\hline $75^{\circ}$ Release & P2 & 0 & 773 & 1262 & 998 & 1129 & 1147 & 890 & 749 & 890 \\
\hline 145 N Impulse & P3 & 0 & 1337 & 1277 & 1100 & 1165 & 1180 & 877 & 862 & 877 \\
\hline & P4 & 0 & 1409 & 1349 & 1274 & 1215 & 1240 & 967 & 946 & 951 \\
\hline
\end{tabular}

Table B.5: Pressure Values (MIN) for Parametric Study 2 


\begin{tabular}{|c|c|c|c|c|c|c|c|c|c|c|}
\hline \multicolumn{11}{|c|}{ All values unless stated in $\mathrm{mmHg}$} \\
\hline \multirow{2}{*}{\multicolumn{2}{|c|}{$\begin{array}{c}\text { Clearance Gap } \\
\text { Marrow Viscosity }\end{array}$}} & \multirow{2}{*}{$\begin{array}{l}0.5 \mathrm{~mm} \\
59 \mathrm{cP} \\
\end{array}$} & \multirow{2}{*}{$\begin{array}{l}0.5 \mathrm{~mm} \\
83 \mathrm{cP}\end{array}$} & \multirow{2}{*}{$\begin{array}{l}0.5 \mathrm{~mm} \\
146 \mathrm{cP}\end{array}$} & \multirow{2}{*}{$\begin{array}{l}1.0 \mathrm{~mm} \\
59 \mathrm{cP}\end{array}$} & \multirow{2}{*}{$\begin{array}{l}1.0 \mathrm{~mm} \\
83 \mathrm{cP}\end{array}$} & \multirow{2}{*}{$\begin{array}{l}1.0 \mathrm{~mm} \\
146 \mathrm{cP} \\
\end{array}$} & \multirow{2}{*}{$\begin{array}{l}1.5 \mathrm{~mm} \\
59 \mathrm{cP}\end{array}$} & \multirow{2}{*}{$\begin{array}{l}1.5 \mathrm{~mm} \\
83 \mathrm{cP}\end{array}$} & \multirow{2}{*}{$\begin{array}{l}1.5 \mathrm{~mm} \\
146 \mathrm{cP}\end{array}$} \\
\hline & & & & & & & & & & \\
\hline & $\mathrm{P} 1$ & 1110 & 1191 & 1031 & 961 & 1023 & 907 & 772 & 857 & 870 \\
\hline $45^{\circ}$ Release & P2 & 1334 & 1208 & 1193 & 1198 & 1222 & 1179 & 1080 & 1027 & 1176 \\
\hline \multirow[t]{3}{*}{$90 \mathrm{~N}$ Impulse } & $\mathrm{P} 3$ & 1362 & 1221 & 1190 & 1280 & 1302 & 1225 & 1150 & 1216 & 1211 \\
\hline & P4 & 1395 & 1317 & 1260 & 1290 & 1303 & 1267 & 1202 & 1258 & 1262 \\
\hline & P1 & 1375 & 1391 & 1286 & 1146 & 1166 & 1187 & 921 & 1016 & 900 \\
\hline $60^{\circ}$ Release & $\mathrm{P} 2$ & 1633 & 1565 & 1493 & 1496 & 1461 & 1431 & 1317 & 1287 & 1344 \\
\hline \multirow[t]{3}{*}{$115 \mathrm{~N}$ Impulse } & P3 & 1677 & 1601 & 1522 & 1594 & 1481 & 1465 & 1511 & 1326 & 1396 \\
\hline & $\mathrm{P} 4$ & 1727 & 1605 & 1532 & 1648 & 1496 & 1488 & 1576 & 1394 & 1448 \\
\hline & $\mathrm{P} 1$ & 1586 & 1628 & 1325 & 1343 & 1435 & 1347 & 1159 & 1029 & 1159 \\
\hline $75^{\circ}$ Release & $\overline{\mathrm{P} 2}$ & 1856 & 1684 & 1519 & 1749 & 1650 & 1578 & 1534 & 1372 & 1534 \\
\hline \multirow[t]{2}{*}{$145 \mathrm{~N}$ Impulse } & P3 & 1901 & 1594 & 1541 & 1843 & 1664 & 1622 & 1677 & 1303 & 1677 \\
\hline & $\mathrm{P} 4$ & 1932 & 1773 & 1557 & 1859 & 1706 & 1630 & 1738 & 1421 & 1639 \\
\hline
\end{tabular}

Table B.6: Pressure Values (MAX) for Parametric Study 2 
5) 61.77 .98 